\title{
Systematic Review on Noninvasive Nonpharmacological Treatment for Chronic Pain: Surveillance Report 1
}

\author{
Literature Update Period: August 2019 through September 2021
}

\section{Background and Purpose}

This is the first update for the 2020 report Noninvasive Nonpharmacological Treatment for Chronic Pain ${ }^{1}$ (available at https://effectivehealthcare.ahrq.gov/products/noninvasive-nonpharmpain-update/research), covering the period August 2019 through September 2021. The 2020 report addressed benefits and harms of noninvasive nonpharmacological therapy for five common chronic pain conditions: low back pain (LBP); neck pain; knee, hip, or hand osteoarthritis (OA); fibromyalgia (FM); and tension headache. Given the clinical and public health importance of this topic, it is important to identify new evidence that could impact practice or policy. The purpose of this surveillance report is to identify new evidence published since the 2020 report and to determine how the new evidence impacts findings of the prior report. Subsequent surveillance reports are planned for January 2022 (based on evidence published from October to December 2021) and April 2022 (based on evidence published from January to March 2022).

\section{Scope}

The scope and eligibility criteria established at the time of the original report ${ }^{1}$ were utilized for this surveillance report; no changes were made. That report included randomized controlled trials (RCTs) reporting outcomes at least 1 month following the completion of treatment and focused on the use of single, active, noninvasive nonpharmacological interventions (including exercise, mind-body practices, psychological therapies, mindfulness practices, manual therapies, physical modalities, acupuncture, and multidisciplinary rehabilitation) for adults with five common chronic pain conditions, LBP (Key Question 1), neck pain (Key Question 2), knee, hip, or hand OA (Key Question 3), FM (Key Question 4), and tension headache (Key Question 5). The report addressed:

- Whether the interventions work overall compared with sham, waitlist control, attention control, no treatment, or usual care;

- Whether the interventions work compared with pharmacological alternatives; and

- How outcomes for individual interventions (e.g., acupuncture) compare with a common comparator (exercise for LBP, neck pain, OA, and FM; biofeedback for headache).

In addition, Key Question 6 addressed whether estimates of benefits and harms differ by age, sex, presence of comorbidities (e.g., emotional or mood disorders), or degree of nociplasticity/central sensitization.

The full protocol for the original report including detailed inclusion criteria using the PICOTS framework

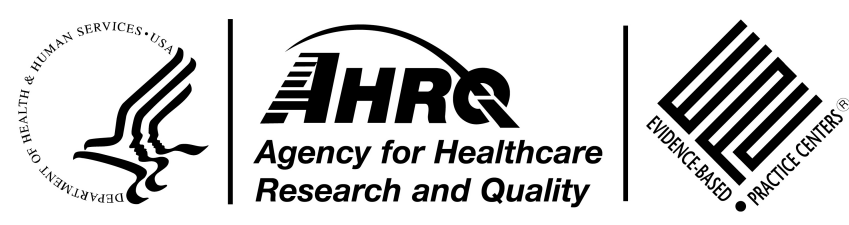


(https:/www.ncbi.nlm.nih.gov/books/NBK556223/table/ch3.tab1/?report=objectonly) and full Key Questions (https://www.ncbi.nlm.nih.gov/books/n/cer227/ch2/\#ch2.s2) is available on the Agency for Healthcare Research and Quality (AHRQ) website (https://effectivehealthcare.ahrq.gov/products/noninvasive-nonpharm-pain-update/protocol) and on the PROSPERO systematic reviews registry (CRD42019132457).

\section{Methods}

Update searches were conducted to identify evidence published from August 2019 through September 2021. Search strategies from the original report were utilized, ${ }^{1}$ and we searched the same databases as in the original report $\left(\mathrm{Ovid}^{\circledR}{ }^{\circledR} \mathrm{MEDLINE}^{\circledR}\right.$, Cochrane Central Register of Controlled Trials, and Cochrane Database of Systematic Reviews). In addition, to capture articles not yet indexed in MEDLINE, we supplemented the original search strategies with a previously developed ${ }^{2}$ optimized (text-word only) search in pre-MEDLINE to identify studies not yet indexed with Medical Subject Headings (MeSH). As in the original report, searches on electronic databases were supplemented by review of reference lists of relevant articles. Search strategies are available in Appendix A.

As in the original review, one investigator screened citations identified through searches for eligibility for full-text review. (Key Questions and inclusion criteria are available in Appendix B.) In addition, to increase efficiency of abstract review, we utilized a machine learning classifier in conjunction with a second investigator to assist in conducting dual reviews. The machine learning classifier was previously shown to have 100 percent recall for identifying eligible studies in update searches for this review. ${ }^{2}$ The machine learning classifier screened all citations; the second investigator performed dual review on all studies except those classified by the machine learning classifier as very low probability. Any citation identified as potentially eligible by either investigator underwent full-text review to determine final eligibility.

We utilized the same methods for data abstraction and quality assessment as for the original report. As in the prior review, we assessed the risk of bias of RCTs using the approaches recommended in the Cochrane Handbook for Systematic Reviews of Interventions (Chapter 8.5, Risk of Bias Tool) ${ }^{3}$ and the AHRQ Methods Guide for Effectiveness and Comparative Effectiveness Research, ${ }^{4}$ in conjunction with criteria and methods developed by the Cochrane Back and Neck Group. ${ }^{5}$ The decision to update meta-analyses from the original report was based on the number and sample sizes of new studies eligible for meta-analysis (meta-analysis performed if new evidence was large relative to the studies in the original meta-analysis); consistency in findings between the new studies and the original meta-analysis (meta-analysis performed if findings from new evidence appear inconsistent and new studies were appropriate for pooling based on similarity in populations, interventions, and comparisons, in order to determine whether new studies impact conclusions); or whether new evidence could impact the strength of evidence (SOE) (meta-analysis performed if the SOE based on the original metaanalysis was low or insufficient and new evidence could increase the strength of evidence due to increased precision, quality, or other factors). The SOE was based on the totality of evidence (evidence in the original report plus new evidence) and determined using the methods described in the original report. We highlighted any changes in the SOE assessments.

A list of studies included in this surveillance report is provided in Appendix C. An evidence table providing data from included studies is available in Appendix D, and quality assessments for each study are shown in Appendix E. A list of articles excluded at full-text review, along 
with reasons for exclusion, is available in Appendix F. Updated and new meta-analyses can be found in Appendix G.

\section{Results}

The update search yielded 5,391 total citations and identified 29 new eligible citations (Figure 1). Of those, 25 were new RCTs ${ }^{6-30}$ ( 3 good, 19 fair, and 7 poor quality) that reported on primary outcomes of interest, and 4 ( $3 \mathrm{LBP}, 1 \mathrm{FM}$ ) were subsequent publications $\mathrm{s}^{31-34}$ for trials already included in the prior report and reported only secondary outcomes. This surveillance report focuses on the primary outcomes and changes in strength of evidence (SOE) based on new evidence. Secondary outcomes are not summarized in this update report but can be found in Appendix D of this report, and Appendix D of the original report.

For chronic LBP, a total of 10 new RCTs R $^{7,14,15,17,18,20,22,27,28,30}$ (9 fair and 1 poor quality) were included that compared exercise versus usual care (2 RCTs), ${ }^{17,27}$ psychological therapy versus usual care (2 RCTs) $)^{7,27}$ and versus exercise (1 RCT), ${ }^{27}$ low-level laser therapy (LLLT) versus sham (1 RCT) ${ }^{14}$ transcutaneous electrical nerve stimulation versus sham (1 RCT) ${ }^{30}$ spinal manipulation versus sham $(1 \mathrm{RCT}),{ }^{28}$ massage versus usual care $(1 \mathrm{RCT}),{ }^{15}$ yoga versus exercise (2 RCTs),$^{20,22}$ and acupuncture versus usual care (1 RCT).$^{18}$ Only one new fair-quality RCT was included for chronic neck pain; it compared manual therapy versus sham and versus exercise. ${ }^{8}$ For knee OA, a total of 9 new RCTs ${ }^{6,12,13,16,19,21,24,26,29}$ ( 3 good, 3 fair, and 3 poor quality) were included that compared exercise versus usual care or attention control ( $3 \mathrm{RCTs}){ }_{19,21,26}$ massage versus usual care (1 RCT), ${ }^{24}$ ultrasound versus sham $(1 \mathrm{RCT}),{ }^{13}$ LLLT versus sham $(1 \mathrm{RCT}),{ }^{6}$ interferential current versus sham (1 RCT), ${ }^{6}$ Tai Chi versus usual care (1 RCT), ${ }^{12}$ Qigong versus exercise (1 RCT) ${ }^{29}$ and acupuncture versus sham $(1 \mathrm{RCT}){ }^{16}$ For FM, a total of 5 new RCTs ${ }^{9-}$ $11,23,25$ ( 2 fair and 3 poor quality) were included that compared exercise versus usual care ( 2 RCTs $),{ }^{11,23}$ spinal manipulation versus sham (1 RCT) ${ }^{10}$ mindfulness-based stress reduction versus usual care (1 RCT), ${ }^{25}$ basic body awareness training versus usual care (1 RCT) ${ }^{9}$ acupuncture versus usual care and versus exercise (1 RCT $),{ }^{11}$ and multidisciplinary rehabilitation (MDR) versus usual care and versus exercise (1 RCT) ${ }^{23}$ One LBP trial, ${ }^{27}$ one knee OA trial, ${ }^{6}$ and two FM trials ${ }^{11,23}$ had more than two arms and provided data for multiple interventions and/or comparators; thus the numbers of RCTs cited above are not mutually exclusive.

No new trials were identified for hip or hand OA or chronic tension-type headache or that compared a nonpharmacological therapy with pharmacological therapy. There was no new evidence for the following interventions for LBP (mindfulness practices, MDR), neck pain (psychological therapies, physical modalities, mindfulness practices, mind-body practices, acupuncture, and MDR), knee OA (psychological therapies, mindfulness practices, MDR), and FM (psychological therapies, physical modalities). No trials in pregnant or breastfeeding women with pre-existing chronic pain or new trials comparing interventions with topical agents, medical cannabis, or muscle relaxants were identified (all Key Questions). No data were available to evaluate nociplasticity as a modifier to treatment effectiveness or safety (Key Question 6). 
Figure 1. Literature flow diagram

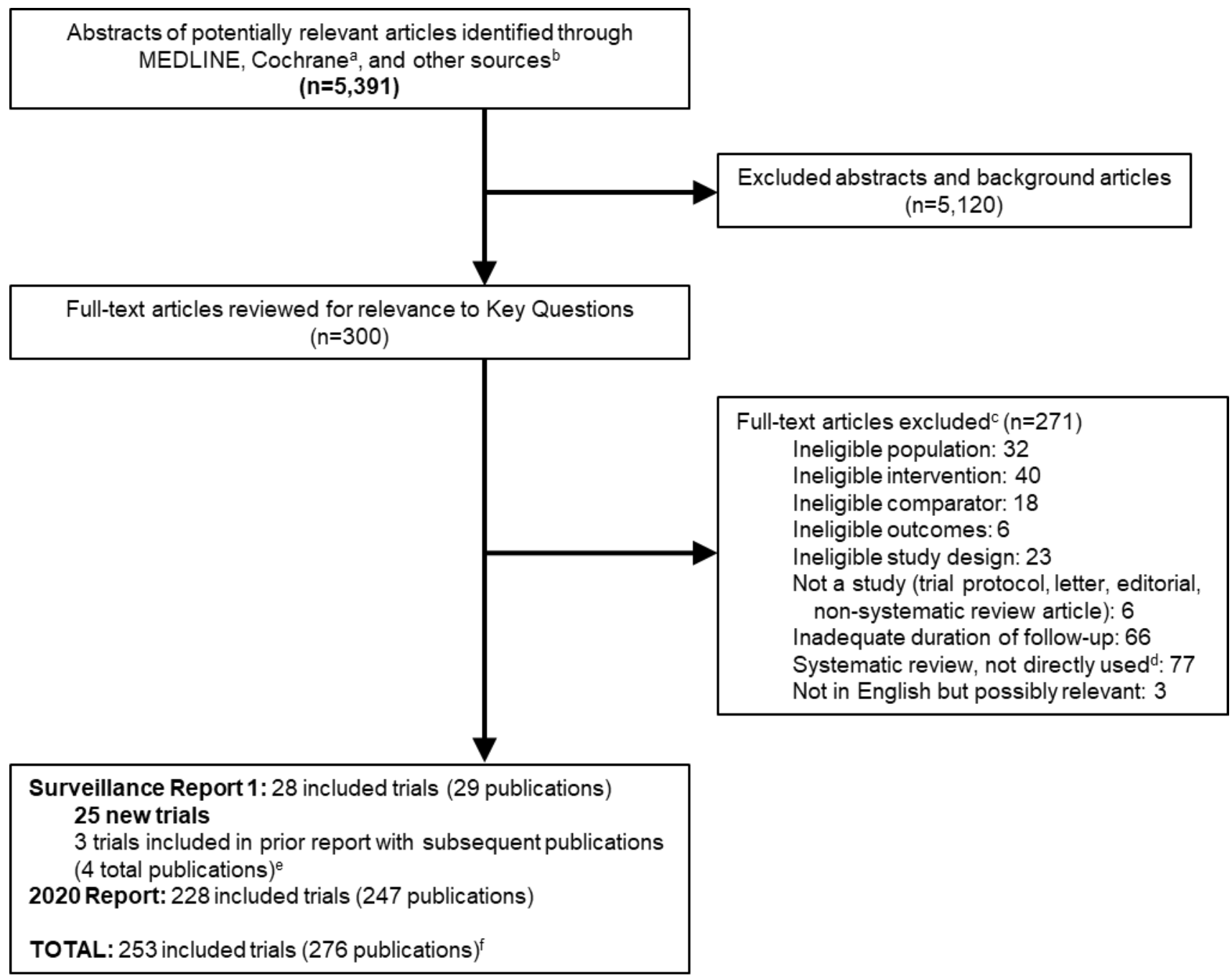

${ }^{a}$ Cochrane databases include the Cochrane Central Register of Controlled Trials and the Cochrane Database of Systematic Reviews

${ }^{\mathrm{b}}$ Other sources include prior reports, reference lists of relevant articles, systematic reviews, etc.

${ }^{c}$ Publications may be included or excluded for multiple interventions

${ }^{\mathrm{d}}$ Used as source documents, studies checked for inclusion eligibility

${ }^{\text {e }}$ These 4 followup publications (to Groessl 2017, Saper 2017 [chronic low back pain], and McCrae 2019 [fibromyalgia] included in the 2020 report) reported only secondary outcomes of interest and are not summarized in this surveillance report, but details can be found in Appendix D.

${ }^{\mathrm{f}}$ The 4 followup publications are not counted in the number of included trials but are counted under total publications. 


\section{Summary of Findings}

- Twenty-five new RCTs that reported on primary outcomes of interest were identified for this update (10 in chronic LBP, 1 in chronic neck pain, 9 in knee OA, and 5 in FM). Nine of the new trials ( 2 in chronic LBP, 1 in chronic neck pain, 2 in knee OA, and 4 in FM; noted below) evaluated interventions, comparators, or timepoints not previously evaluated; otherwise, the trials evaluated comparisons with at least some prior evidence.

\section{Chronic Low Back Pain}

- Exercise: The addition of two new fair-quality trials comparing exercise with usual care did not change the previous report's conclusions of a small improvement in function short term (SOE: moderate), nor did it change the conclusion of no effect with the addition of one new fair-quality trial at intermediate term (SOE: low) based on updated metaanalyses. Similarly, data from these trials did not change the prior report's conclusion of a small improvement in pain with exercise short term (adding both new trials) or intermediate term (1 new trial) compared with usual care (SOE: low for both timepoints).

- Psychological therapies: The inclusion of one new fair-quality RCT of pain reprocessing therapy (PRT) to our previous meta-analysis resulted in a similar effect size and conclusion of a small improvement in function with psychological therapies short term, as found in the 2020 report. We downgraded the SOE from moderate to low based on increased inconsistency. The other new trial of relaxation therapy was excluded from the updated meta-analysis of function short term as an outlier. (The effect estimate was substantially larger than those in other included trials.) Addition of the PRT study to our previous meta-analysis did not change our previous conclusions of small improvements in function at intermediate term and long term (SOE: moderate). PRT was associated with small improvements in pain ( 0 to 10 scale) compared with usual care at short term, intermediate term, and long term (SOE: moderate), which is consistent with the conclusion of the 2020 report. Evidence was insufficient for one new small fair-quality trial comparing psychological therapy with exercise.

- Physical modalities, low-level laser therapy: The addition of one new small poorquality trial of low-level laser therapy versus sham did not change the previous report's conclusions of a small improvement in function and moderate improvement in pain short term (SOE: low).

- Physical modalities, transcutaneous electrical nerve stimulation: The prior report did not contain studies of this modality. One new fair-quality RCT of transcutaneous electrical nerve stimulation (TENS) compared with sham TENS found no difference in function or pain short term (SOE: low).

- Manual therapies, spinal manipulation: Effect size based on updated meta-analysis including one new fair-quality RCT of manipulation and sham laser is consistent with the small improvement in function observed short term in the prior report. Similarly, the new trial's finding of no difference in pain short term was consistent with the 2020 report. SOE remained low.

- Manual therapies, massage: One new small fair-quality RCT of massage versus usual care found no difference between groups for function or pain short term. Its addition, it 
did not change our previous conclusion of small improvements in function and pain short term (SOE: moderate).

- Mind-body practices, yoga: Two new fair-quality RCTs found no differences between yoga and exercise for function or pain short term, which is consistent with findings of no effect from the 2020 report; the SOE remained low.

- Acupuncture: One new fair-quality RCT compared two different forms of acupuncture with usual care. Standard acupuncture was associated with moderate improvements in function and pain, while hand and ear acupuncture was associated with large improvements in function and pain versus usual care at short-term followup. Findings from this new RCT are consistent with our prior meta-analyses for the comparison with usual care; SOE remained low for function and moderate for pain.

\section{Chronic Neck Pain}

- Exercise: One new small fair-quality trial found exercise associated with moderate improvement in function and large improvement in pain versus a sham procedure short term; given the small sample size, it did not change our prior conclusions of no effect for function or pain (SOE: low).

- Manual therapies (manipulation): One new small fair-quality trial found that manipulation was associated with moderate improvement in function and large improvement in pain short term compared with a sham procedure (suboccipital inhibition). There was no difference in either function or pain short term between manual therapy and exercise. The prior report did not include comparisons of manipulation with sham treatment or with exercise. SOE was low for function and pain across both comparisons.

\section{Knee OA}

- Exercise: Addition of one poor-quality and two fair-quality RCTs comparing exercise with usual care or attention control in patients with knee OA did not change the 2020 report's conclusions or SOE for small improvement in function and pain short and long term, and moderate improvements in both at intermediate term (SOE moderate for both at short term and low at intermediate and long term).

- Physical modalities, low-level laser therapy: One new good-quality RCT compared LLLT versus sham. Its incorporation into a new meta-analysis for function revealed a small improvement at short and intermediate term. Its addition to a prior meta-analysis of two trials for pain did not change prior findings of no difference at short or intermediate term. With the addition of the new trial, the SOE was upgraded from insufficient to low for all.

- Physical modalities, ultrasound: One new good-quality RCT comparing ultrasound with sham reported no difference between groups in function or pain short term; this is consistent with the prior report and SOE remained low.

- Physical modalities, inferential current: No trials of this modality were identified for the prior report. The new good-quality RCT found no improvement in either function or 
pain at short or intermediate term for interferential current compared with sham (SOE: low).

- Manual therapies, massage: One new small poor-quality RCT of massage versus usual care did not change our conclusion of insufficient evidence.

- Mind-body therapies, Tai Chi and Qigong: One new small poor-quality RCT comparing Tai Chi with usual care does not change conclusions of insufficient evidence from the prior report. Evidence for a new comparison of Qigong with exercise from one fair-quality trial was considered insufficient.

- Acupuncture: One new good quality RCT of acupuncture versus sham reported no difference between groups in function or pain short term; this is consistent with the prior report and SOE remained low.

\section{Fibromyalgia}

- Exercise: Two new poor-quality trials comparing exercise with usual care reported no difference between groups in short term function. Given the poor quality of these trials, our conclusions for a small improvement in function short term (SOE: low) did not change.

- Manual therapy, spinal manipulation. The prior report did not contain evidence for spinal manipulation versus sham manipulation. One new fair-quality RCT found no difference between groups in either function or pain at short or intermediate term (SOE: low).

- Mindfulness practices, mindfulness-based stress reduction: One new poor-quality trial reported a small improvement in function following mindfulness-based stress reduction compared with usual care. This is consistent with the original report and SOE remained low.

- Mind-body therapies, basic body awareness therapy: No trials of this modality were identified for the prior report. Evidence from one new small fair-quality trial of basic body awareness therapy was considered insufficient.

- Acupuncture: The prior report did not contain evidence for acupuncture versus usual care or versus exercise. Evidence from one new poor-quality RCT was considered insufficient.

- Multidisciplinary rehabilitation: One new poor-quality RCT compared MDR with usual care and with exercise, and found no difference between MDR and either comparator in function short term. The prior report found a small improvement in function short term compared with usual care (SOE: low); given the poor quality of the new RCT, the 2020 report's conclusions and SOE remain unchanged. For the comparison of MDR with exercise, we graded the evidence as insufficient; the prior report did not contain evidence for this comparison at short term.

\section{Harms}

- Consistent with the 2020 report, adverse events were not consistently reported in new studies and intervention-related serious life-threatening events requiring medical attention were not reported. 


\section{Summary of New Evidence}

Table 1 provides the conclusions from the 2020 report and the new findings from studies identified in this surveillance report. Table 1 focuses on Key Questions and interventions with new evidence; the full SOE table is available in the prior report (https:/www.ncbi.nlm.nih.gov/books/n/cer227/appg/).

Table 1. Summary of conclusions and assessments informed by new evidence

\begin{tabular}{|c|c|c|c|c|}
\hline $\begin{array}{l}\text { Condition: } \\
\text { Intervention, } \\
\text { Comparator }\end{array}$ & $\begin{array}{l}\text { Outcome, } \\
\text { Timing }\end{array}$ & $\begin{array}{l}\text { Prior (2020) } \\
\text { Update }^{\mathrm{a}}\end{array}$ & $\begin{array}{l}2021 \text { Surveillance } \\
\text { Report }^{\mathrm{a}}\end{array}$ & Change \\
\hline \multirow[t]{4}{*}{$\begin{array}{l}\text { LBP: Exercise vs. } \\
\text { UC, AC or placebo }\end{array}$} & $\begin{array}{l}\text { Function, } \\
\text { short term }\end{array}$ & $\begin{array}{l}\text { Small effect } \\
\text { SOE: Moderate } \\
10 \mathrm{RCTs}(\mathrm{N}=940) \\
\text { [Excluding an outlier } \\
\text { trial] }\end{array}$ & $\begin{array}{l}2 \text { fair-quality RCTs } \\
(\mathrm{N}=147)^{17,27} \\
\text { MA updated } \\
12 \text { RCTs }(\mathrm{N}=1,011)\end{array}$ & $\begin{array}{l}\text { No change in } \\
\text { conclusions }\end{array}$ \\
\hline & $\begin{array}{l}\text { Function, } \\
\text { intermediate } \\
\text { term }\end{array}$ & $\begin{array}{l}\text { No effect } \\
\text { SOE: Low } \\
5 \text { RCTs }(\mathrm{N}=616)\end{array}$ & $\begin{array}{l}1 \text { fair-quality RCT }(\mathrm{N}=96)^{17} \\
\text { MA updated } \\
6 \text { RCTs }(\mathrm{N}=712)\end{array}$ & $\begin{array}{l}\text { No change in } \\
\text { conclusions }\end{array}$ \\
\hline & $\begin{array}{l}\text { Pain, short } \\
\text { term }\end{array}$ & $\begin{array}{l}\text { Moderate effect } \\
\text { SOE: Low } \\
11 \text { RCTs }(\mathrm{N}=981)\end{array}$ & $\begin{array}{l}1 \text { fair-quality RCT } \\
(\mathrm{N}=111)^{17} \\
\text { No effect }\end{array}$ & $\begin{array}{l}\text { No change in } \\
\text { conclusions }\end{array}$ \\
\hline & $\begin{array}{l}\text { Pain, } \\
\text { intermediate } \\
\text { term }\end{array}$ & $\begin{array}{l}\text { Small effect } \\
\text { SOE: Low } \\
\text { 5 RCTs }(\mathrm{N}=616)\end{array}$ & $\begin{array}{l}1 \text { fair-quality RCT }(\mathrm{N}=96)^{17} \\
\text { No effect }\end{array}$ & $\begin{array}{l}\text { No change in } \\
\text { conclusions }\end{array}$ \\
\hline \multirow[t]{6}{*}{$\begin{array}{l}\text { LBP: Psychological } \\
\text { therapies vs. UC }\end{array}$} & $\begin{array}{l}\text { Function, } \\
\text { short term }\end{array}$ & $\begin{array}{l}\text { Small effect } \\
\text { SOE: Moderate } \\
3 \text { RCTs }(\mathrm{N}=906)\end{array}$ & $\begin{array}{l}2 \text { fair-quality RCTs } \\
(\mathrm{N}=146)^{7,27} \\
\text { MA updated } \\
4 \text { RCTs }(\mathrm{N}=1,018)^{\mathrm{b}}\end{array}$ & $\begin{array}{l}\text { Small effect } \\
\text { SOE: Low } \\
\text { (downgraded one } \\
\text { level) }\end{array}$ \\
\hline & $\begin{array}{l}\text { Function, } \\
\text { intermediate } \\
\text { term }\end{array}$ & $\begin{array}{l}\text { Small effect } \\
\text { SOE: Moderate } \\
3 \text { RCTs }(N=1,026)\end{array}$ & $\begin{array}{l}1 \text { fair-quality RCT } \\
(\mathrm{N}=116)^{7} \\
\text { MA updated } \\
\text { 4 RCTs }(\mathrm{N}=1,142)\end{array}$ & $\begin{array}{l}\text { No change in } \\
\text { conclusions }\end{array}$ \\
\hline & $\begin{array}{l}\text { Function, } \\
\text { long term }\end{array}$ & $\begin{array}{l}\text { Small effect } \\
\text { SOE: Moderate } \\
3 \text { RCTs }(N=815)\end{array}$ & $\begin{array}{l}1 \text { fair-quality RCT } \\
(\mathrm{N}=124)^{7} \\
\text { MA updated } \\
\text { 4 RCTs }(\mathrm{N}=939)\end{array}$ & $\begin{array}{l}\text { No change in } \\
\text { conclusions }\end{array}$ \\
\hline & $\begin{array}{l}\text { Pain, short } \\
\text { term }\end{array}$ & $\begin{array}{l}\text { Small effect } \\
\text { SOE: Moderate } \\
\text { 3 RCTs }(N=906) \\
\end{array}$ & $\begin{array}{l}1 \text { fair-quality RCT } \\
(\mathrm{N}=112)^{7} \\
\text { Small effect }\end{array}$ & $\begin{array}{l}\text { No change in } \\
\text { conclusions }\end{array}$ \\
\hline & $\begin{array}{l}\text { Pain, } \\
\text { intermediate } \\
\text { term }\end{array}$ & $\begin{array}{l}\text { Small effect } \\
\text { SOE: Moderate } \\
\text { 3 RCTs }(N=1,026)\end{array}$ & $\begin{array}{l}1 \text { fair-quality RCT } \\
(\mathrm{N}=116)^{7} \\
\text { Small effect }\end{array}$ & $\begin{array}{l}\text { No change in } \\
\text { conclusions }\end{array}$ \\
\hline & $\begin{array}{l}\text { Pain, long } \\
\text { term }\end{array}$ & $\begin{array}{l}\text { Small effect } \\
\text { SOE: Moderate } \\
3 \text { RCTs }(N=815)\end{array}$ & $\begin{array}{l}1 \text { fair-quality RCT } \\
(\mathrm{N}=124)^{7} \\
\text { Small effect }\end{array}$ & $\begin{array}{l}\text { No change in } \\
\text { conclusions }\end{array}$ \\
\hline $\begin{array}{l}\text { LBP: Psychological } \\
\text { therapies vs. } \\
\text { exercise }\end{array}$ & $\begin{array}{l}\text { Function, } \\
\text { short term }\end{array}$ & $\begin{array}{l}\text { No evidence at short } \\
\text { term }\end{array}$ & $\begin{array}{l}1 \text { fair-quality RCT }(\mathrm{N}=34)^{27} \\
\text { No effect }\end{array}$ & Insufficient evidence \\
\hline \multirow[t]{2}{*}{$\begin{array}{l}\text { LBP: Physical } \\
\text { modalities: } \\
\text { LLLT vs. sham }\end{array}$} & $\begin{array}{l}\text { Function, } \\
\text { short term }\end{array}$ & $\begin{array}{l}\text { Small effect } \\
\text { SOE: Low } \\
1 \mathrm{RCT}(\mathrm{N}=56)\end{array}$ & $\begin{array}{l}1 \text { poor-quality RCT } \\
(\mathrm{N}=34)^{14} \\
\text { Large effect }\end{array}$ & $\begin{array}{l}\text { No change in } \\
\text { conclusions }\end{array}$ \\
\hline & $\begin{array}{l}\text { Pain, short } \\
\text { term }\end{array}$ & $\begin{array}{l}\text { Moderate effect } \\
\text { SOE: Low } \\
1 \mathrm{RCT}(\mathrm{N}=56)\end{array}$ & $\begin{array}{l}1 \text { poor-quality RCT } \\
(\mathrm{N}=34)^{14} \\
\text { Large effect }\end{array}$ & $\begin{array}{l}\text { No change in } \\
\text { conclusions }\end{array}$ \\
\hline $\begin{array}{l}\text { LBP: Physical } \\
\text { modalities: Burst }\end{array}$ & $\begin{array}{l}\text { Function, } \\
\text { short term }\end{array}$ & No evidence & $\begin{array}{l}1 \text { fair-quality RCT }(\mathrm{N}=73)^{30} \\
\text { No effect }\end{array}$ & $\begin{array}{l}\text { New intervention } \\
\text { No effect }\end{array}$ \\
\hline
\end{tabular}




\begin{tabular}{|c|c|c|c|c|}
\hline $\begin{array}{l}\text { Condition: } \\
\text { Intervention, } \\
\text { Comparator }\end{array}$ & $\begin{array}{l}\text { Outcome, } \\
\text { Timing }\end{array}$ & $\begin{array}{l}\text { Prior (2020) } \\
\text { Update }^{\mathrm{a}}\end{array}$ & $\begin{array}{l}2021 \text { Surveillance } \\
\text { Report }^{\mathrm{a}}\end{array}$ & Change \\
\hline \multirow{2}{*}{$\begin{array}{l}\text { TENS vs. continuous } \\
\text { TENS vs. sham }\end{array}$} & & & & SOE: Low \\
\hline & $\begin{array}{l}\text { Pain, short } \\
\text { term }\end{array}$ & No evidence & $\begin{array}{l}1 \text { fair-quality RCT }(\mathrm{N}=73)^{30} \\
\text { No effect }\end{array}$ & $\begin{array}{l}\text { New intervention } \\
\text { No effect } \\
\text { SOE: Low }\end{array}$ \\
\hline \multirow[t]{2}{*}{$\begin{array}{l}\text { LBP: Manual } \\
\text { therapy: Spinal } \\
\text { manipulation vs. } \\
\text { sham, UC, AC }\end{array}$} & $\begin{array}{l}\text { Function, } \\
\text { short term }\end{array}$ & $\begin{array}{l}\text { Small effect } \\
\text { SOE: Low } \\
\text { 3 RCTs }(\mathrm{N}=704)\end{array}$ & $\begin{array}{l}1 \text { fair-quality RCT } \\
(\mathrm{N}=155)^{28} \\
\text { MA updated } \\
4 \mathrm{RCTs}(\mathrm{N}=859)\end{array}$ & $\begin{array}{l}\text { No change in } \\
\text { conclusions }\end{array}$ \\
\hline & $\begin{array}{l}\text { Pain, short } \\
\text { term }\end{array}$ & $\begin{array}{l}\text { No effect } \\
\text { SOE: Low } \\
3 \text { RCTs }(N=530)\end{array}$ & $\begin{array}{l}1 \text { fair-quality RCT } \\
(\mathrm{N}=155)^{28} \\
\text { No effect }\end{array}$ & $\begin{array}{l}\text { No change in } \\
\text { conclusions }\end{array}$ \\
\hline \multirow[t]{2}{*}{$\begin{array}{l}\text { LBP: Manual } \\
\text { therapy: Massage } \\
\text { vs. sham, UC, AC }\end{array}$} & $\begin{array}{l}\text { Function, } \\
\text { short term }\end{array}$ & $\begin{array}{l}\text { Small effect } \\
\text { SOE: Moderate } \\
6 \text { RCTs }(N=694)\end{array}$ & $\begin{array}{l}1 \text { fair-quality RCT }(\mathrm{N}=59)^{15} \\
\text { No effect }\end{array}$ & $\begin{array}{l}\text { No change in } \\
\text { conclusions }\end{array}$ \\
\hline & $\begin{array}{l}\text { Pain, short } \\
\text { term }\end{array}$ & $\begin{array}{l}\text { Small effect } \\
\text { SOE: Moderate } \\
5 \mathrm{RCT} \text { ( }(\mathrm{N}=644)\end{array}$ & $\begin{array}{l}1 \text { fair-quality RCT }(\mathrm{N}=59)^{15} \\
\text { No effect }\end{array}$ & $\begin{array}{l}\text { No change in } \\
\text { conclusions }\end{array}$ \\
\hline \multirow[t]{2}{*}{$\begin{array}{l}\text { LBP: Mind-body } \\
\text { practices: Yoga vs. } \\
\text { exercise }\end{array}$} & $\begin{array}{l}\text { Function, } \\
\text { short term }\end{array}$ & $\begin{array}{l}\text { No effect } \\
\text { SOE: Low } \\
\text { 4 RCTs }(\mathrm{N}=559)\end{array}$ & $\begin{array}{l}2 \text { fair-quality RCTs } \\
(\mathrm{N}=252)^{20,22} \\
\text { No effect }\end{array}$ & $\begin{array}{l}\text { No change in } \\
\text { conclusions }\end{array}$ \\
\hline & $\begin{array}{l}\text { Pain, short } \\
\text { term }\end{array}$ & $\begin{array}{l}\text { No effect } \\
\text { SOE: Low } \\
5 \text { RCTs }(N=575)\end{array}$ & $\begin{array}{l}2 \text { fair-quality RCTs } \\
(\mathrm{N}=252)^{20,22} \\
\text { No effect }\end{array}$ & $\begin{array}{l}\text { No change in } \\
\text { conclusions }\end{array}$ \\
\hline \multirow[t]{2}{*}{$\begin{array}{l}\text { LBP: Acupuncture } \\
\text { vs. sham, UC, or AC }\end{array}$} & $\begin{array}{l}\text { Function, } \\
\text { short term }\end{array}$ & $\begin{array}{l}\text { Small effect } \\
\text { SOE: Low } \\
\text { 4 RCTs }(\mathrm{N}=2,066)\end{array}$ & $\begin{array}{l}1 \text { fair-quality RCT } \\
(\mathrm{N}=152)^{18} \\
\text { Large effect }\end{array}$ & $\begin{array}{l}\text { No change in } \\
\text { conclusions }\end{array}$ \\
\hline & $\begin{array}{l}\text { Pain, short } \\
\text { term }\end{array}$ & $\begin{array}{l}\text { Small effect } \\
\text { SOE: Moderate } \\
5 \text { RCTs }(N=2,109)\end{array}$ & $\begin{array}{l}1 \text { fair-quality RCT } \\
(\mathrm{N}=152)^{18} \\
\text { Moderate effect }\end{array}$ & $\begin{array}{l}\text { No change in } \\
\text { conclusions }\end{array}$ \\
\hline \multirow[t]{2}{*}{$\begin{array}{l}\text { Neck pain: } \\
\text { Exercise vs. AC, WL, } \\
\text { or NT }\end{array}$} & $\begin{array}{l}\text { Function, } \\
\text { short term }\end{array}$ & $\begin{array}{l}\text { No effect [excluding } \\
\text { outlier] } \\
\text { SOE: Low } \\
3 \text { RCTs }(\mathrm{N}=444)\end{array}$ & $\begin{array}{l}1 \text { fair-quality } \mathrm{RCT}(\mathrm{N}=43)^{8} \\
\text { Moderate effect }\end{array}$ & $\begin{array}{l}\text { No change in } \\
\text { conclusions }\end{array}$ \\
\hline & $\begin{array}{l}\text { Pain, short } \\
\text { term }\end{array}$ & $\begin{array}{l}\text { No effect [excluding } \\
\text { outlier] } \\
\text { SOE: Low } \\
3 \text { RCTs }(\mathrm{N}=444)\end{array}$ & $\begin{array}{l}1 \text { fair-quality } \mathrm{RCT}(\mathrm{N}=43)^{8} \\
\text { Large effect }\end{array}$ & $\begin{array}{l}\text { No change in } \\
\text { conclusions }\end{array}$ \\
\hline \multirow{2}{*}{$\begin{array}{l}\text { Neck pain: } \\
\text { Manual therapy: } \\
\text { Manipulation vs. } \\
\text { sham }\end{array}$} & $\begin{array}{l}\text { Function, } \\
\text { short term }\end{array}$ & No evidence & $\begin{array}{l}1 \text { fair-quality } \mathrm{RCT}(\mathrm{N}=42)^{8} \\
\text { Moderate effect }\end{array}$ & $\begin{array}{l}\text { New intervention } \\
\text { Moderate effect } \\
\text { SOE: Low }\end{array}$ \\
\hline & $\begin{array}{l}\text { Pain, short } \\
\text { term }\end{array}$ & No evidence & $\begin{array}{l}1 \text { fair-quality } \mathrm{RCT}(\mathrm{N}=42)^{8} \\
\text { Large effect }\end{array}$ & $\begin{array}{l}\text { New intervention } \\
\text { Large effect } \\
\text { SOE: Low }\end{array}$ \\
\hline \multirow{2}{*}{$\begin{array}{l}\text { Neck pain: } \\
\text { Manual therapy: } \\
\text { Manipulation vs. } \\
\text { exercise }\end{array}$} & $\begin{array}{l}\text { Function, } \\
\text { short term }\end{array}$ & No evidence & $\begin{array}{l}1 \text { fair-quality RCT }(\mathrm{N}=43)^{8} \\
\text { No effect }\end{array}$ & $\begin{array}{l}\text { New intervention } \\
\text { No effect } \\
\text { SOE: Low }\end{array}$ \\
\hline & $\begin{array}{l}\text { Pain, short } \\
\text { term }\end{array}$ & No evidence & $\begin{array}{l}1 \text { fair-quality } \mathrm{RCT}(\mathrm{N}=43)^{8} \\
\text { No effect }\end{array}$ & $\begin{array}{l}\text { New intervention } \\
\text { No effect } \\
\text { SOE: Low }\end{array}$ \\
\hline $\begin{array}{l}\text { Knee OA: Exercise } \\
\text { vs. UC, AC, sham, or } \\
\text { NT }\end{array}$ & $\begin{array}{l}\text { Function, } \\
\text { short term }\end{array}$ & $\begin{array}{l}\text { Small effect } \\
\text { SOE: Moderate } \\
\text { 8 RCTs }(\mathrm{N}=748)\end{array}$ & $\begin{array}{l}1 \text { poor-quality RCT } \\
(\mathrm{N}=84)^{26} \\
\text { MA updated } \\
9 \text { RCTs }(\mathrm{N}=832)\end{array}$ & $\begin{array}{l}\text { No change in } \\
\text { conclusions }\end{array}$ \\
\hline
\end{tabular}




\begin{tabular}{|c|c|c|c|c|}
\hline $\begin{array}{l}\text { Condition: } \\
\text { Intervention, } \\
\text { Comparator }\end{array}$ & $\begin{array}{l}\text { Outcome, } \\
\text { Timing }\end{array}$ & $\begin{array}{l}\text { Prior (2020) } \\
\text { Update }\end{array}$ & $\begin{array}{l}2021 \text { Surveillance } \\
\text { Report }^{\mathrm{a}}\end{array}$ & Change \\
\hline & $\begin{array}{l}\text { Function, } \\
\text { intermediate } \\
\text { term }\end{array}$ & $\begin{array}{l}\text { Moderate effect } \\
\text { SOE: Low } \\
11 \text { RCTs }(N=879)\end{array}$ & $\begin{array}{l}1 \text { fair-quality RCT } \\
(\mathrm{N}=265)^{19} \\
\text { MA updated } \\
\text { 12 RCTs }(\mathrm{N}=1,144)\end{array}$ & $\begin{array}{l}\text { No change in } \\
\text { conclusions }\end{array}$ \\
\hline & $\begin{array}{l}\text { Function, } \\
\text { long term }\end{array}$ & $\begin{array}{l}\text { Small effect } \\
\text { SOE: Low } \\
\text { 4 RCTs }(N=1,199)\end{array}$ & $\begin{array}{l}2 \text { fair-quality RCTs } \\
(\mathrm{N}=342)^{19,21} \\
\text { MA updated } \\
6 \text { RCTs }(\mathrm{N}=1,541)\end{array}$ & $\begin{array}{l}\text { No change in } \\
\text { conclusions }\end{array}$ \\
\hline & $\begin{array}{l}\text { Pain, short } \\
\text { term }\end{array}$ & $\begin{array}{l}\text { Small effect } \\
\text { SOE: Moderate } \\
\text { 8 RCTs ( } N=748)\end{array}$ & $\begin{array}{l}1 \text { poor-quality RCT } \\
(\mathrm{N}=84)^{26} \\
\text { MA updated } \\
9 \text { RCTs }(\mathrm{N}=832) \\
\end{array}$ & $\begin{array}{l}\text { No change in } \\
\text { conclusions }\end{array}$ \\
\hline & $\begin{array}{l}\text { Pain, } \\
\text { intermediate } \\
\text { term }\end{array}$ & $\begin{array}{l}\text { Moderate effect } \\
\text { SOE: Low } \\
11 \text { RCTs }(\mathrm{N}=879)\end{array}$ & $\begin{array}{l}1 \text { fair-quality RCT } \\
(\mathrm{N}=261)^{19} \\
\text { MA updated } \\
12 \text { RCTs }(\mathrm{N}=1,140)\end{array}$ & $\begin{array}{l}\text { No change in } \\
\text { conclusions }\end{array}$ \\
\hline & $\begin{array}{l}\text { Pain, long } \\
\text { term }\end{array}$ & $\begin{array}{l}\text { Small effect } \\
\text { SOE: Low } \\
\text { 4 RCTs }(N=1,199)\end{array}$ & $\begin{array}{l}2 \text { fair-quality RCTs } \\
(\mathrm{N}=338)^{19,21} \\
\text { MA updated } \\
6 \text { RCTs }(\mathrm{N}=1,537)\end{array}$ & $\begin{array}{l}\text { No change in } \\
\text { conclusions }\end{array}$ \\
\hline \multirow[t]{4}{*}{$\begin{array}{l}\text { Knee OA: Physical } \\
\text { modalities: LLLT vs. } \\
\text { sham or UC }\end{array}$} & $\begin{array}{l}\text { Function, } \\
\text { short term }\end{array}$ & $\begin{array}{l}\text { Insufficient evidence } \\
1 \mathrm{RCT}(\mathrm{N}=49)\end{array}$ & $\begin{array}{l}1 \text { good-quality RCT } \\
(\mathrm{N}=84)^{6} \\
\text { New MA } \\
2 \text { RCTs }(\mathrm{N}=133)\end{array}$ & $\begin{array}{l}\text { Small effect } \\
\text { SOE: Low } \\
\text { (upgraded one level) }\end{array}$ \\
\hline & $\begin{array}{l}\text { Function, } \\
\text { intermediate } \\
\text { term }\end{array}$ & $\begin{array}{l}\text { Insufficient evidence } \\
2 \mathrm{RCTs}(\mathrm{N}=109)\end{array}$ & $\begin{array}{l}1 \text { good-quality RCT } \\
(\mathrm{N}=84)^{6} \\
\text { New MA } \\
3 \text { RCTs }(\mathrm{N}=193)\end{array}$ & $\begin{array}{l}\text { Small effect } \\
\text { SOE: Low } \\
\text { (upgraded one level) }\end{array}$ \\
\hline & $\begin{array}{l}\text { Pain, short } \\
\text { term }\end{array}$ & $\begin{array}{l}\text { Insufficient evidence } \\
2 \text { RCTs }(N=76)\end{array}$ & $\begin{array}{l}1 \text { good-quality RCT } \\
(\mathrm{N}=84)^{6} \\
\text { MA updated } \\
3 \text { RCTs }(\mathrm{N}=160)\end{array}$ & $\begin{array}{l}\text { No effect } \\
\text { SOE: Low } \\
\text { (upgraded one level) }\end{array}$ \\
\hline & $\begin{array}{l}\text { Pain, } \\
\text { intermediate } \\
\text { term }\end{array}$ & $\begin{array}{l}\text { Insufficient evidence } \\
2 \text { RCTs }(\mathrm{N}=109)\end{array}$ & $\begin{array}{l}1 \text { good-quality RCT } \\
(\mathrm{N}=84)^{6} \\
\text { MA updated } \\
3 \text { RCTs }(\mathrm{N}=193)\end{array}$ & $\begin{array}{l}\text { No effect } \\
\text { SOE: Low } \\
\text { (upgraded one level) }\end{array}$ \\
\hline $\begin{array}{l}\text { Knee OA: } \\
\text { Physical modalities: } \\
\text { Continuous and } \\
\text { pulsed US vs. sham }\end{array}$ & $\begin{array}{l}\text { Function and } \\
\text { pain, short } \\
\text { term }\end{array}$ & $\begin{array}{l}\text { No effect } \\
\text { SOE: Low } \\
3 \text { RCTs }(N=249)\end{array}$ & $\begin{array}{l}1 \text { good-quality RCT } \\
(\mathrm{N}=75)^{13} \\
\text { No effect }\end{array}$ & $\begin{array}{l}\text { No change in } \\
\text { conclusions }\end{array}$ \\
\hline \multirow[t]{2}{*}{$\begin{array}{l}\text { Knee OA: } \\
\text { Physical modalities: } \\
\text { Interferential current } \\
\text { vs. sham }\end{array}$} & $\begin{array}{l}\text { Function, } \\
\text { short and } \\
\text { intermediate } \\
\text { term } \\
\end{array}$ & No evidence & $\begin{array}{l}1 \text { good-quality RCT } \\
(\mathrm{N}=84)^{6} \\
\text { No effect }\end{array}$ & $\begin{array}{l}\text { New intervention } \\
\text { No effect } \\
\text { SOE: Low }\end{array}$ \\
\hline & $\begin{array}{l}\text { Pain, short } \\
\text { and } \\
\text { intermediate } \\
\text { term } \\
\end{array}$ & No evidence & $\begin{array}{l}1 \text { good-quality RCT } \\
(\mathrm{N}=84)^{6} \\
\text { No effect }\end{array}$ & $\begin{array}{l}\text { New intervention } \\
\text { No effect } \\
\text { SOE: Low }\end{array}$ \\
\hline \multirow[t]{2}{*}{$\begin{array}{l}\text { Knee OA: } \\
\text { Manual therapies: } \\
\text { Massage vs. UC }\end{array}$} & $\begin{array}{l}\text { Function, } \\
\text { short term }\end{array}$ & $\begin{array}{l}\text { Insufficient evidence } \\
1 \mathrm{RCT}(\mathrm{N}=125)\end{array}$ & $\begin{array}{l}1 \text { poor-quality RCT } \\
(\mathrm{N}=60)^{24} \\
\text { No effect }\end{array}$ & $\begin{array}{l}\text { No change in } \\
\text { conclusions }\end{array}$ \\
\hline & $\begin{array}{l}\text { Pain, short } \\
\text { term }\end{array}$ & $\begin{array}{l}\text { Insufficient evidence } \\
1 \mathrm{RCT}(\mathrm{N}=125)\end{array}$ & $\begin{array}{l}1 \text { poor-quality RCT } \\
(\mathrm{N}=60)^{24} \\
\text { Small effect }\end{array}$ & $\begin{array}{l}\text { No change in } \\
\text { conclusions }\end{array}$ \\
\hline
\end{tabular}




\begin{tabular}{|c|c|c|c|c|}
\hline $\begin{array}{l}\text { Condition: } \\
\text { Intervention, } \\
\text { Comparator }\end{array}$ & $\begin{array}{l}\text { Outcome, } \\
\text { Timing }\end{array}$ & $\begin{array}{l}\text { Prior (2020) } \\
\text { Update }^{\mathrm{a}}\end{array}$ & $\begin{array}{l}2021 \text { Surveillance } \\
\text { Report }^{\mathrm{a}}\end{array}$ & Change \\
\hline $\begin{array}{l}\text { Knee OA: Mind- } \\
\text { body therapies: Tai } \\
\text { Chi vs. AC or UC }\end{array}$ & $\begin{array}{l}\text { Function and } \\
\text { pain, } \\
\text { intermediate } \\
\text { term }\end{array}$ & $\begin{array}{l}\text { Insufficient evidence } \\
1 \mathrm{RCT}(\mathrm{N}=40)\end{array}$ & $\begin{array}{l}1 \text { poor-quality RCT } \\
(\mathrm{N}=92)^{12} \\
\text { Moderate effect }\end{array}$ & $\begin{array}{l}\text { No change in } \\
\text { conclusions }\end{array}$ \\
\hline $\begin{array}{l}\text { Knee OA: } \\
\text { Mind-body } \\
\text { therapies: Qigong } \\
\text { vs. exercise }\end{array}$ & $\begin{array}{l}\text { Function and } \\
\text { pain, } \\
\text { intermediate } \\
\text { term } \\
\end{array}$ & $\begin{array}{l}\text { No evidence vs. } \\
\text { exercise }\end{array}$ & $\begin{array}{l}1 \text { fair-quality trial }(\mathrm{N}=68)^{29} \\
\text { No effect }\end{array}$ & $\begin{array}{l}\text { New comparator } \\
\text { Insufficient evidence }\end{array}$ \\
\hline \multirow[t]{2}{*}{$\begin{array}{l}\text { Knee OA: } \\
\text { Acupuncture vs. UC, } \\
\text { NT, or sham }\end{array}$} & $\begin{array}{l}\text { Function, } \\
\text { short term }\end{array}$ & $\begin{array}{l}\text { No effect } \\
\text { SOE: Low } \\
\text { 5 RCTs }(\mathrm{N}=944)\end{array}$ & $\begin{array}{l}1 \text { good-quality RCT } \\
(\mathrm{N}=83)^{16} \\
\text { No effect }\end{array}$ & $\begin{array}{l}\text { No change in } \\
\text { conclusions }\end{array}$ \\
\hline & $\begin{array}{l}\text { Pain, short } \\
\text { term }\end{array}$ & $\begin{array}{l}\text { No effect } \\
\text { SOE: Low } \\
6 \text { RCTs }(N=1065)\end{array}$ & $\begin{array}{l}1 \text { good-quality RCT } \\
(\mathrm{N}=83)^{16} \\
\text { No effect }\end{array}$ & $\begin{array}{l}\text { No change in } \\
\text { conclusions }\end{array}$ \\
\hline $\begin{array}{l}\text { FM: Exercise vs. UC, } \\
\text { NT, sham, or AC }\end{array}$ & $\begin{array}{l}\text { Function, } \\
\text { short term }\end{array}$ & $\begin{array}{l}\text { Small effect } \\
\text { SOE: Low } \\
7 \text { RCTs }(\mathrm{N}=410)\end{array}$ & $\begin{array}{l}2 \text { poor-quality RCTs } \\
(\mathrm{N}=135)^{11,23} \\
\text { No effect }\end{array}$ & $\begin{array}{l}\text { No change in } \\
\text { conclusions }\end{array}$ \\
\hline \multirow[t]{2}{*}{$\begin{array}{l}\text { FM: Manual therapy: } \\
\text { Spinal manipulation } \\
\text { vs. sham }\end{array}$} & $\begin{array}{l}\text { Function, } \\
\text { short and } \\
\text { intermediate } \\
\text { term }\end{array}$ & No evidence & $\begin{array}{l}1 \text { fair-quality RCT } \\
(\mathrm{N}=101)^{10} \\
\text { No effect }\end{array}$ & $\begin{array}{l}\text { New intervention } \\
\text { No effect } \\
\text { SOE: Low }\end{array}$ \\
\hline & $\begin{array}{l}\text { Pain, short } \\
\text { and } \\
\text { intermediate } \\
\text { term } \\
\end{array}$ & No evidence & $\begin{array}{l}1 \text { fair-quality RCT } \\
(\mathrm{N}=101)^{10} \\
\text { No effect }\end{array}$ & $\begin{array}{l}\text { New intervention } \\
\text { No effect } \\
\text { SOE: Low }\end{array}$ \\
\hline $\begin{array}{l}\text { FM; Mindfulness } \\
\text { practices: MBSR, } \\
\text { MAT vs. AC or WL }\end{array}$ & $\begin{array}{l}\text { Function, } \\
\text { intermediate } \\
\text { term }\end{array}$ & $\begin{array}{l}\text { Small effect } \\
\text { SOE: Low } \\
\text { 1 RCT }(N=148)\end{array}$ & $\begin{array}{l}1 \text { poor-quality RCT } \\
(\mathrm{N}=98)^{25} \\
\text { Small effect }\end{array}$ & $\begin{array}{l}\text { No change in } \\
\text { conclusions }\end{array}$ \\
\hline $\begin{array}{l}\text { FM: Mind-body } \\
\text { therapies: BBAT vs. } \\
\text { UC }\end{array}$ & $\begin{array}{l}\text { Pain, short } \\
\text { and } \\
\text { intermediate } \\
\text { term }\end{array}$ & No evidence & $\begin{array}{l}1 \text { fair-quality RCT }(\mathrm{N}=39)^{9} \\
\text { No effect }\end{array}$ & $\begin{array}{l}\text { New intervention } \\
\text { Insufficient evidence }\end{array}$ \\
\hline $\begin{array}{l}\text { FM: Acupuncture } \\
\text { vs. UC }\end{array}$ & $\begin{array}{l}\text { Function, } \\
\text { short term }\end{array}$ & $\begin{array}{l}\text { No evidence vs. } \\
\text { usual care }\end{array}$ & $\begin{array}{l}1 \text { poor-quality RCT } \\
(\mathrm{N}=67)^{11} \\
\text { No effect }\end{array}$ & $\begin{array}{l}\text { New comparator } \\
\text { Insufficient evidence }\end{array}$ \\
\hline $\begin{array}{l}\text { FM: Acupuncture } \\
\text { vs. exercise }\end{array}$ & $\begin{array}{l}\text { Function, } \\
\text { short term }\end{array}$ & $\begin{array}{l}\text { No evidence vs. } \\
\text { exercise }\end{array}$ & $\begin{array}{l}1 \text { poor-quality RCT } \\
(\mathrm{N}=67)^{11} \\
\text { No effect }\end{array}$ & $\begin{array}{l}\text { New comparator } \\
\text { Insufficient evidence }\end{array}$ \\
\hline $\begin{array}{l}\text { FM: MDR vs. UC or } \\
\text { WL }\end{array}$ & $\begin{array}{l}\text { Function, } \\
\text { short term }\end{array}$ & $\begin{array}{l}\text { Small effect } \\
\text { SOE: Low } \\
\text { 3 RCTs }(N=381)\end{array}$ & $\begin{array}{l}1 \text { poor-quality RCT } \\
(\mathrm{N}=64)^{23} \\
\text { No effect }\end{array}$ & $\begin{array}{l}\text { No change in } \\
\text { conclusions }\end{array}$ \\
\hline $\begin{array}{l}\text { FM: MDR vs. } \\
\text { exercise }\end{array}$ & $\begin{array}{l}\text { Function, } \\
\text { short term }\end{array}$ & $\begin{array}{l}\text { No evidence at short } \\
\text { term }\end{array}$ & $\begin{array}{l}1 \text { poor-quality RCT } \\
(\mathrm{N}=64)^{23} \\
\text { No effect }\end{array}$ & $\begin{array}{l}\text { New timepoint (short } \\
\text { term) } \\
\text { Insufficient evidence }\end{array}$ \\
\hline
\end{tabular}

Abbreviations: $\mathrm{AC}=$ attention control; $\mathrm{BBAT}=$ basic body awareness training; $\mathrm{FM}=$ fibromyalgia; $\mathrm{LBP}=$ low back pain; LLLT

= low-level laser therapy; MA = meta-analysis; MAT = meditation awareness training; MBSR = mindfulness-based stress reduction; $\mathrm{MDR}=$ multidisciplinary rehabilitation; $\mathrm{NT}=$ no treatment; $\mathrm{RCT}=$ randomized controlled trial; $\mathrm{SOE}=$ strength of evidence; TENS $=$ transcutaneous electrical nerve stimulation; $\mathrm{UC}=$ usual care; $\mathrm{US}=$ ultrasound; vs. $=$ versus; $\mathrm{WL}=$ waitlist. ${ }^{a}$ The sample size $(\mathrm{N})$ reported is as analyzed.

${ }^{\mathrm{b}}$ One new trial, Shariat 2019, was an outlier and conclusions are based on inclusion of the one new fair-quality RCT (Ashar 2021) which increased heterogeneity leading to downgrade from moderate to low SOE.

${ }^{\mathrm{c}}$ In the previous report, $3 \mathrm{RCTs}$ were included that compared acupuncture with sham acupuncture and found a small improvement in function short term (moderate SOE). 


\title{
Evidence Details
}

\section{Key Question 1: Chronic Low Back Pain}

\author{
Exercise for Chronic Low Back Pain
}

\section{Exercise Compared With Usual Care, an Attention Control, or a Placebo Intervention}

Two new fair-quality trials of exercise (pedometer-based walking program [5 consecutive days per week for 12 weeks] and mobility/flexibility exercises [18 sessions over 6 weeks]) versus usual care were identified. ${ }^{17,27}$ One moderate-sized RCT $(\mathrm{n}=96)^{17}$ contributed data on function and pain short and intermediate term. The other, smaller RCT $(n=36)^{27}$ provided data for short-term function only.

In the short term, updated pooled estimates across 12 trials $(\mathrm{n}=1,011)$ did not change our previous conclusions of a small improvement in function (SOE moderate) with exercise versus usual care (pooled standardized mean difference [SMD] $-0.36,95 \%$ confidence interval $[\mathrm{CI}]$ -0.58 to $-0.17, \mathrm{I}^{2}=47.3 \%$ excluding the same outlier trial as the 2020 report). One of the new trials also reported results at intermediate term. ${ }^{17}$ The conclusion of no difference in function between groups ( 6 RCTs, $n=712$; updated pooled SMD $-0.18,95 \% \mathrm{CI}-0.42$ to $0.03, \mathrm{I}^{2}=31.3 \%$ ) is consistent with the 2020 report and SOE remained low. (See Appendix G, Figure G-1 for updated function plot.) The same trial also found no difference in pain between exercise and usual care at short term ( $\mathrm{n}=111$; difference -0.6 on a 0 to 10 scale, $95 \% \mathrm{CI}-1.26$ to 0.06 ) or intermediate term ( $\mathrm{n}=96$; difference -0.8 on a 0 to 10 scale, $95 \% \mathrm{CI}-1.60$ to 0.01 ). The addition of these data did not change the prior report's conclusion of a small improvement in pain with exercise short term (11 RCTs) or intermediate term (5 RCTs) compared with usual care or SOE of low at either timepoint.

Of the two new trials, only one reported adverse events and it reported that no interventionrelated adverse events occurred. ${ }^{17}$

\section{Psychological Therapies for Chronic Low Back Pain}

\section{Psychological Therapies Compared With Usual Care or an Attention Control}

Psychological therapies were associated with small functional improvements compared with usual care or attention control at short, intermediate, and long term (SOE: moderate for all) in the 2020 report. Cognitive behavioral therapy (CBT) was the most common psychological treatment reported and three trials reported for each time frame. We identified two new fair-quality trials comparing psychological therapies with usual care that reported on function. In one small RCT from Iran ( $\mathrm{N}=34)$, patients received relaxation therapy for three 40-45-minute sessions per week for 6 weeks or continued usual care. ${ }^{27}$ Patients in the other, U.S.-based trial $(\mathrm{N}=151$ randomized) ${ }^{7}$ received a proprietary pain reprocessing therapy (PRT) that aims to promote patients' reconceptualization of primary chronic pain as a brain-generated false alarm or usual care, which consisted of a chronic pain workbook or videos describing placebo treatments combined with an open-label subcutaneous saline injection at the site of greatest back pain. The PRT group received individual hourly sessions delivered twice weekly for 8 weeks.

An updated meta-analysis including the two new trials showed a moderate improvement in short-term function ( 5 RCTs, $\mathrm{n}=1,052$, pooled SMD $-0.58,95 \% \mathrm{CI}-1.27$ to $0.01, \mathrm{I}^{2}=90.7 \%$ ) and 
a substantial increase in heterogeneity compared with the original analyses' $\mathrm{I}^{2}$ of 0 percent. The effect estimate from the new trial of relaxation therapy ${ }^{27}$ was substantially larger (SMD -1.89) than those in other included trials (SMD range from -0.08 to 0.93). Exclusion of this outlier resulted in less heterogeneity and a smaller pooled effect size ( 4 RCTs, $n=1,018$, pooled SMD $-0.34,95 \% \mathrm{CI}-0.74$ to $0.02, \mathrm{I}^{2}=70.5 \%$ ), which was more consistent with, but larger than, the original report (prior report analysis, $3 \mathrm{RCTS}, \mathrm{n}=906$, pooled SMD $-0.24,95 \% \mathrm{CI}-0.38$ to $-0.04, \mathrm{I}^{2}=0 \%$ ); see Appendix G, Figure G-2 for updated plot. While the pooled estimate from the updated meta-analysis including the new PRT trial was similar to the prior report estimate, the heterogeneity was substantially higher. This may in part be due to differences in the therapeutic approach in the PRT trial compared with previously included trials. The bulk of the evidence for psychological therapies in the original report was from large trials focused on CBT. While PRT incorporates aspects of CBT, it also includes other psychological interventions used in pain management and emphasizes exposure-based interventions in conjunction with reappraising pain. Only the new trial of $\mathrm{PRT}^{7}$ reported on intermediate- and long-term function. Updated meta-analyses to include this RCT resulted in a small increase in effect size for each time frame but did not change conclusions from the original report that psychological therapies were associated with small improvements in function at intermediate term ( 4 RCTs, $n=1,142$, pooled $\mathrm{SMD}-0.30,95 \% \mathrm{CI}-0.60$ to $\left.-0.11, \mathrm{I}^{2}=0 \%\right)$ and long term ( 4 RCTs, $\mathrm{n}=939$, pooled $\mathrm{SMD}-0.31$, $95 \% \mathrm{CI}-0.47$ to $-0.18, \mathrm{I}^{2}=0 \%$ ). PRT was associated with small improvements in pain (0 to 10 scale) compared with usual care at short term (difference $-0.95,95 \% \mathrm{CI}-1.43$ to -0.46 ), intermediate term (difference $-0.91,95 \% \mathrm{CI}-1.37$ to -0.44 ), and long term (difference -0.89 , $95 \% \mathrm{CI}-1.34$ to -0.42 ), which is consistent with the conclusion of the 2020 report. No adverse events were observed for PRT; the other trial did not report on adverse events.

\section{Psychological Therapies Compared With Exercise}

One new small fair-quality trial $(n=36)^{27}$ compared relaxation training versus mobility/flexibility exercises (modified from the McKenzie method) over 6 weeks (18 sessions total for both) and found no difference between groups in function at short-term followup (difference 0.00 on the 0 to 40 Functional Rating Index, 95\% CI -1.09 to 1.09 ). This is the only trial identified to date evaluating short term outcomes for this comparison. Data were considered insufficient to draw conclusions. Harms were not reported.

\section{Physical Modalities for Chronic Low Back Pain}

\section{Low-Level Laser Therapy Compared With Sham}

One new poor-quality small $(n=34)$ industry-funded trial from Iran compared LLLT with sham laser. ${ }^{14}$ It was rated as poor quality primarily due to unclear concealment of treatment allocation, lack of patient and caregiver blinding, and differential loss to followup. The authors reported a large improvement in function (difference -5.70 on 0 to 24 Roland Morris Disability Questionnaire [RDQ], 95\% CI -8.47 to -2.93 ) and large improvement in pain (difference -4.40 on a 0 to 10 scale, $95 \%$ CI -5.31 to -3.49 ) short term. The 2020 report found that LLLT was associated with a small improvement in function and moderate improvement in pain short term (SOE: low for both) compared with sham laser based on one small $(n=56)$ fair-quality trial. ${ }^{35}$ Given the small size and poor quality of the new trial, conclusions from the original report did not change. In the new trial, about 52 percent of the patients in the true laser group reported a temporary increase in pain following the first treatment session. Other adverse events were all 
observed in the sham laser group; authors intimate that they were related to concomitant use of naproxen by participants.

\section{Transcutaneous Electrical Nerve Stimulation Compared With Sham}

There were no trials of TENS for chronic LBP in the prior report. One new fair-quality trial $(n=73)^{30}$ compared two applications of TENS, burst and conventional, versus sham TENS and found no differences between groups over the short term in function as measured by the modified Oswestry Disability Index (ODI) (burst vs. sham TENS: difference -2.90 on a 0 to 50 scale, $95 \%$ CI -7.97 to 2.17; conventional vs. sham TENS: difference -2.30 on a 0 to 50 scale, $95 \% \mathrm{CI}$ -7.77 to 3.17 ) or in pain (burst vs. sham TENS: difference -0.80 on a 0 to 10 scale, $95 \%$ CI -2.24 to 0.64 ; conventional vs. sham TENS: difference -1.30 on a 0 to 10 scale, $95 \% \mathrm{CI}-2.74$ to 0.14). Results were similar across other measures of pain. SOE was low. No TENS-associated side effects occurred in any patient.

\section{Manual Therapies for Chronic Low Back Pain}

\section{Spinal Manipulation Compared With Sham Manipulation, Usual Care, an Attention Control, or a Placebo Intervention}

One new good-quality RCT $(\mathrm{N}=155)^{28}$ compared groups receiving spinal manipulation, mobilization or sham laser treatment and reported on function and pain short term. Manipulation consisted of rapid thrust applied to the shoulder and pelvis; mobilization consisted of having the patient gently push the shoulder and pelvis into the clinician's hands. The sham laser treatment was done with the patient in the same position as the active interventions, and the machine appeared operational to patients and clinicians but delivered no energy. All sessions were twice weekly for 3 weeks. There were no differences in mean change scores for function (RDQ, 0 to 24 scale) between manipulation and sham treatment $(-0.07,95 \% \mathrm{CI}-1.43$ to 1.29$)$ or mobilization and sham treatment $(0.9,95 \% \mathrm{CI}-0.41$ to 2.29$)$. Given this, and the fact that studies in the 2020 report appear to have used a combination of manipulation and mobilization techniques, these active treatment groups were combined to update the meta-analysis. Inclusion of the new trial decreased the effect size estimate somewhat for functional improvement ( 4 RCTs, $n=859$, pooled SMD $-0.24,95 \% \mathrm{CI}-0.61$ to $0.09, \mathrm{I}^{2}=61.8 \%$ ), and there was greater imprecision compared with the 2020 report ( 3 RCTs, $n=704$, pooled SMD $-0.34,95 \%$ CI -0.75 to $-0.02, \mathrm{I}^{2}=44.6 \%$ ); see Appendix G, Figure G-3 for updated plot. Our prior conclusion of a small improvement in function and low SOE did not change.

There were no differences in mean change scores for numerical rating scale (NRS) pain (0 to 10 scale) short term for either manipulation versus sham (difference $-0.03,95 \% \mathrm{CI}-0.65$ to 0.59 ) or mobilization versus sham (difference $-0.26,95 \% \mathrm{CI}-0.38$ to 0.85 ). In the 2020 report, there was no difference in pain short term between spinal manipulation and placebo/sham intervention or attention control across three studies. The addition of the new study did not change this conclusion and SOE remained low. Adverse events were not reported.

\section{Massage Compared With Sham Massage, Usual Care, or an Attention Control}

One new fair-quality trial $(\mathrm{n}=59)^{15}$ compared Shiatsu massage (4 weekly 1-hour sessions) with usual care and found no differences between groups in function (difference in change scores -1.60 on the 0 to $24 \mathrm{RDQ}, 95 \% \mathrm{CI}-3.27$ to 0.07 ) or pain (difference in change scores -0.80 on a 0 to 10 scale, $95 \% \mathrm{CI}-1.92$ to 0.32 ) at short-term followup. The addition of the new trial did not change the prior report's conclusion (small effect for function and pain short term) and SOE 
remained moderate. Regarding harms, in the Shiatsu massage group, 10 percent of patients reported muscle pain and 3 percent reported headache; in the usual care group, 3 percent of patents reported each of the following events: dizziness, herpes zoster, and abdominal pain.

\section{Mind-Body Practices for Chronic Low Back Pain}

\section{Yoga Compared With Exercise}

Two new fair-quality trials $(\mathrm{N}=252)^{20,22}$ comparing yoga with combination exercise (strengthening and stretching with or without stabilization) found no differences between groups in function or pain at short-term followup, consistent with the findings of the prior report (SOE remained low). Across trials, patients underwent weekly sessions of different duration (35 and 75 minutes) over 6 and 8 weeks. Both trials reported function according to the RDQ ( 0 to 24 scale); the difference in change scores from baseline was $-0.06(95 \% \mathrm{CI}-1.55$ to 1.43$)$ in the larger trial $(\mathrm{n}=182),{ }^{20}$ and in the second trial $(\mathrm{n}=70)$ the median (interquartile range [IQR]) scores were 6 (3.5 to 12 ) versus 6 ( 1 to 11 ), $\mathrm{p}=0.26 .{ }^{22}$ For pain, the difference in change scores was 0.04 on a 0 to 10 visual analog scale (VAS) $(95 \% \mathrm{CI}-0.50$ to 0.58$)$ in the larger trial, ${ }^{20}$ and in the second trial the median (IQR) scores on the Defense and Veterans Pain Rating Scale (0 to 10 scale) were 4 ( 2.5 to 5 ) versus 4 ( 2 to 5 ), $\mathrm{p}=0.70 .{ }^{22}$

No serious adverse events occurred in either trial. The larger trial reported significantly fewer minor events in the yoga group compared with the exercise group, which included mild and selflimited exacerbating back pain ( $7 \%$ vs. $30 \%$; risk ratio [RR] $0.23,95 \%$ CI 0.10 to 0.50 ), general pain ( $4 \%$ vs. $18 \%$; RR $0.33,95 \%$ CI 0.11 to 1.00$)$, and muscle pain $(0 \%$ vs. $8 \%, p=0.001) .{ }^{20}$ The second trial reported that three patients experienced a slight increase in pain; the authors did not indicate to which group the patients were randomized. ${ }^{22}$

\section{Acupuncture for Chronic Low Back Pain}

\section{Acupuncture Compared With Sham Acupuncture, Usual Care, an Attention Control, or a Placebo Intervention}

One new fair-quality trial $(n=43)^{18}$ compared two types of acupuncture, hand-ear acupuncture and standard acupuncture, with usual care for 7 weeks. At short-term followup, hand-ear acupuncture was associated with large improvements in both function (difference -7.34 on the 0 $24 \mathrm{RDQ}, 95 \% \mathrm{CI}-9.50$ to -5.18 ) and pain (difference -2.29 on a 0 to 10 scale, $95 \% \mathrm{CI}-3.01$ to -1.57 ), and standard acupuncture was associated with moderate improvements in both function (difference -4.89 on the $0-24 \mathrm{RDQ}, 95 \% \mathrm{CI}-7.47$ to -52.31 ) and pain (difference -1.15 on a 0 to 10 scale, $95 \% \mathrm{CI}-1.86$ to -0.44 ) compared with usual care. The addition of the new trial did not change the prior report's conclusion (small effects short term), and SOE remained low for function and moderate for pain.

One patient (2\%) who received hand-ear acupuncture complained of needling pain and two patients $(4 \%)$ in the standard acupuncture group experienced anxiety. No other complications were reported. 


\section{Key Question 2: Chronic Neck Pain}

\section{Exercise for Chronic Neck Pain}

\section{Exercise Compared With No Treatment, Waitlist, an Attention Control, or Sham Intervention}

One new small fair-quality trial $(\mathrm{n}=43),{ }^{8}$ compared therapeutic muscle performance exercise (21 total sessions) with sham suboccipital inhibition for 3 weeks in patients with nonspecific chronic neck pain. ${ }^{8}$ Exercise was associated with a moderate improvement in function (difference -16.81 on the 0 to 100 Neck Disability Index [NDI], 95\% CI -25.00 to -8.62 ) and a large improvement in pain (difference -2.43 on a 0 to 10 scale, $95 \%$ CI -2.69 to -2.17 ) over the short term. Given the small size of the new trial, its addition did not change the prior report's conclusion (no effect for pain and function) and SOE remained low.

\section{Manual Therapies for Chronic Neck Pain}

\section{Spinal Manipulation Compared With Sham Manipulation and With Exercise}

There were no trials of spinal manipulation for chronic nonspecific neck pain in the prior report. One new small fair-quality trial $(\mathrm{n}=42)^{8}$ compared spinal manipulation versus sham suboccipital inhibition and versus therapeutic exercise $(\mathrm{n}=45)$ for 3 weeks. Spinal manipulation was associated with a moderate improvement in function (difference -18.67 on the 0 to $100 \mathrm{NDI}$, $95 \% \mathrm{CI}-26.04$ to -11.30 ) and a large improvement in pain (difference -3.05 on a 0 to 10 scale, $95 \%$ CI -3.30 to -2.80 ) over the short term compared with sham manipulation but when compared with exercise therapy, there were no differences between groups for either outcome. The SOE was low. Harms were not reported.

\section{Key Question 3: Osteoarthritis Knee Pain}

\section{Exercise for Osteoarthritis Knee Pain}

\section{Exercise Compared With Usual Care, No Treatment, Sham, or an Attention Control}

Three new trials comparing group muscle performance exercises with usual care or attention control in patients with knee OA were identified. ${ }^{19,21,26}$ Aquatic exercise was compared with usual care in two trials: cycling 45 minutes twice weekly for 12 weeks ( 24 sessions) was done in one poor-quality trial ( $\mathrm{N}=102$ randomized $)^{26}$ and one-hour sessions of lower limb resistance training three times per week for 4 months (total of 48 sessions) was done in a fair-quality trial in post-menopausal women $(\mathrm{N}=87$ randomized $){ }^{21}$ In the third, fair-quality, trial $(\mathrm{N}=377$ randomized) ${ }^{19} 60$-minute high-intensity or low-intensity strength training sessions three times per week for 18 months were compared with an attention control consisting of 24, 60-minute group workshops over 18 months. To update meta-analyses the high and low intensity groups were combined.

Across time frames, the addition of these new trials did not change the 2020 report's conclusions or strength of evidence regarding function.

At short term, the new poor-quality RCT reported no difference in function between exercise and usual care ${ }^{26}$ Its addition to the previous meta-analysis did not change effect estimates substantially or change conclusions that exercise was associated with a small improvement in 
function compared with usual care ( 9 RCTs, $n=832$, pooled SMD $-0.29,95 \% \mathrm{CI}-0.44$ to -0.12 , $\mathrm{I}^{2}=4.2 \%$, SOE remained moderate). Similarly, one new fair-quality trial reporting function at intermediate term found no difference between groups $;{ }^{19}$ its addition to the prior meta-analysis did not change the 2020 report's conclusions of moderate functional improvement with exercise (12 RCTs, $n=1,144$, pooled SMD $-0.57,95 \% \mathrm{CI}-1.07$ to $-0.08, \mathrm{I}^{2}=92 \%$, excluding the same outlier as the 2020 report, SOE remained low). Neither of the two new fair-quality trials ${ }^{19,21}$ found a difference in function between exercise and usual care or attention control at long term. Their addition to the prior meta-analysis did not alter our 2020 report's conclusions of small functional improvement with exercise or low SOE (6 RCTs, $n=1,541$, pooled SMD $-0.18,95 \%$ CI -0.38 to $-0.03, \mathrm{I}^{2}=0 \%$ ). See Appendix G, Figure G-4 for updated function plot.

For pain, across the new trials, no differences between exercise and usual care or attention control were seen, and their contributions to updated meta-analyses did not alter the 2020 report's conclusions. At short term, there continued to be small improvement in pain with exercise compared with usual care, attention control, or sham intervention ( 9 RCTs, $n=832$, pooled difference $0.50,95 \% \mathrm{CI}-0.84$ to $-0.16, \mathrm{I}^{2}=37.5 \%$ ) with the inclusion of the one new poor-quality trial ${ }^{26}$ (SOE remained moderate). As seen in the 2020 report, moderate improvement in pain ( 0 to 10 scale) was seen at intermediate term with the addition of one new fair-quality trial $\left(12 \mathrm{RCTs}, \mathrm{n}=1,140\right.$, pooled difference $-1.21,95 \% \mathrm{CI}-1.96$ to $-0.44, \mathrm{I}^{2}=92.1 \%$, SOE: low), and there were small improvements in pain that persisted long term with the addition of the two new fair-quality trials ( 6 RCTs, pooled difference $-0.26,95 \% \mathrm{CI}-0.43$ to 0.01 , $\mathrm{I}^{2}=0 \%$, SOE remained low). ${ }^{19,21}$ See Appendix G, Figure G-5 for updated pain plot.

Regarding harms, one new poor-quality trial reported that one patient in the exercise group with a history of cardiovascular disease hyperventilated and was hospitalized overnight, and continued with training after 2 weeks of rest. ${ }^{26}$ Twenty patients experienced body pain in the trial of strength training, 19 experienced falls, and 10 experienced muscle strain. ${ }^{19}$ The third trial did not report on adverse events. ${ }^{21}$

\section{Manual Therapies for Osteoarthritis Knee Pain}

\section{Massage Compared With Usual Care}

One new poor-quality trial $(\mathrm{n}=60)^{24}$ compared six sessions (over 3 weeks) of massage therapy with usual care in elderly patients (mean age 77 years) with knee pain due to OA. There was no difference between groups in short-term function according to the Western Ontario and McMaster Universities Osteoarthritis Index (WOMAC) physical function (difference -1.63 on a 0 to 68 scale, $95 \% \mathrm{CI}-6.72$ to 3.46 ), but massage was associated with a small improvement in short-term pain according to WOMAC pain (difference -1.65 on a 0 to 20 scale, $95 \%$ CI -2.93 to -0.37 ). The trial included in the prior report found no difference between massage and usual care for any outcome short term. The addition of the new poor-quality trial did not change the prior report's conclusion; the evidence remained insufficient to draw conclusions. Harms were not reported.

\section{Physical Modalities for Osteoarthritis Knee Pain}

\section{Ultrasound Compared With Sham}

One new good-quality trial $(n=75)^{13}$ compared 24 sessions of pulsed ultrasound (US) compared with sham US over 8 weeks and found no difference between groups in function according to WOMAC physical function (difference -2.47 on a 0 to 68 scale, $95 \% \mathrm{CI}-8.07$ to 
3.13) or in pain either at rest (difference -0.03 on a 0 to 10 scale, $95 \%$ CI -1.13 to 1.07 ) or with activities of daily living (difference -0.69 on a 0 to 10 scale, $95 \% \mathrm{CI}-1.95$ to 0.57 ) at short-term followup. The addition of the new trial did not change the prior report's conclusion (no effect for function and pain short term) and SOE remained low. Harms were not reported but two (4\%) patients in the sham US group withdrew due to severe knee pain.

\section{Low-Level Laser Therapy Compared With Sham}

One new good-quality trial $(\mathrm{n}=84)^{6}$ comparing LLLT to sham laser reported on pain and function at short and intermediate term. Evidence in the 2020 report for LLLT versus sham laser, which included one fair-quality trial $(\mathrm{n}=49)^{36}$ and two poor-quality trials $(\mathrm{n}=27$ and $\mathrm{n}=60),{ }^{37,38}$ was judged to be insufficient for function and pain. There was a small improvement in function at short term between LLLT and sham laser in pooled analysis including the new good-quality and the previously included fair-quality trial ( 2 RCTs, $n=133$, pooled SMD $-0.39,95 \%$ CI -0.80 to $0.00, \mathrm{I}^{2}=0 \%$ ) and a small improvement at intermediate term when the new trial was added to two previously included trials ( $3 \mathrm{RCTs}, \mathrm{n}=193$, pooled SMD $-0.54,95 \% \mathrm{CI}-1.19$ to 0.05 , $\mathrm{I}^{2}=46.5 \%$ ); see Appendix G, Figure G-6 for new plot. Inclusion of the new trial in meta-analysis resulted in no clear difference in pain ( 0 to 10 scale) between LLLT and sham short term (3 RCTs, $\mathrm{n}=160$, difference $-1.50,95 \% \mathrm{CI}-3.18$ to $0.16, \mathrm{I}^{2}=76.5 \%$ ) or intermediate term ( $3 \mathrm{RCTs}$, $\mathrm{n}=193$, difference $-1.24,95 \%$ CI -2.22 to $0.12, \mathrm{I}^{2}=6.5 \%$ ); see Appendix G, Figure G-7 for updated plot. Based on the addition of the new good-quality trial, the SOE for short- and intermediate-term followup for both function and pain was upgraded from insufficient to low. No trial reported long-term outcomes. Adverse events were not reported in the new trial.

\section{Interferential Current Compared With Sham}

There were no trials of interferential current for OA knee pain in the prior report. One new, good-quality trial $(\mathrm{n}=84)^{6}$ compared 1250 -minute sessions of interferential current with sham intervention (sham interferential current and sham photobiomodulation) over 4 weeks and found no differences between groups on any measure of function or pain at short- and intermediateterm followup (SOE: low). Function was measured using the WOMAC total score (0 to 96 scale) (short term: difference $0.55,95 \% \mathrm{CI}-24.31$ to 7.05 ; intermediate term: difference $1.42,95 \% \mathrm{CI}$ -6.73 to 9.58 ) and the Lequesne Functional Index ( 0 to 24 scale) (short term: difference -1.10 , $95 \% \mathrm{CI}-3.11$ to 0.89 ; intermediate term: difference $-0.16,95 \% \mathrm{CI}-2.15$ to 1.81$)$. Pain was measured on the NRS ( 0 to 10 scale) both at rest (short term: difference $-0.87,95 \% \mathrm{CI}-2.01$ to 0.26 ; intermediate term: difference $-0.32,95 \% \mathrm{CI}-1.34$ to 0.70 ) and during activity (short term: difference $-0.42,95 \% \mathrm{CI}-1.65$ to 0.80 ; intermediate term: difference $0.49,95 \% \mathrm{CI}-1.63$ to 0.64). Harms were not reported.

\section{Mind-Body Therapies for Osteoarthritis Knee Pain}

\section{Tai Chi Compared With Attention Control}

One new poor-quality trial $(\mathrm{n}=92)^{12}$ compared Tai Chi ( 72 sessions total) versus an attention control (health education lectures and discussion) over a treatment period of 6 months. Tai Chi was associated with moderate improvements in both function (difference -17.47 on a 0 to 68 WOMAC physical function scale, $95 \% \mathrm{CI}-22.10$ to -12.84 ) and pain (difference -1.07 on a 0 to 10 scale, $95 \% \mathrm{CI}-1.74$ to -0.40 ) at intermediate-term followup. The addition of the new trial does not change the prior report's conclusion; the evidence remained insufficient to draw conclusions. Harms were not reported. 


\section{Qigong Compared With Exercise}

There were no trials of Qigong compared with exercise for OA knee pain in the prior report. One new fair-quality trial $(\mathrm{n}=68)^{29}$ compared Qigong with combination exercise (strength and aerobic training) in older participants (mean age 70 years); both groups received treatment 4 days a week for 6 months (96 sessions total). At intermediate-term followup, there were no betweengroup differences on measures of function (difference -2.20 on the 0 to 68 WOMAC physical function scale, $95 \% \mathrm{CI}-6.24$ to 1.84 ) or pain (difference -1.20 on the 0 to 20 WOMAC pain scale, $95 \% \mathrm{CI}-3.04$ to 0.64 ). The SOE was considered insufficient to draw conclusions. Attrition in this study was over 30 percent. The authors also note that adherence to Qigong was high while adherence in the exercise group was very low, possibly due to differences in the comfort level of older patients for performing the exercise types. This may have impacted the findings. Harms were not reported.

\section{Acupuncture for Osteoarthritis Knee Pain}

\section{Acupuncture Compared With Usual Care, Waitlist, or Sham}

One new good-quality trial $(n=83)^{16}$ compared superficial needling acupuncture with sham acupuncture (10 sessions total over 4 weeks) and found no differences between groups in function (difference -45.3 on a 0 to 1700 WOMAC physical function scale, $95 \% \mathrm{CI}-183.8$ to 93.3) or pain (difference -0.22 on a 0 to 10 scale, $95 \% \mathrm{CI}-1.31$ to 0.88 ) at short-term followup. No differences were seen in the proportion of patients with 30 percent or more $(59 \% \mathrm{vs} .56 \%)$ or 50 percent or more (39\% vs. 36\%) improvement on VAS pain. Similar results were seen across other measures of function and pain. These results are consistent with the prior report; the addition of the new trial did not change the prior report's conclusion (no effect for function and pain short term) and SOE remained low.

Adverse events occurred with greater frequency in the true acupuncture (4.4\%) versus the sham acupuncture (0.8\%) group; (RR 5.86, 95\% CI 1.87 to 18.39$)$, due primarily to pain during needle insertion or needle adjustment. Pain during needle removal, bleeding, bruising, and numbness were also reported by patients randomized to true acupuncture (range of frequencies, $0.2 \%$ to $0.7 \%$ ).

\section{Key Question 4: Fibromyalgia}

\section{Exercise for Fibromyalgia}

\section{Exercise Compared With Usual Care, Waitlist, an Attention Control, or No Treatment}

Two new small poor-quality trials compared exercise therapies with usual care for fibromyalgia and reported only short-term function. ${ }^{11,23}$ One trial $(n=69)^{11}$ evaluated core stability-based physiotherapy and found no difference between groups on the Fibromyalgia Impact Questionnaire (FIQ) physical function item (difference -0.15 on a 0 to 10 scale, $95 \%$ CI -1.05 to 0.75$)$. The second trial $(n=66)^{23}$ reported that combination exercise (aerobics, balance, postural, stretching, and Pilates) was associated with improved function compared with usual care but that the difference did not reach statistical significance (mean [standard deviation]: 52.8 [17.9] vs. 68.9 [17.5] on the 0-100 FIQ). The addition of the two new poor-quality trials did not change the prior report's conclusion (small effect for function short term) and SOE remained low. 
Only one of the trials reported harms. One patient in the exercise group experienced knee pain exacerbation and had to rest during the last three sessions; no other events were reported. ${ }^{11}$

\section{Manual Therapies for Fibromyalgia}

\section{Spinal Manipulation Compared With Sham Manipulation}

There were no trials of spinal manipulation for fibromyalgia in the prior report. One new fairquality trial $(\mathrm{n}=101)^{10}$ comparing six sessions (over 6 weeks) of spinal manipulation versus sham manipulation reported no differences between groups in function on the 0 to 100 FIQ at short term (adjusted difference 1.2, 95\% CI -4.9 to 7.3 ) and intermediate term (adjusted difference $-1.1,95 \% \mathrm{CI}-7.9$ to 5.6 ) or in pain on a 0 to $10 \mathrm{VAS}$ scale at short term (adjusted difference $-0.56,95 \% \mathrm{CI}-2.21$ to 1.08 ) and intermediate term (adjusted difference $-0.50,95 \% \mathrm{CI}-2.48$ to 1.47). Similarly, there were no differences between groups in estimated odds ratios (ORs) for global improvement in pain at either timepoint (short term: OR 1.44, 95\% CI 0.60 to 3.43; intermediate term: OR $1.51,95 \%$ CI 0.65 to 3.51$)$. Attrition in this trial was high ( $48 \%$ at both timepoints). The strength of evidence was considered low.

\section{Mindfulness Practices for Fibromyalgia}

\section{Mindfulness-Based Stress Reduction or Meditation Awareness Training Compared With Usual Care, Waitlist, or Attention Control}

One new poor-quality trial $(\mathrm{n}=98)^{25}$ found that mindfulness-based stress reduction (MBSR) ( 8 weekly sessions) was associated with a small improvement in function versus usual care over intermediate-term followup (difference -9.77 on the $0-100 \mathrm{FIQ}, 95 \% \mathrm{CI}-17.99$ to -1.55 ). The addition of the new trial does not change the prior report's conclusion (small effect for function intermediate term) and SOE remained low.

Eight (16\%) patients randomized to MBSR reported adverse events that occurred during and/or after the intervention. These events occurred at a very low intensity and frequency in five patients (no other information provided) and with "significant frequency" in three patients (mild fatigue, intense palpitations, and a variety of moderate adverse effects such as fatigue, tension, headaches, dizziness, somnolence, gain of weight, and loss of sexual desire).

\section{Mind-Body Therapies for Fibromyalgia}

\section{Basic Body Awareness Therapy Compared With Usual Care}

There were no trials of basic body awareness therapy (BBAT) for fibromyalgia in the prior report. One new small fair-quality trial $(\mathrm{n}=39)^{9}$ found no difference in pain (on a 0 to 10 scale) at short term (mean 6.9 vs. $7.4, p>0.05$ ) and intermediate term (mean 7.1 vs. 7.5, $p>0.05$ ) between BBAT (10 sessions over 5 weeks) and usual care. Means were estimated from author figures; no information on variability (e.g., standard deviation) was provided, precluding estimation of effect size with corresponding confidence intervals. The data were judged to be insufficient to draw conclusions. Harms were not reported. 


\section{Acupuncture for Fibromyalgia}

\section{Acupuncture Compared With Usual Care and With Exercise}

There were no trials of acupuncture compared with usual care (there were 3 trials vs. sham acupuncture) or with exercise in the prior report. One new small, poor-quality trial $(n=69)^{11}$ compared 10 sessions (over 5 weeks) of Traditional Chinese Medicine needle acupuncture versus usual care and versus core stability exercise, and found no differences between groups in shortterm function according to the FIQ physical function item (versus usual care: difference -0.62 on a 0 to 10 scale, $95 \%$ CI -1.62 to 0.38 ; versus exercise: difference -0.47 on a 0 to 10 scale, $95 \%$ $\mathrm{CI}-1.44$ to 0.50 ). The evidence was considered insufficient to draw conclusions. Intermediateand long-term data and pain outcomes were not reported. No harms were reported in either group.

\section{Multidisciplinary Rehabilitation for Fibromyalgia}

\section{Multidisciplinary Rehabilitation Compared With Usual Care or Waitlist and With Exercise}

One new poor-quality trial $(\mathrm{n}=66)^{23}$ compared 12 sessions (over 12 weeks) of MDR (i.e., CBT and occupational therapy) versus usual care and versus combination exercise (aerobics, balance, postural, stretching, and Pilates) and reported only short-term function. There was no difference between MDR and usual care (difference -0.30 on the 0 to 100 FIQ, 95\% CI -8.61 to 8.00); MDR was associated with less improvement in function compared with exercise, but the difference did not reach statistical significance (mean [standard deviation]: 68.6 [15.7] vs. 52.8 [17.9]). The addition of the new trial does not change the prior report's conclusion for MDR versus usual care or waitlist (small effect for function short term, SOE remained low). There was no evidence for function at short-term followup for MDR versus exercise in the prior report; the evidence from this new trial was considered insufficient to draw conclusions.

\section{Conclusions}

The original report evaluated noninvasive nonpharmacological treatments for five common chronic pain conditions (LBP, neck pain, OA, FM, and tension headache). Across trials in the prior report, exercise, MDR, acupuncture, CBT, mindfulness practices, and mind-body practices were most consistently associated with durable small to moderate improvements in function and pain for specific chronic pain conditions, although the data were sparse for many interventions. There was very little evidence for chronic tension headache specifically. The majority of trials compared interventions with usual care, with very few trials employing pharmacological treatments or exercise as comparators. Harms were poorly reported across interventions. No serious intervention-related adverse events (e.g., leading to death or disability. or requiring intensive medical attention) were identified; reported adverse events were generally minor and time limited.

New evidence for noninvasive nonpharmacological treatments for chronic LBP, chronic neck pain, knee OA, and FM for this surveillance report was generally consistent with the prior report and did not alter its conclusions. For chronic LBP, new trials for psychological interventions versus usual care resulted in downgrading of SOE from moderate to low for short-term function. For knee OA, a new trial of low-level laser therapy with sham allowed us to pool data with previously included trials, upgrading SOE from insufficient to low for small improvements in 
function but no effect on pain at short or intermediate term. New interventions or comparators for which there was at least low strength of evidence of no effect for function and/or pain were: TENS versus sham TENS in chronic LBP, spinal manipulation versus exercise for chronic neck pain, inferential current versus sham for knee OA, and spinal manipulation versus sham manipulation for FM. Spinal manipulation was associated with improvements in function and pain short term compared with sham laser for chronic neck pain. SOE for all these findings was low. Consistent with the original report, no trials in pregnant or breastfeeding women with preexisting chronic pain or trials comparing interventions with opioids, topical agents, medical cannabis, or muscle relaxants were identified for this update, and no new data were available to evaluate nociplasticity as a modifier to treatment effectiveness or safety.

The next surveillance report is scheduled for February 2022. 


\section{References}

1. Skelly AC, Chou R, Dettori JR, et al. Noninvasive Nonpharmacological Treatment for Chronic Pain: A Systematic Review Update. Comparative Effectiveness Review No. 227. (Prepared by the Pacific Northwest Evidence-based Practice Center under Contract No. 290-2015-00009-I.) AHRQ Publication No. 20-EHC009. Rockville, MD: Agency for Healthcare Research and Quality; April 2020. https://effectivehealthcare.ahrq.gov/products /noninvasive-nonpharm-painupdate/research. PMID: 32338846.

2. Chou R, Dana T, Shetty KD. Testing a Machine Learning Tool for Facilitating Living Systematic Reviews of Chronic Pain Treatments. Methods Research Report. (Prepared by the Pacific Northwest Evidence-based Practice Center under Contract No. 290-2015-00009-I and the Southern California Evidence-based Practice Center-RAND Corporation under Contract No. 290-2015-00010-I.) AHRQ Publication No. 21-EHC004. Rockville, MD: Agency for Healthcare Research and Quality; November 2020. Posted final reports are located on the Effective Health Care Program search page. DOI: 10.23970/AHRQEPCMETHTESTINGMAC HINELEARNING.

3. Higgins JPT, Green S, eds. Cochrane Handbook for Systematic Reviews of Interventions. Version 5.1.0 [updated March 2011]. The Cochrane Collaboration. Available from http://handbook.cochrane.org.; 2011.

4. Methods Guide for Effectiveness and Comparative Effectiveness Reviews. AHRQ Publication No. 10(14)-EHC063-EF. Rockville, MD: Agency for Healthcare Research and Quality. January 2014. Chapters available at: www.effectivehealthcare.ahrq.gov.

5. Furlan AD, Malmivaara A, Chou R, et al. 2015 Updated Method Guideline for Systematic Reviews in the Cochrane Back and Neck Group. Spine (Phila Pa 1976). 2015 Nov;40(21):1660-73. doi: 10.1097/BRS.0000000000001061. PMID: 26208232 .
6. Alqualo-Costa R, Rampazo EP, Thome GR, et al. Interferential current and photobiomodulation in knee osteoarthritis: A randomized, placebo-controlled, doubleblind clinical trial. Clinical Rehabilitation. 2021 Apr 26:2692155211012004. doi: https://dx.doi.org/10.1177/02692155211012 004. PMID: 33896234.

7. Ashar YK, Gordon A, Schubiner H, et al. Effect of Pain Reprocessing Therapy vs Placebo and Usual Care for Patients With Chronic Back Pain: A Randomized Clinical Trial. JAMA Psychiatry. 2021 Sep 29doi: 10.1001/jamapsychiatry.2021.2669. PMID: 34586357.

8. Bernal-Utrera C, Gonzalez-Gerez JJ, Anarte-Lazo E, et al. Manual therapy versus therapeutic exercise in non-specific chronic neck pain: a randomized controlled trial. Trials [Electronic Resource]. $2020 \mathrm{Jul}$ 28;21(1):682. doi: https://dx.doi.org/10.1186/s13063-02004610-w. PMID: 32723399.

9. Bravo C, Skjaerven LH, Espart A, et al. Basic Body Awareness Therapy in patients suffering from fibromyalgia: a randomized clinical trial. Physiotherapy theory and practice. 2019;35(10):919-29. PMID: CN01980930.

10. Coste J, Medkour T, Maigne JY, et al. Osteopathic medicine for fibromyalgia: a sham-controlled randomized clinical trial. Therapeutic Advances in Musculoskeletal Disease. 2021;13:1759720X211009017. doi: https://dx.doi.org/10.1177/1759720X211009 017. PMID: 33948127.

11. Garrido-Ardila EM, Gonzalez-Lopez-Arza MV, Jimenez-Palomares M, et al. Effectiveness of acupuncture vs. core stability training in balance and functional capacity of women with fibromyalgia: a randomized controlled trial. Clinical Rehabilitation. 2020 May;34(5):630-45. doi: https://dx.doi.org/10.1177/02692155209119 92. PMID: 32204612. 
12. Hu X, Lai Z, Wang L. Effects of Taichi exercise on knee and ankle proprioception among individuals with knee osteoarthritis. Research in Sports Medicine. 2020 AprJun;28(2):268-78. doi: https://dx.doi.org/10.1080/15438627.2019.1 663520. PMID: 31524502.

13. Karakas A, Dilek B, Sahin MA, et al. The effectiveness of pulsed ultrasound treatment on pain, function, synovial sac thickness and femoral cartilage thickness in patients with knee osteoarthritis: a randomized, doubleblind clinical, controlled study. Clinical Rehabilitation. 2020 Dec;34(12):1474-84. doi:

https://dx.doi.org/10.1177/02692155209429 53. PMID: 32715744.

14. Kholoosy L, Elyaspour D, Akhgari MR, et al. Evaluation of the Therapeutic Effect of Low Level Laser in Controlling Low Back Pain: A Randomized Controlled Trial. Journal of Lasers in Medical Sciences. 2020;11(2):120-5. doi:

https://dx.doi.org/10.34172/jlms.2020.21. PMID: 32273951.

15. Kobayashi D, Shimbo T, Hayashi H, et al. Shiatsu for chronic lower back pain: Randomized controlled study. Complementary Therapies in Medicine. 2019 Aug;45:33-7. doi: https://dx.doi.org/10.1016/j.ctim.2019.05.01 9. PMID: 31331579.

16. Lam WC, Au KY, Qin Z, et al. Superficial needling acupuncture versus sham acupuncture for knee osteoarthritis: a randomized controlled trial. American Journal of Medicine. 2021 Jun 11;11:11. doi:

https://dx.doi.org/10.1016/j.amjmed.2021.05 .002. PMID: 34126097.

17. Lang AE, Hendrick PA, Clay L, et al. A randomized controlled trial investigating effects of an individualized pedometer driven walking program on chronic low back pain. BMC Musculoskeletal Disorders. 2021 Feb 19;22(1):206. doi: https://dx.doi.org/10.1186/s12891-02104060-8. PMID: 33607979.
18. Luo Y, Yang M, Liu T, et al. Effect of handear acupuncture on chronic low-back pain: a randomized controlled trial. Journal of traditional chinese medicine $=$ chung $\mathrm{i}$ tsa chih ying wen pan. 2019;39(4):587-98. PMID: CN-02144857.

19. Messier SP, Mihalko SL, Beavers DP, et al. Effect of High-Intensity Strength Training on Knee Pain and Knee Joint Compressive Forces Among Adults With Knee Osteoarthritis: The START Randomized Clinical Trial. JAMA. 202102 16;325(7):646-57. doi: https://dx.doi.org/10.1001/jama.2021.0411. PMID: 33591346.

20. Michalsen A, Jeitler M, Kessler CS, et al. Yoga, Eurythmy Therapy and Standard Physiotherapy (YES-Trial) for Patients With Chronic Non-specific Low Back Pain: A Three-Armed Randomized Controlled Trial. Journal of Pain. 2021 Apr 20;20:20. doi: https://dx.doi.org/10.1016/j.jpain.2021.03.15 4. PMID: 33892154.

21. Munukka M, Waller B, Hakkinen A, et al. Effects of progressive aquatic resistance training on symptoms and quality of life in women with knee osteoarthritis: A secondary analysis. Scandinavian Journal of Medicine \& Science in Sports. 2020 Jun;30(6):1064-72. doi: https://dx.doi.org/10.1111/sms.13630. PMID: 31999876.

22. Neyaz O, Sumila L, Nanda S, et al. Effectiveness of Hatha Yoga Versus Conventional Therapeutic Exercises for Chronic Nonspecific Low-Back Pain. Journal of Alternative \& Complementary Medicine. 2019 Sep;25(9):938-45. doi: https://dx.doi.org/10.1089/acm.2019.0140. PMID: 31347920.

23. Patru S, Padureanu R, Dumitrescu F, et al. Influence of multidisciplinary therapeutic approach on fibromyalgia patients. Experimental \& Therapeutic Medicine. 2021 May;21(5):528. doi: https://dx.doi.org/10.3892/etm.2021.9960. PMID: 33815601.

24. Pehlivan S, Karadakovan A. Effects of aromatherapy massage on pain, functional state, and quality of life in an elderly individual with knee osteoarthritis. Japan journal of nursing science. 2019;16(4):4508. PMID: CN-02078086 NEW. 
25. Perez-Aranda A, Feliu-Soler A, MonteroMarin J, et al. A randomized controlled efficacy trial of mindfulness-based stress reduction compared with an active control group and usual care for fibromyalgia: the EUDAIMON study. Pain. 2019

11;160(11):2508-23. doi: https://dx.doi.org/10.1097/j.pain.000000000 0001655. PMID: 31356450.

26. Rewald S, Lenssen AFT, Emans PJ, et al. Aquatic Cycling Improves Knee Pain and Physical Functioning in Patients With Knee Osteoarthritis: A Randomized Controlled Trial. Archives of Physical Medicine \& Rehabilitation. 2020 08;101(8):1288-95. doi:

https://dx.doi.org/10.1016/j.apmr.2019.12.0 23. PMID: 32169459.

27. Shariat A, Alizadeh R, Moradi V, et al. The impact of modified exercise and relaxation therapy on chronic lower back pain in office workers: a randomized clinical trial. Journal of Exercise Rehabilitation. 2019

Oct;15(5):703-8. doi:

https://dx.doi.org/10.12965/jer.1938490.245. PMID: 31723560.

28. Thomas JS, Clark BC, Russ DW, et al. Effect of Spinal Manipulative and Mobilization Therapies in Young Adults With Mild to Moderate Chronic Low Back Pain: A Randomized Clinical Trial. JAMA Network Open. 202008 03;3(8):e2012589. doi:

https://dx.doi.org/10.1001/jamanetworkopen .2020.12589. PMID: 32756930 .

29. Xiao CM, Li JJ, Kang Y, et al. Follow-up of a Wuqinxi exercise at home programme to reduce pain and improve function for knee osteoarthritis in older people: a randomised controlled trial. Age \& Ageing. 202102 26;50(2):570-5. doi:

https://dx.doi.org/10.1093/ageing/afaa179. PMID: 32931545.

30. Yaksi E, Ketenci A, Baslo MB, et al. Does transcutaneous electrical nerve stimulation affect pain, neuropathic pain, and sympathetic skin responses in the treatment of chronic low back pain? A randomized, placebo-controlled study. The Korean journal of pain. 2021 Apr 01;34(2):217-28. doi:

https://dx.doi.org/10.3344/kjp.2021.34.2.217 . PMID: 33785674.
31. Groessl EJ, Liu L, Schmalzl L, et al. Secondary Outcomes from a Randomized Controlled Trial of Yoga for Veterans with Chronic Low-Back Pain. Int J Yoga Therap. 2020 Jan 1;30(1):69-76. doi: 10.17761/2020-D-19-00036. PMID: 31509451 .

32. Joyce C, Roseen EJ, Keysor JJ, et al. Can Yoga or Physical Therapy for Chronic Low Back Pain Improve Depression and Anxiety Among Adults From a Racially Diverse, Low-Income Community? A Secondary Analysis of a Randomized Controlled Trial. Archives of Physical Medicine \& Rehabilitation. 2021 Jun;102(6):1049-58. doi:

https://dx.doi.org/10.1016/j.apmr.2021.01.0 72. PMID: 33556352.

33. McCrae CS, Curtis AF, Miller MB, et al. Effect of cognitive behavioural therapy on sleep and opioid medication use in adults with fibromyalgia and insomnia. Journal of Sleep Research. 2020 12;29(6):e13020. doi: https://dx.doi.org/10.1111/jsr.13020. PMID: 32126156.

34. Roseen EJ, Gerlovin H, Femia A, et al. Yoga, Physical Therapy, and Back Pain Education for Sleep Quality in Low-Income Racially Diverse Adults with Chronic Low Back Pain: a Secondary Analysis of a Randomized Controlled Trial. Journal of General Internal Medicine. 2020 01;35(1):167-76. doi: https://dx.doi.org/10.1007/s11606-01905329-4. PMID: 31667747.

35. Basford JR, Sheffield CG, Harmsen WS. Laser therapy: a randomized, controlled trial of the effects of low-intensity Nd:YAG laser irradiation on musculoskeletal back pain. Arch Phys Med Rehabil. 1999 Jun;80(6):647-52. doi: 10.1016/s00039993(99)90167-3. PMID: 10378490.

36. Al Rashoud AS, Abboud RJ, Wang W, et al. Efficacy of low-level laser therapy applied at acupuncture points in knee osteoarthritis: a randomised double-blind comparative trial. Physiotherapy. 2014 Sep;100(3):242-8. doi: 10.1016/j.physio.2013.09.007. PMID: 24418801 . 
37. Hegedus B, Viharos L, Gervain M, et al. The effect of low-level laser in knee osteoarthritis: a double-blind, randomized, placebo-controlled trial. Photomed Laser Surg. 2009 Aug;27(4):577-84. doi: 10.1089/pho.2008.2297. PMID: 19530911.

38. Tascioglu F, Armagan O, Tabak Y, et al. Low power laser treatment in patients with knee osteoarthritis. Swiss Med Wkly. 2004 May 1;134(17-18):254-8. doi:

2004/17/smw-10518. PMID: 15243853. 


\section{Authors}

Andrea C. Skelly, Ph.D., M.P.H

Erika D. Brodt, B.S.

Shelby Kantner, B.A.

Andrea Diulio-Nakamura, Ph.D.

Kim Mauer, M.D.

Kanaka D. Shetty, M.D., M.S.

\section{Acknowledgments}

The authors gratefully acknowledge the following individuals for their contributions to this project: research associate and librarian Tracy Dana, M.L.S., and research associate Christina Bougatsos, M.P.H., both from Oregon Health \& Science University; Task Order Officer Suchitra Iyer, Ph.D., at the Agency for Healthcare Research and Quality.

\section{Disclaimers}

This report is based on research conducted by the Pacific Northwest Evidence-based Practice Center under contract to the Agency for Healthcare Research and Quality (AHRQ), Rockville, MD (Contract No. 75Q80120D00006). The findings and conclusions in this document are those of the authors, who are responsible for its contents; the findings and conclusions do not necessarily represent the views of AHRQ. Therefore, no statement in this report should be construed as an official position of AHRQ or of the U.S. Department of Health and Human Services.

None of the investigators have any affiliations or financial involvement that conflicts with the material presented in this report.

The information in this report is intended to help healthcare decision makers - patients and clinicians, health system leaders, and policymakers, among others - make well-informed decisions and thereby improve the quality of health care services. This report is not intended to be a substitute for the application of clinical judgment. Anyone who makes decisions concerning the provision of clinical care should consider this report in the same way as any medical reference and in conjunction with all other pertinent information, i.e., in the context of available resources and circumstances presented by individual patients.

This report is made available to the public under the terms of a licensing agreement between the author and the Agency for Healthcare Research and Quality. This report may be used and reprinted without permission except those copyrighted materials that are clearly noted in the report. Further reproduction of those copyrighted materials is prohibited without the express permission of copyright holders.

AHRQ or U.S. Department of Health and Human Services endorsement of any derivative products that may be developed from this report, such as clinical practice guidelines, other quality enhancement tools, or reimbursement or coverage policies, may not be stated or implied.

AHRQ appreciates appropriate acknowledgment and citation of its work. Suggested language for acknowledgment: This work is a quarterly update report of a living systematic evidence report based on Noninvasive Nonpharmacological Treatments for Chronic Pain, by the Evidence-based Practice Center Program at the Agency for Healthcare Research and Quality (AHRQ).

Suggested citation: Skelly AC, Brodt ED, Kantner S, Diulio-Nakamura A, Mauer K, Shetty KD. Systematic Review on Noninvasive Nonpharmacological Treatments for Chronic Pain: Surveillance Report 1. (Prepared by the Pacific Northwest Evidence-based Practice Center under Contract No. 75Q80120D00006.) AHRQ Publication No. 22-EHC008. Rockville, MD: Agency for Healthcare Research and Quality; February 2022. DOI: https://doi.org/10.23970/AHRQEPCSURVEILLANCENONINVASIVENONPHARMA. Posted final reports are located on the Effective Health Care Program search page. 


\section{Afterword}

The Agency for Healthcare Research and Quality (AHRQ), through its Evidence-based Practice Centers (EPCs), sponsors the development of systematic reviews to assist public- and private-sector organizations in their efforts to improve the quality of healthcare in the United States. These reviews provide comprehensive, science-based information on common, costly medical conditions, and new healthcare technologies and strategies.

Systematic reviews are the building blocks underlying evidence-based practice; they focus attention on the strength and limits of evidence from research studies about the effectiveness and safety of a clinical intervention. In the context of developing recommendations for practice, systematic reviews can help clarify whether assertions about the value of the intervention are based on strong evidence from clinical studies. For more information about AHRQ EPC systematic reviews, see https://effectivehealthcare.ahrq.gov/about/epc/evidence-synthesis.

This and future quarterly progress reports will provide up-to-date information about the evidence base to inform health plans, providers, purchasers, government programs, and the healthcare system as a whole on the state of the science. Transparency and stakeholder input are essential to the Effective Health Care Program. Please visit the website (www.effectivehealthcare.ahrq.gov) to see draft research questions and reports or to join an email list to learn about new program products and opportunities for input.

If you have comments on this report, they may be sent by mail to the Task Order Officer named below at: Agency for Healthcare Research and Quality, 5600 Fishers Lane, Rockville, MD 20857, or by email to epc@ahrq.hhs.gov. They will be considered in the next update of this report.

David Meyers, M.D.

Acting Director

Agency for Healthcare Research and Quality

Craig A. Umscheid, M.D., M.S.

Director

Evidence-based Practice Center Program

Center for Evidence and Practice Improvement

Agency for Healthcare Research and Quality
Arlene S. Bierman, M.D., M.S.

Director

Center for Evidence and Practice Improvement

Agency for Healthcare Research and Quality

Suchitra Iyer, Ph.D.

Task Order Officer

Evidence-based Practice Center Program

Center for Evidence and Practice Improvement

Agency for Healthcare Research and Quality 


\section{Appendix Contents}

Appendix A. Literature Search Strategies ...................................................................... A-1

Appendix B. Key Questions and Inclusion and Exclusion Criteria........................................ B-1

Key Questions .................................................................................................... B-1

Key Question 1: Adults with chronic low back pain ................................................. B-1

Key Question 2: Adults with chronic neck pain ..................................................... B-1

Key Question 3: Adults with osteoarthritis-related pain.......................................... B-1

Key Question 4: Adults with fibromyalgia ........................................................... B-1

Key Question 5: Adults with chronic tension headache ................................................. B-1

Key Question 6: Do estimates of benefits and harms differ by age, sex, presence of comorbidities (e.g., emotional or mood disorders), or degree of nociplasticity/central

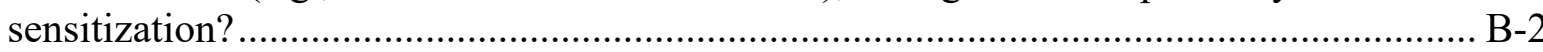

Inclusion and Exclusion Criteria............................................................................. B-2

Appendix C. Included Studies List .................................................................................. C-1

Appendix D. Evidence Tables .................................................................................... D-1

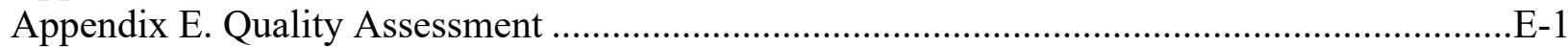

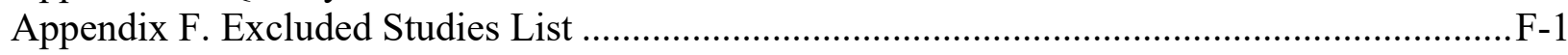

Appendix G. Updated or New Meta-Analyses ............................................................. G-1 


\section{Appendix A. Literature Search Strategies}

\section{Database: Ovid MEDLINE(R) and Epub Ahead of Print, In-Process \& Other Non-Indexed Citations, Daily and Versions(R), All 2020 through September 30, 2021}

1 exp Low Back Pain/ or ((back or spine or spinal) adj2 pain).ti,ab.

2 exp Chronic Pain/

3 Neck Pain/ or neck.ti,ab.

4 exp Osteoarthritis/ or osteoarthritis.ti,ab.

5 Headache/ or headache.ti,ab.

6 Fibromyalgia/ or fibromyalgia.ti,ab.

7 exp Exercise Therapy/

8 exp Physical Therapy Modalities/

9 exp Braces/

10 exp Mind-Body Therapies/

$11 \exp$ Acupuncture Therapy/

$12 \exp$ Rehabilitation/

13 exp Psychotherapy/

14 exp Musculoskeletal Manipulations/

15 (noninvasive or non-invasive or nonpharmacologic* or non-pharmacologic*).ti,ab.

16 (exercise or physical therapy or cognitive or behavioral or feedback or relaxation or acceptance or commitment or traction or ultrasound or stimulation or laser or magnet* or inferential or electromuscular or diathermy or heat or cold or manipulation or manual or craniosacral or mindfulness or meditation or mind-body or yoga or pilates or Qigong or acupuncture or functional restoration or multidisciplin* or interdisciplin*).ti,ab.

17 rh.fs.

18 or/1-6

19 or/7-17

2018 and 19

21 randomized controlled trial.pt.

22 controlled clinical trial.pt.

23 clinical trials as topic.sh.

24 (random* or trial or placebo).ti,ab.

25 clinical trials as topic.sh.

26 exp animals/ not humans.sh.

27 or/21-25

2827 not 26

2920 and 28

30 limit 29 to english language

31 limit 30 to humans

3231 and (20171\$ or 2018 ).dt,ed,ep.

33 meta-analysis.pt.

34 meta-analysis/ or systematic review/ or meta-analysis as topic/ or "meta analysis (topic)"/ or "systematic review (topic)"/ or exp technology assessment, biomedical/

35 ((systematic* adj3 (review* or overview*)) or (methodologic* adj3 (review* or overview*))).ti,ab.

36 ((quantitative adj3 (review* or overview* or synthes*)) or (research adj3 (integrati* or overview*))).ti,ab. 
37 ((integrative adj3 (review* or overview*)) or (collaborative adj3 (review* or overview*)) or (pool* adj3 analy*)).ti,ab.

38 (data synthes* or data extraction* or data abstraction*).ti,ab.

39 (handsearch* or hand search*).ti,ab.

40 (mantel haenszel or peto or der simonian or dersimonian or fixed effect* or latin square*).ti,ab.

41 (met analy* or metanaly* or technology assessment* or HTA or HTAs or technology overview* or technology appraisal*).ti,ab.

42 (meta regression* or metaregression*).ti,ab.

43 (meta-analy* or metaanaly* or systematic review* or biomedical technology assessment* or bio-medical technology assessment*).mp,hw.

44 (medline or cochrane or pubmed or medlars or embase or cinahl).ti,ab,hw.

45 (cochrane or (health adj2 technology assessment) or evidence report).jw.

46 (meta-analysis or systematic review).ti,ab.

47 (comparative adj3 (efficacy or effectiveness)).ti,ab.

48 (outcomes research or relative effectiveness).ti,ab.

49 ((indirect or indirect treatment or mixed-treatment) adj comparison*).ti,ab.

50 or $/ 33-49$

5120 and 50

52 limit 51 to english language

53 limit 52 to humans

5453 and (20171\$ or 2018\$).dt,ed,ep.

5532 or 54

Database: EBM Reviews - Cochrane Central Register of Controlled Trials, All 2020 through September 30, 2021

1 exp Low Back Pain/ or ((back or spine or spinal) adj2 pain).ti,ab.

2 exp Chronic Pain/

3 Neck Pain/ or neck.ti,ab.

4 exp Osteoarthritis/ or osteoarthritis.ti,ab.

5 Headache/ or headache.ti,ab.

6 Fibromyalgia/ or fibromyalgia.ti,ab.

7 exp Exercise Therapy/

8 exp Physical Therapy Modalities/

9 exp Braces/

10 exp Mind-Body Therapies/

11 exp Acupuncture Therapy/

$12 \exp$ Rehabilitation/

13 exp Psychotherapy/

14 exp Musculoskeletal Manipulations/

15 (noninvasive or non-invasive or nonpharmacologic* or non-pharmacologic*).ti,ab.

16 (exercise or physical therapy or cognitive or behavioral or feedback or relaxation or acceptance or commitment or traction or ultrasound or stimulation or laser or magnet* or inferential or electromuscular or diathermy or heat or cold or manipulation or manual or craniosacral or mindfulness or meditation or mind-body or yoga or pilates or Qigong or acupuncture or functional restoration or multidisciplin* or interdisciplin*).ti,ab. 
17 rh.fs.

18 or/1-6

19 or/7-17

2018 and 19

21 limit 20 to $\mathrm{yr}=" 2017$-Current"

22 limit 21 to medline records

2321 not 22

24 limit 23 to english language

Database: EBM Reviews - Cochrane Database of Systematic Reviews, All 2020 through September 30, 2021

1 ((back or spine or spinal) adj2 pain).ti.

2 (neck adj2 pain).ti.

3 osteoarthritis.ti.

4 headache.ti.

5 fibromyalgia.ti.

6 (noninvasive or non-invasive or nonpharmacologic* or non-pharmacologic*).ti,ab. (295)

7 (exercise or physical therapy or cognitive or behavioral or feedback or relaxation or acceptance or commitment or traction or ultrasound or stimulation or laser or magnet* or inferential or electromuscular or diathermy or heat or cold or manipulation or manual or craniosacral or mindfulness or meditation or mind-body or yoga or pilates or Qigong or acupuncture or functional restoration or multidisciplin* or interdisciplin*).ti,ab.

96 or 7

108 and 9

11 limit 10 to new reviews 


\section{Appendix B. Key Questions and Inclusion and Exclusion Criteria}

\section{Key Questions}

Key Question 1: Adults with chronic low back pain

Key Question 2: Adults with chronic neck pain

Key Question 3: Adults with osteoarthritis-related pain

Key Question 4: Adults with fibromyalgia

Key Question 5: Adults with chronic tension headache

Key Questions 1-5 incorporate the following subquestions:

a. What are the benefits and harms of noninvasive nonpharmacological therapies compared with sham treatment, no treatment, waitlist, attention control, or usual care?

b. What are the benefits and harms of noninvasive nonpharmacological therapies compared with pharmacological therapy (e.g., opioids, nonsteroidal anti-inflammatory drugs, acetaminophen, antiseizure medications, antidepressants, topical agents, medical cannabis, and muscle relaxants)?

c. What are the benefits and harms of noninvasive nonpharmacological therapies compared with exercise or, for headache, biofeedback?

The three-part format for Key Questions 1-5 reflects the following research concepts:

Part "a" answers the question of whether the various interventions work overall compared with sham, waitlist control, attention control, no treatment, or usual care. For this review, usual care was defined as care that might be provided or recommended by a primary care provider.

Part " $b$ " answers the question of whether the various interventions work compared with pharmacological alternatives.

Part "c" answers the question of how outcomes for individual interventions (e.g., acupuncture) compare with a common comparator. Exercise is the most frequent comparison in the literature for many chronic pain conditions, so it provides a common comparator for analysis. It is also recommended in most guidelines for conditions including low back pain, neck pain, fibromyalgia, and osteoarthritis and is widely available. Exercise served as common comparator for these conditions. For chronic headache, biofeedback provided a common comparator for analysis. 


\section{Key Question 6: Do estimates of benefits and harms differ by age, sex, presence of comorbidities (e.g., emotional or mood disorders), or degree of nociplasticity/central sensitization?}

\section{Inclusion and Exclusion Criteria}

Table B-1. Inclusion and exclusion criteria

\begin{tabular}{|c|c|c|}
\hline PICOTS & Inclusion & Exclusion \\
\hline $\begin{array}{l}\text { Population } \\
\text { All KQs }\end{array}$ & $\begin{array}{l}\text { General Inclusion Criteria } \\
\text { - Adults with the following chronic } \\
\text { pain (defined as pain lasting } 12 \\
\text { weeks or longer or pain persisting } \\
\text { past the time for normal tissue } \\
\text { healing) conditions: low back pain, } \\
\text { neck pain, osteoarthritis pain, } \\
\text { fibromyalgia, or tension headache. } \\
\text { - Pregnant or breastfeeding women } \\
\text { who have a history of chronic pain } \\
\text { prior to pregnancy }\end{array}$ & $\begin{array}{l}\text { General Exclusion Criteria } \\
\text { - Acute pain } \\
\text { - Children (<18 years), pregnant or } \\
\text { breastfeeding women with pregnancy-related } \\
\text { back or pelvic pain or who do not have chronic } \\
\text { pain prior to pregnancy; } \\
\text { - Patients with chronic pain related to "active" } \\
\text { cancer, infection, inflammatory arthropathy, } \\
\text { - }<90 \% \text { of study sample has the defined } \\
\text { condition of interest or }<90 \% \text { received the } \\
\text { treatment(s) of interest } \\
\text { - Treatment for addiction } \\
\text { - Pain at the end of life } \\
\text { - Neuropathic pain }\end{array}$ \\
\hline $\begin{array}{l}\text { Population } \\
\text { KQ1 }\end{array}$ & $\begin{array}{l}\text { KQ1: Low back pain } \\
\text { - Adults with chronic, nonradicular } \\
\text { low back pain }\end{array}$ & $\begin{array}{l}\text { KQ1: Low back pain } \\
\text { - Patients with radiculopathy } \\
\text { - Low back pain associated with severe or } \\
\text { progressive neurological deficits } \\
\text { - Failed back surgery syndrome }\end{array}$ \\
\hline $\begin{array}{l}\text { Population } \\
\text { KQ2 }\end{array}$ & $\begin{array}{l}\text { KQ2: Neck pain } \\
\text { - Adults with chronic neck pain }\end{array}$ & $\begin{array}{l}\text { KQ2: Neck pain } \\
\text { - Patients with radiculopathy or myelopathy } \\
\text { - Traumatic spinal cord injury } \\
\text { - Neck pain associated with progressive } \\
\text { neurological deficit, loss of strength }\end{array}$ \\
\hline $\begin{array}{l}\text { Population } \\
\text { KQ3 }\end{array}$ & $\begin{array}{l}\text { KQ3: Osteoarthritis } \\
\text { - Adults with osteoarthritis-related } \\
\text { pain (primary or secondary } \\
\text { osteoarthritis) of the hip, knee or } \\
\text { hand }\end{array}$ & $\begin{array}{l}\text { KQ3: Osteoarthritis } \\
\text { - Other types of arthritis (e.g., rheumatoid) } \\
\text { - Patients with joint replacement }\end{array}$ \\
\hline $\begin{array}{l}\text { Population } \\
\text { KQ4 }\end{array}$ & $\begin{array}{l}\text { KQ4: Fibromyalgia } \\
\text { - Adults with fibromyalgia }\end{array}$ & $\begin{array}{l}\text { KQ4: Fibromyalgia } \\
\text { - Conditions with generalized pain not consistent } \\
\text { with fibromyalgia } \\
\text { - Systemic exertion intolerance disease, (myalgic } \\
\text { encephalomyelitis/chronic fatigue syndrome) } \\
\text { - Somatization disorder (Briquet's syndrome) }\end{array}$ \\
\hline
\end{tabular}




\begin{tabular}{|c|c|c|}
\hline PICOTS & Inclusion & Exclusion \\
\hline $\begin{array}{l}\text { Population } \\
\text { KQ5 }\end{array}$ & $\begin{array}{l}\text { KQ5: Headache } \\
\text { - Adults with primary chronic tension } \\
\text { headache (International } \\
\text { Classification of Headache } \\
\text { Disorders, 3rd edition definition). } \\
\text { O Primary headaches are } \\
\text { attributed to the headache } \\
\text { condition itself, not headache } \\
\text { caused by another disease or } \\
\text { medical condition. Tension } \\
\text { headaches are the most } \\
\text { common. } \\
\text { Chronic headache is defined as } 15 \text { or } \\
\text { more days each month for at least } 12 \\
\text { weeks or history of headache more } \\
\text { than } 180 \text { days a year. }\end{array}$ & $\begin{array}{l}\text { KQ5: Headache } \\
\text { - Migraine headache } \\
\text { - Mixed headache (also known as coexistent } \\
\text { tension and migraine headache, chronic daily } \\
\text { headache, transformed migraine) } \\
\text { - Trigeminal neuralgia } \\
\text { - Cluster headache } \\
\text { - Secondary headache types as defined in The } \\
\text { International Classification of Headache } \\
\text { Disorders, 3rd edition (i.e., headaches due to } \\
\text { an underlying pathology such as cancer, } \\
\text { prior medical procedures, } \\
\text { temporomandibular joint disorders, neck } \\
\text { pathology, cervicogenic headache, and } \\
\text { medication over-use headache) } \\
\text { - Traumatic brain injury }\end{array}$ \\
\hline Interventions & $\begin{array}{l}\text { All KQs: } \\
\text { - Exercise (exercise as part of } \\
\text { physical therapy, supervised } \\
\text { exercise, home exercise, group } \\
\text { exercise, formal exercise program) } \\
\text { - Psychological therapies (cognitive } \\
\text { and/or behavioral therapy, } \\
\text { biofeedback, relaxation training) } \\
\text { - Physical modalities (traction, } \\
\text { ultrasound, transcutaneous } \\
\text { electrical nerve stimulation, low- } \\
\text { level laser therapy, interferential } \\
\text { therapy, electro-muscular } \\
\text { stimulation diathermy, superficial } \\
\text { heat or cold, bracing for knee, } \\
\text { back, neck, hand and magnets) } \\
\text { - Manual therapies (musculoskeletal } \\
\text { manipulation, massage) } \\
\text { - Mindfulness practices (meditation, } \\
\text { mindfulness-based stress } \\
\text { reduction practices) } \\
\text { - Mind-body practices (yoga, tai chi, } \\
\text { qigong) } \\
\text { - Acupuncture } \\
\text { - Multidisciplinary/interdisciplinary } \\
\text { rehabilitationa }\end{array}$ & $\begin{array}{l}\text { All KQs: } \\
\text { - Invasive nonsurgical treatments (e.g., injections, } \\
\text { nerve block, spinal cord stimulators, } \\
\text { parenterally-administered medications) } \\
\text { - Surgical interventions (including minimally } \\
\text { invasive surgical interventions) } \\
\text { - Diet interventions or dietary supplementation } \\
\text { - Studies evaluating incremental value of adding a } \\
\text { noninvasive nonpharmacological intervention to } \\
\text { another noninvasive nonpharmacological } \\
\text { intervention } \\
\text { - Self-management interventions or programs, } \\
\text { self-management education programs } \\
\text { - Others not listed for inclusion }\end{array}$ \\
\hline
\end{tabular}




\begin{tabular}{|c|c|c|}
\hline PICOTS & Inclusion & Exclusion \\
\hline Comparators & $\begin{array}{l}\text { All KQs, subquestion a } \\
\text { - Sham treatment } \\
\text { - Waitlist } \\
\text { - Usual care } \\
\text { - No treatment } \\
\text { - Attention control intended to } \\
\text { control for nonspecific effects (e.g., } \\
\text { time, attention, expectations); } \\
\text { All KQs subquestion b } \\
\text { - Commonly used nonopioid } \\
\text { pharmacological therapy used to } \\
\text { treat chronic pain [NSAIDS, } \\
\text { acetaminophen, anti-seizure } \\
\text { medications, antidepressants } \\
\text { (SNRIs, TCAs), muscle relaxants } \\
\text { (including benzodiazepines)] } \\
\text { - Topical agents (lidocaine, } \\
\text { diclofenac, capsaicin) } \\
\text { - Medical cannabis (inhaled, oral, } \\
\text { topical); phytocannabinoids (plant } \\
\text { derived, THC and CBD); FDA } \\
\text { approved synthetic cannabinoids } \\
\text { [Dronabionol (THC), Nabilone } \\
\text { (similar to THC)] } \\
\text { - Opioid analgesics } \\
\text { KQs 1-4, } 6 \text { subquestion c } \\
\text { - Exercise } \text { b }^{\text {b }} \text { K, } 6 \text { subquestion c } \\
\text { - Biofeedback }\end{array}$ & $\begin{array}{l}\text { All KQs: } \\
\text { - Supplements (e.g., glucosamine, chondroitin, } \\
\text { d-ribose, herbal or homeopathic } \\
\text { treatments)Invasive nonsurgical treatments } \\
\text { (e.g., injections, nerve block, spinal cord } \\
\text { stimulators, parenterally-administered } \\
\text { medications) } \\
\text { - Antidepressants not typically used for chronic } \\
\text { pain including SSRIs and MAOls } \\
\text { - Anti-seizure medications not typically used to } \\
\text { treat chronic pain including topiramate, } \\
\text { lamotrigine, levetiracetam, phenytoin, valproic } \\
\text { acid, zonisamide, tiagabine } \\
\text { - Surgical interventions (including minimally } \\
\text { invasive surgical interventions) } \\
\text { - Studies evaluating incremental value of adding a } \\
\text { noninvasive nonpharmacological intervention to } \\
\text { another noninvasive nonpharmacological } \\
\text { intervention } \\
\text { - Comparisons within nonpharmacological } \\
\text { intervention types (e.g., comparisons of different } \\
\text { types of exercise with each other, different types } \\
\text { of massage with each other) } \\
\text { - Corticosteroids, biologic drugs } \\
\text { - Salicylates (oral and topical) } \\
\text { - Topical menthol preparations } \\
\text { - Others not listed for inclusion }\end{array}$ \\
\hline Outcomes & $\begin{array}{l}\text { All KQs: } \\
\text { Primary efficacy outcomes; we will } \\
\text { focus on outcomes from validated } \\
\text { measures for } \\
\text { - Function/disability/pain } \\
\text { interference }^{d} \\
\text { - Pain }{ }^{d} \\
\text { Harms and Adverse effects } \\
\text { Secondary outcomes } \\
\text { - Psychological distress (including } \\
\text { measures of depression and } \\
\text { - Qnxiety) } \\
\text { - Opuality of life } \\
\text { - Sleep quality, sleep disturbance } \\
\text { - Health care utilization }\end{array}$ & $\begin{array}{l}\text { All KQs: } \\
\text { - Intermediate outcomes (e.g., biomarkers for } \\
\text { inflammation) } \\
\text { - Other nonclinical outcomes }\end{array}$ \\
\hline
\end{tabular}




\begin{tabular}{|c|c|c|}
\hline PICOTS & Inclusion & Exclusion \\
\hline Timing & $\begin{array}{l}\text { Duration of followup: short term ( } 1 \text { to } \\
<6 \text { months), intermediate term ( } \geq 6 \text { to } \\
<12 \text { months) and long term }(\geq 12 \\
\text { months); focus on longer term ( }>12 \\
\text { month) effects. } \\
\text { Trials lasting } \geq 6 \text { months that include a } \\
\text { supervised intervention followed by } \\
\text { continued home treatment as part of } \\
\text { the intervention will be included even } \\
\text { though the only followup occurs directly } \\
\text { after the intervention. }\end{array}$ & - Studies with $<1$ month followup after treatment \\
\hline Studies & $\begin{array}{l}\text { Randomized controlled trials or high } \\
\text { quality systematic reviews of } \\
\text { randomized controlled trials published } \\
\text { in English; cross-over trials with } \\
\text { random assignment of initial treatment } \\
\text { will be considered. }\end{array}$ & $\begin{array}{l}\text { All KQs: } \\
\text { - Studies reporting on intermediate outcomes only } \\
\text { - Nonrandomized studies } \\
\text { - Abstracts, editorials, letters, conference } \\
\text { proceedings } \\
\text { - Duplicate publications of the same study that do } \\
\text { not report on different outcomes } \\
\text { - Single site reports from multicenter trials } \\
\text { - White papers } \\
\text { - Narrative reviews } \\
\text { - Articles identified as preliminary reports when } \\
\text { results are published in later versions } \\
\text { - Indirect comparisons } \\
\text { - Studies with fewer than } 15 \text { patients per } \\
\text { treatment arm } \\
\text { - Systematic reviews on treatment of chronic neck } \\
\text { pain, fibromyalgia, chronic headache, or } \\
\text { osteoarthritis that are of low methodological } \\
\text { quality. Those that do not report outcomes or } \\
\text { time frames of interest may be excluded. } \\
\text { Systematic reviews may be excluded based on } \\
\text { currency or relevance (e.g., if there is a } \\
\text { substantial new body of evidence reflected in a } \\
\text { later review). }\end{array}$ \\
\hline Settings & $\begin{array}{l}\text { Any nonhospital setting or in self- } \\
\text { directed care }\end{array}$ & $\begin{array}{l}\text { - Hospital care, hospice care, emergency } \\
\text { department care }\end{array}$ \\
\hline \multicolumn{3}{|c|}{ 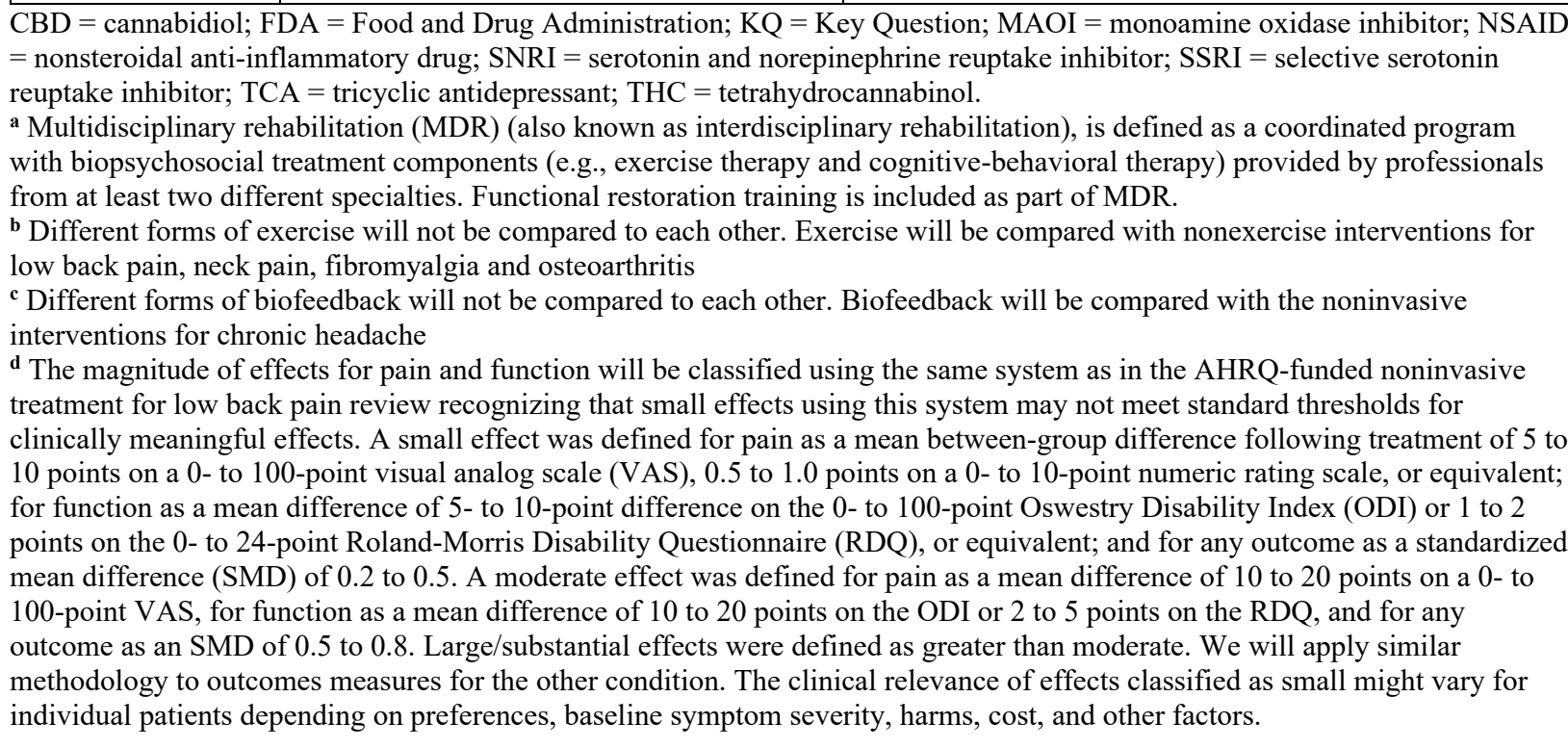 } \\
\hline
\end{tabular}




\section{Appendix C. Included Studies List}

1. Alqualo-Costa R, Rampazo EP, Thome GR, et al. Interferential current and photobiomodulation in knee osteoarthritis: A randomized, placebo-controlled, doubleblind clinical trial. Clinical Rehabilitation. 2021 Apr 26:2692155211012004. doi: https://dx.doi.org/10.1177/02692155211012 004. PMID: 33896234.

2. Ashar YK, Gordon A, Schubiner H, et al. Effect of Pain Reprocessing Therapy vs Placebo and Usual Care for Patients With Chronic Back Pain: A Randomized Clinical Trial. JAMA Psychiatry. 2021 Sep 29doi: 10.1001/jamapsychiatry.2021.2669. PMID: 34586357.

3. Bernal-Utrera C, Gonzalez-Gerez JJ, Anarte-Lazo E, et al. Manual therapy versus therapeutic exercise in non-specific chronic neck pain: a randomized controlled trial. Trials [Electronic Resource]. $2020 \mathrm{Jul}$ 28;21(1):682. doi: https://dx.doi.org/10.1186/s13063-02004610-w. PMID: 32723399.

4. Bravo C, Skjaerven LH, Espart A, et al. Basic Body Awareness Therapy in patients suffering from fibromyalgia: a randomized clinical trial. Physiotherapy theory and practice. 2019;35(10):919-29. PMID: CN01980930.

5. Coste J, Medkour T, Maigne JY, et al. Osteopathic medicine for fibromyalgia: a sham-controlled randomized clinical trial. Therapeutic Advances in Musculoskeletal Disease. 2021;13:1759720X211009017. doi: https://dx.doi.org/10.1177/1759720X211009 017. PMID: 33948127.

6. Garrido-Ardila EM, Gonzalez-Lopez-Arza MV, Jimenez-Palomares M, et al.

Effectiveness of acupuncture vs. core stability training in balance and functional capacity of women with fibromyalgia: a randomized controlled trial. Clinical Rehabilitation. 2020 May;34(5):630-45. doi: https://dx.doi.org/10.1177/02692155209119 92. PMID: 32204612.
7

Groessl EJ, Liu L, Schmalzl L, et al. Secondary Outcomes from a Randomized Controlled Trial of Yoga for Veterans with Chronic Low-Back Pain. Int J Yoga Therap. 2020 Jan 1;30(1):69-76. doi: 10.17761/2020-D-19-00036. PMID: 31509451 .

8. Hu X, Lai Z, Wang L. Effects of Taichi exercise on knee and ankle proprioception among individuals with knee osteoarthritis. Research in Sports Medicine. 2020 AprJun;28(2):268-78. doi: https://dx.doi.org/10.1080/15438627.2019.1 663520. PMID: 31524502.

9. Joyce C, Roseen EJ, Keysor JJ, et al. Can Yoga or Physical Therapy for Chronic Low Back Pain Improve Depression and Anxiety Among Adults From a Racially Diverse, Low-Income Community? A Secondary Analysis of a Randomized Controlled Trial. Archives of Physical Medicine \& Rehabilitation. 2021 Jun;102(6):1049-58. doi:

https://dx.doi.org/10.1016/j.apmr.2021.01.0 72. PMID: 33556352.

10. Karakas A, Dilek B, Sahin MA, et al. The effectiveness of pulsed ultrasound treatment on pain, function, synovial sac thickness and femoral cartilage thickness in patients with knee osteoarthritis: a randomized, doubleblind clinical, controlled study. Clinical Rehabilitation. 2020 Dec;34(12):1474-84. doi:

https://dx.doi.org/10.1177/02692155209429 53. PMID: 32715744.

11. Kholoosy L, Elyaspour D, Akhgari MR, et al. Evaluation of the Therapeutic Effect of Low Level Laser in Controlling Low Back Pain: A Randomized Controlled Trial. Journal of Lasers in Medical Sciences. 2020;11(2):120-5. doi: https://dx.doi.org/10.34172/jlms.2020.21. PMID: 32273951.

12. Kobayashi D, Shimbo T, Hayashi H, et al. Shiatsu for chronic lower back pain: Randomized controlled study. Complementary Therapies in Medicine. 2019 Aug;45:33-7. doi: https://dx.doi.org/10.1016/j.ctim.2019.05.01 9. PMID: 31331579. 
13. Lam WC, Au KY, Qin Z, et al. Superficial needling acupuncture versus sham acupuncture for knee osteoarthritis: a randomized controlled trial. American Journal of Medicine. 2021 Jun 11;11:11. doi:

https://dx.doi.org/10.1016/j.amjmed.2021.05 .002. PMID: 34126097.

14. Lang AE, Hendrick PA, Clay L, et al. A randomized controlled trial investigating effects of an individualized pedometer driven walking program on chronic low back pain. BMC Musculoskeletal Disorders. 2021 Feb 19;22(1):206. doi: https://dx.doi.org/10.1186/s12891-02104060-8. PMID: 33607979.

15. Luo Y, Yang M, Liu T, et al. Effect of handear acupuncture on chronic low-back pain: a randomized controlled trial. Journal of traditional chinese medicine $=$ chung $\mathrm{i}$ tsa chih ying wen pan. 2019;39(4):587-98. PMID: CN-02144857.

16. McCrae CS, Curtis AF, Miller MB, et al. Effect of cognitive behavioural therapy on sleep and opioid medication use in adults with fibromyalgia and insomnia. Journal of Sleep Research. 2020 12;29(6):e13020. doi: https://dx.doi.org/10.1111/jsr.13020. PMID: 32126156 .

17. Messier SP, Mihalko SL, Beavers DP, et al. Effect of High-Intensity Strength Training on Knee Pain and Knee Joint Compressive Forces Among Adults With Knee Osteoarthritis: The START Randomized Clinical Trial. JAMA. 202102 16;325(7):646-57. doi: https://dx.doi.org/10.1001/jama.2021.0411. PMID: 33591346.

18. Michalsen A, Jeitler M, Kessler CS, et al. Yoga, Eurythmy Therapy and Standard Physiotherapy (YES-Trial) for Patients With Chronic Non-specific Low Back Pain: A Three-Armed Randomized Controlled Trial. Journal of Pain. 2021 Apr 20;20:20. doi: https://dx.doi.org/10.1016/j.jpain.2021.03.15 4. PMID: 33892154.
19. Munukka M, Waller B, Hakkinen A, et al. Effects of progressive aquatic resistance training on symptoms and quality of life in women with knee osteoarthritis: A secondary analysis. Scandinavian Journal of Medicine \& Science in Sports. 2020 Jun;30(6):1064-72. doi: https://dx.doi.org/10.1111/sms.13630. PMID: 31999876.

20. Neyaz O, Sumila L, Nanda S, et al. Effectiveness of Hatha Yoga Versus Conventional Therapeutic Exercises for Chronic Nonspecific Low-Back Pain. Journal of Alternative \& Complementary Medicine. 2019 Sep;25(9):938-45. doi: https://dx.doi.org/10.1089/acm.2019.0140. PMID: 31347920.

21. Patru S, Padureanu R, Dumitrescu F, et al. Influence of multidisciplinary therapeutic approach on fibromyalgia patients. Experimental \& Therapeutic Medicine. 2021 May;21(5):528. doi: https://dx.doi.org/10.3892/etm.2021.9960. PMID: 33815601.

22. Pehlivan S, Karadakovan A. Effects of aromatherapy massage on pain, functional state, and quality of life in an elderly individual with knee osteoarthritis. Japan journal of nursing science. 2019;16(4):4508. PMID: CN-02078086 NEW.

23. Perez-Aranda A, Feliu-Soler A, MonteroMarin J, et al. A randomized controlled efficacy trial of mindfulness-based stress reduction compared with an active control group and usual care for fibromyalgia: the EUDAIMON study. Pain. 2019 11;160(11):2508-23. doi: https://dx.doi.org/10.1097/j.pain.000000000 0001655. PMID: 31356450.

24. Rewald S, Lenssen AFT, Emans PJ, et al. Aquatic Cycling Improves Knee Pain and Physical Functioning in Patients With Knee Osteoarthritis: A Randomized Controlled Trial. Archives of Physical Medicine \& Rehabilitation. 2020 08;101(8):1288-95. doi:

https://dx.doi.org/10.1016/j.apmr.2019.12.0 23. PMID: 32169459. 
25. Roseen EJ, Gerlovin H, Femia A, et al. Yoga, Physical Therapy, and Back Pain Education for Sleep Quality in Low-Income Racially Diverse Adults with Chronic Low Back Pain: a Secondary Analysis of a Randomized Controlled Trial. Journal of General Internal Medicine. 2020 01;35(1):167-76. doi: https://dx.doi.org/10.1007/s11606-01905329-4. PMID: 31667747.

26. Shariat A, Alizadeh R, Moradi V, et al. The impact of modified exercise and relaxation therapy on chronic lower back pain in office workers: a randomized clinical trial. Journal of Exercise Rehabilitation. 2019

Oct;15(5):703-8. doi:

https://dx.doi.org/10.12965/jer.1938490.245. PMID: 31723560.
27. Thomas JS, Clark BC, Russ DW, et al. Effect of Spinal Manipulative and Mobilization Therapies in Young Adults With Mild to Moderate Chronic Low Back Pain: A Randomized Clinical Trial. JAMA Network Open. 202008 03;3(8):e2012589. doi:

https://dx.doi.org/10.1001/jamanetworkopen 2020.12589. PMID: 32756930.

28. Xiao CM, Li JJ, Kang Y, et al. Follow-up of a Wuqinxi exercise at home programme to reduce pain and improve function for knee osteoarthritis in older people: a randomised controlled trial. Age \& Ageing. 202102 26;50(2):570-5. doi: https://dx.doi.org/10.1093/ageing/afaa179. PMID: 32931545.

29. Yaksi E, Ketenci A, Baslo MB, et al. Does transcutaneous electrical nerve stimulation affect pain, neuropathic pain, and sympathetic skin responses in the treatment of chronic low back pain? A randomized, placebo-controlled study. The Korean journal of pain. 2021 Apr 01;34(2):217-28. doi:

https://dx.doi.org/10.3344/kjp.2021.34.2.217 . PMID: 33785674. 


\section{Appendix D. Evidence Tables}

Shown in associated Excel files for Surveillance Report 1 at

https://effectivehealthcare.ahrq.gov/products/noninvasive-nonpharm-pain-update/research. 


\section{Appendix E. Quality Assessment}

Shown in associated Excel files for Surveillance Report 1 at

https://effectivehealthcare.ahrq.gov/products/noninvasive-nonpharm-pain-update/research. 


\section{Appendix F. Excluded Studies List}

1. Abdel-Aal NM, Elsayyad MM, Megahed AA. Short-term effect of adding graston technique to exercise program in treatment of patients with cervicogenic headache: a single-blinded, randomized controlled trial. European journal of physical \& rehabilitation medicine. 2021 May 05;05:05. doi: https://dx.doi.org/10.23736/S19739087.21.06595-3. PMID: 33947825.

Exclusion: Ineligible population

2. Abdelbasset WK, Nambi G, Alsubaie SF, et al. A Randomized Comparative Study between High-Intensity and Low-Level Laser Therapy in the Treatment of Chronic Nonspecific Low Back Pain. EvidenceBased Complementary \& Alternative Medicine: eCAM. 2020;2020:1350281. doi: https://dx.doi.org/10.1155/2020/1350281. PMID: 33178306. Exclusion: Inadequate duration of followup

3. Ahmadnezhad L, Yalfani A, Gholami Borujeni B. Inspiratory Muscle Training in Rehabilitation of Low Back Pain: A Randomized Controlled Trial. Journal of Sport Rehabilitation. 202011 01;29(8):1151-8. doi: https://dx.doi.org/10.1123/jsr.2019-0231. PMID: 31910393. Exclusion: Inadequate duration of followup

4. Akaltun MS, Altindag O, Turan N, et al. Efficacy of high intensity laser therapy in knee osteoarthritis: a double-blind controlled randomized study. Clinical Rheumatology. 2021 May;40(5):1989-95. doi: https://dx.doi.org/10.1007/s10067-02005469-7. PMID: 33074393. Exclusion: Ineligible intervention

5. Alayat MSM, Aly THA, Elsayed AEM, et al. Correction to: Efficacy of pulsed $\mathrm{Nd}$ :YAG laser in the treatment of patients with knee osteoarthritis: a randomized controlled trial. Lasers in Medical Science. 2020 Oct;35(8):1875. doi: https://dx.doi.org/10.1007/s10103-02003088-x. PMID: 32647935. Exclusion: Not a study
6.

Alayat MSM, Atya AM, Ali MME, et al. Correction to: Long-term effect of highintensity laser therapy in the treatment of patients with chronic low back pain: a randomized blinded placebo-controlled trial. Lasers in Medical Science. 2020

Feb;35(1):297. doi: https://dx.doi.org/10.1007/s10103-01902926-x. PMID: 31788745. Exclusion: Not a study

7. Albuquerque NF, Lopes BS. Musculoskeletal applications of infrared thermography on back and neck syndromes: a systematic review. European journal of physical \& rehabilitation medicine. 2021 Jun;57(3):386-96. doi: https://dx.doi.org/10.23736/S19739087.20.06287-5. PMID: 33111511.

Exclusion: Systematic review used as source document

8. Allen KD, Woolson S, Hoenig HM, et al. Stepped Exercise Program for Patients With Knee Osteoarthritis : A Randomized Controlled Trial. Annals of Internal Medicine. 2021 03;174(3):298-307. doi: https://dx.doi.org/10.7326/M20-4447. PMID: 33370174. Exclusion: Ineligible intervention

9. Alrwaily M, Schneider M, Sowa G, et al. Stabilization exercises combined with neuromuscular electrical stimulation for patients with chronic low back pain: a randomized controlled trial. Brazilian Journal of Physical Therapy. 2019 Nov Dec;23(6):506-15. doi:

https://dx.doi.org/10.1016/j.bjpt.2018.10.00 3. PMID: 30482602. Exclusion: Ineligible intervention

10. Alzayed KA, Alsaadi SM. Efficacy of Pulsed Low-Frequency Magnetic Field Therapy on Patients with Chronic Low Back Pain: A Randomized Double-Blind PlaceboControlled Trial. Asian Spine Journal. 2020 Feb;14(1):33-42. doi: https://dx.doi.org/10.31616/asj.2019.0043. PMID: 31575112. Exclusion: Ineligible intervention 
11. Amaral DDV, Miyamoto GC, Franco KFM, et al. Examination of a Subgroup of Patients With Chronic Low Back Pain Likely to Benefit More From Pilates-Based Exercises Compared to an Educational Booklet. Journal of Orthopaedic \& Sports Physical Therapy. 2020 Apr;50(4):189-97. doi: https://dx.doi.org/10.2519/jospt.2019.8839. PMID: 31443627. Exclusion: Ineligible study design

12. Amaral LKB, Souza MB, Campos MGM, et al. Efficacy of conservative therapy in older people with nonspecific low back pain: A systematic review with meta-analysis and GRADE recommendations. Archives of Gerontology \& Geriatrics. 2020 Sep Oct;90:104177. doi:

https://dx.doi.org/10.1016/j.archger.2020.10 4177. PMID: 32682168. Exclusion:

Systematic review used as source document

13. An J, Ryu HK, Lyu SJ, et al. Effects of Preoperative Telerehabilitation on Muscle Strength, Range of Motion, and Functional Outcomes in Candidates for Total Knee Arthroplasty: A Single-Blind Randomized Controlled Trial. International Journal of Environmental Research \& Public Health [Electronic Resource]. 202106 04;18(11):04. doi: https://dx.doi.org/10.3390/ijerph18116071. PMID: 34199913. Exclusion: Ineligible population

14. Andersen TE, Ravn SL, Armfield N, et al. Trauma-focused cognitive behavioural therapy and exercise for chronic whiplash with comorbid posttraumatic stress disorder: a randomised controlled trial. Pain. 202104 01;162(4):1221-32. doi: https://dx.doi.org/10.1097/j.pain.000000000 0002117. PMID: 33086286. Exclusion: Ineligible comparator

15. Anheyer D, Klose P, Lauche R, et al. Yoga for Treating Headaches: a Systematic Review and Meta-analysis. Journal of General Internal Medicine. 2020

03;35(3):846-54. doi:

https://dx.doi.org/10.1007/s11606-01905413-9. PMID: 31667736. Exclusion:

Systematic review used as source document
16. Annaswamy TM, Cunniff KJ, Kroll M, et al. Lumbar Bracing for Chronic Low Back Pain: A Randomized Controlled Trial. American Journal of Physical Medicine \& Rehabilitation. 202108 01;100(8):742-9.

doi:

https://dx.doi.org/10.1097/PHM.000000000 0001743. PMID: 33789322. Exclusion: Ineligible intervention

17. Areeudomwong P, Buttagat V. Proprioceptive neuromuscular facilitation training improves pain-related and balance outcomes in working-age patients with chronic low back pain: a randomized controlled trial. Brazilian Journal of Physical Therapy. 2019 Sep - Oct;23(5):428-36. doi: https://dx.doi.org/10.1016/j.bjpt.2018.10.00 5. PMID: 30361077. Exclusion: Inadequate duration of followup

18. Arguisuelas MD, Lison JF, DomenechFernandez J, et al. Effects of myofascial release in erector spinae myoelectric activity and lumbar spine kinematics in non-specific chronic low back pain: randomized controlled trial. Clinical biomechanics. 2019;63:27-33. PMID: CN-01707030. Exclusion: Inadequate duration of followup

19. Atalay SG, Durmus A, Gezginaslan O. The Effect of Acupuncture and Physiotherapy on Patients with Knee Osteoarthritis: A Randomized Controlled Study. Pain Physician. 2021 May;24(3):E269-E78. PMID: 33988943. Exclusion: Ineligible comparator

20. Avendano-Coy J, Comino-Suarez N, Grande-Munoz J, et al. Extracorporeal shockwave therapy improves pain and function in subjects with knee osteoarthritis: A systematic review and meta-analysis of randomized clinical trials. International Journal Of Surgery. 2020 Oct;82:64-75. doi: https://dx.doi.org/10.1016/j.ijsu.2020.07.055 . PMID: 32798759. Exclusion: Systematic review used as source document 
21. Barassi G, Supplizi M, Prosperi L, et al. Dual-wavelength high-power laser therapy and neuromuscular manual therapy in chronic neck pain: a randomized clinical trial. Journal of Biological Regulators \& Homeostatic Agents. 2021 Mar-

Apr;35(2):767-73. doi: https://dx.doi.org/10.23812/21-37-L. PMID: 33902272. Exclusion:Ineligible study design

22. Batistella CE, Bidin F, Giacomelli I, et al. Effects of the Russian current in the treatment of low back pain in women: A randomized clinical trial. Journal of Bodywork \& Movement Therapies. 2020 Apr;24(2):118-22. doi: https://dx.doi.org/10.1016/j.jbmt.2019.10.00 9. PMID: 32507136. Exclusion:: Ineligible study design

23. Bauer CM, Kankaanpaa MJ, Meichtry A, et al. Efficacy of six months neuromuscular exercise on lumbar movement variability - A randomized controlled trial. Journal of Electromyography \& Kinesiology. 2019 Oct;48:84-93. doi:

https://dx.doi.org/10.1016/j.jelekin.2019.06. 008. PMID: 31252284. Exclusion:

Ineligible outcomes

24. Baumeister H, Paganini S, Sander LB, et al. Effectiveness of a Guided Internet- and Mobile-Based Intervention for Patients with Chronic Back Pain and Depression (WARDBP): A Multicenter, Pragmatic Randomized Controlled Trial. Psychotherapy \& Psychosomatics. 2021;90(4):255-68. doi: https://dx.doi.org/10.1159/000511881.

PMID: 33321501. Exclusion: Ineligible intervention

25. Bellomo TR, Schrepf A, Kruger GH, et al. Pressure Pain Tolerance Predicts the Success of Emotional Awareness and Expression Therapy in Patients With Fibromyalgia. Clin J Pain. 2020 Jul;36(7):562-6. doi: 10.1097/AJP.0000000000000829. PMID: 32271184. Exclusion: Inadequate duration of followup
26. Beltrame R, Ronconi G, Ferrara PE, et al. Capacitive and resistive electric transfer therapy in rehabilitation: a systematic review. International Journal of Rehabilitation Research. 2020 Dec;43(4):291-8. doi: https://dx.doi.org/10.1097/MRR.000000000 0000435. PMID: 32909988. Exclusion: Systematic review used as source document

27. Bendrik R, Kallings LV, Broms K, et al. Physical activity on prescription in patients with hip or knee osteoarthritis: A randomized controlled trial. Clinical Rehabilitation. 2021 Apr 11:2692155211008807. doi: https://dx.doi.org/10.1177/02692155211008 807. PMID: 33843297. Exclusion:

Ineligible population

28. Bernard S, Gentilcore-Saulnier E, MasseAlarie $\mathrm{H}$, et al. Is adding pelvic floor muscle training to an exercise intervention more effective at improving pain in patients with non-specific low back pain? A systematic review of randomized controlled trials. Physiotherapy. 2021 03;110:15-25. doi: https://dx.doi.org/10.1016/j.physio.2020.02. 005. PMID: 32349867. Exclusion:

Systematic review used as source document

29. Bidonde J, Busch AJ, Schachter CL, et al. Mixed exercise training for adults with fibromyalgia. Cochrane Database of Systematic Reviews. 2019(5) PMID: 00075320-100000000-11748. Exclusion: Systematic review used as source document

30. Bokaeian HR, Esfandiarpour F, Zahednejad $\mathrm{S}$, et al. Effects of an Exercise Therapy Targeting Knee Kinetics on Pain, Function, and Gait Kinetics in Patients With Knee Osteoarthritis: A Randomized Clinical Trial. Adapted Physical Activity Quarterly. 2021 Mar 30;38(3):377-95. doi: https://dx.doi.org/10.1123/apaq.2020-0144. PMID: 33785660. Exclusion:Ineligible comparator

31. Bronfort G, Haas M, Evans RL, et al. Noninvasive physical treatments for chronic/recurrent headache. Cochrane Database of Systematic Reviews. 2019(8) PMID: 00075320-100000000-01345. Exclusion: Systematic review used as source document 
32. Burgess DJ, Evans R, Allen KD, et al. Learning to Apply Mindfulness to Pain (LAMP): Design for a Pragmatic Clinical Trial of Two Mindfulness-Based Interventions for Chronic Pain. Pain Medicine. 202012 12;21(Suppl 2):S29-S36. doi: https://dx.doi.org/10.1093/pm/pnaa337. PMID: 33313730. Exclusion: Not a study

33. Buttagat $\mathrm{V}$, Muenpan $\mathrm{K}$, Wiriyasakunphan $\mathrm{W}$, et al. A comparative study of Thai massage and muscle energy technique for chronic neck pain: A single-blinded randomized clinical trial. J Bodyw Mov Ther. 2021 Jul;27:647-53. doi: 10.1016/j.jbmt.2021.05.007. PMID: 34391301. Exclusion: Inadequate duration of followup

34. Calatayud J, Guzman-Gonzalez B, Andersen LL, et al. Effectiveness of a Group-Based Progressive Strength Training in Primary Care to Improve the Recurrence of Low Back Pain Exacerbations and Function: A Randomised Trial. International Journal of Environmental Research \& Public Health [Electronic Resource]. 202011

11;17(22):11. doi: https://dx.doi.org/10.3390/ijerph17228326. PMID: 33187076. Exclusion: Ineligible comparator

35. Callaghan MJ, Palmer E, O'Neill T. Management of patellofemoral joint osteoarthritis using biomechanical device therapy: a systematic review with metaanalysis. Systematic Reviews. 202106 09;10(1):173. doi:

https://dx.doi.org/10.1186/s13643-02101708-3. PMID: 34108025. Exclusion:

Systematic review used as source document

36. Cejudo J, Garcia-Castillo FJ, Luna P, et al. Using a Mindfulness-Based Intervention to Promote Subjective Well-Being, Trait Emotional Intelligence, Mental Health, and Resilience in Women With Fibromyalgia. Frontiers in Psychology. 2019;10:2541. doi: https://dx.doi.org/10.3389/fpsyg.2019.02541 . PMID: 31798502. Exclusion: Ineligible outcomes
37. Chao J, Jing Z, Xuehua B, et al. Effect of Systematic Exercise Rehabilitation on Patients With Knee Osteoarthritis: A Randomized Controlled Trial. Cartilage. 2020 Feb 10:1947603520903443. doi: https://dx.doi.org/10.1177/19476035209034 43. PMID: 32037857. Exclusion: Inadequate duration of followup

38. Chen H, Wang Y, Liu C, et al. Benefits of a transtheoretical model-based program on exercise adherence in older adults with knee osteoarthritis: A cluster randomized controlled trial. Journal of Advanced Nursing. 2020 Jul;76(7):1765-79. doi: https://dx.doi.org/10.1111/jan.14363. PMID: 32202313. Exclusion: Ineligible comparator

39. Chen H, Zheng X, Huang H, et al. The effects of a home-based exercise intervention on elderly patients with knee osteoarthritis: a quasi-experimental study. BMC musculoskeletal disorders. 2019;20(1):160. PMID: CN-01937404. Exclusion: Inadequate duration of followup

40. Chen L, Li M, Fan L, et al. Optimized acupuncture treatment (acupuncture and intradermal needling) for cervical spondylosis-related neck pain: a multicenter randomized controlled trial. Pain. 202103 01;162(3):728-39. doi:

https://dx.doi.org/10.1097/j.pain.000000000 0002071. PMID: 32947547. Exclusion: Ineligible intervention

41. Chen PY, Song CY, Yen HY, et al. Impacts of tai chi exercise on functional fitness in community-dwelling older adults with mild degenerative knee osteoarthritis: a randomized controlled clinical trial. BMC Geriatr. 2021 Jul 31;21(1):449. doi: 10.1186/s12877-021-02390-9. PMID: 34332537. Exclusion: Inadequate duration of followup

42. Chen Z, Wu J, Wang X, et al. The effects of myofascial release technique for patients with low back pain: A systematic review and meta-analysis. Complementary Therapies in Medicine. 2021 Jun;59:102737. doi:

https://dx.doi.org/10.1016/j.ctim.2021.10273 7. PMID: 33984499. Exclusion: Systematic review used as source document 
43. Cheng CA, Chiu YW, Wu D, et al. Effectiveness of Tai Chi on fibromyalgia patients: A meta-analysis of randomized controlled trials. Complementary Therapies in Medicine. 2019 Oct;46:1-8. doi: https://dx.doi.org/10.1016/j.ctim.2019.07.00 7. PMID: 31519264. Exclusion: Systematic review used as source document

44. Cheung DST, Yeung WF, Suen LK, et al. Self-administered acupressure for knee osteoarthritis in middle-aged and older adults: a pilot randomized controlled trial. Acupuncture in Medicine. 2020 04;38(2):75-85. doi: https://dx.doi.org/10.1177/09645284198832 69. PMID: 31718229. Exclusion:

Inadequate duration of followup

45. Cho SJ. A Self-Efficacy Reinforcement Stretching Exercise Program for Community-Dwelling Older Women With Osteoarthritis: A Pilot Study. Rehabilitation Nursing Journal. 2021 Jan-Feb 01;46(1):1123. doi:

https://dx.doi.org/10.1097/RNJ.0000000000 000290. PMID: 32932424. Exclusion: Ineligible study design

46. Coccetta CA, Sale P, Ferrara PE, et al. Effects of capacitive and resistive electric transfer therapy in patients with knee osteoarthritis: a randomized controlled trial. International journal of rehabilitation research. 2019; Internationale Zeitschrift fur Rehabilitationsforschung. Revue internationale de recherches de readaptation. 42(2):106-11. PMID: CN-01937563.

Exclusion: Ineligible intervention

47. Corp N, Mansell G, Stynes S, et al. Evidence-based treatment recommendations for neck and low back pain across Europe: A systematic review of guidelines. European Journal of Pain. 2021 02;25(2):275-95. doi: https://dx.doi.org/10.1002/ejp.1679. PMID: 33064878. Exclusion: Systematic review used as source document

48. Corvillo I, Armijo F, Alvarez-Badillo A, et al. Efficacy of aquatic therapy for neck pain: a systematic review. International Journal of Biometeorology. 2020 Jun;64(6):915-25. doi: https://dx.doi.org/10.1007/s00484-01901738-6. PMID: 31209599. Exclusion:

Systematic review used as source document
49. Daneau C, Cantin V, Descarreaux M. Effect of Massage on Clinical and Physiological Variables During Muscle Fatigue Task in Participants With Chronic Low Back Pain: a Crossover Study. Journal of manipulative and physiological therapeutics. 2019;42(1):55-65. PMID: CN-02001930. Exclusion: Ineligible study design

50. de Campos TF, Pocovi NC, Maher CG, et al. An individualised self-management exercise and education program did not prevent recurrence of low back pain but may reduce care seeking: a randomised trial. Journal of Physiotherapy. 2020 Jul;66(3):166-73. doi: https://dx.doi.org/10.1016/j.jphys.2020.06.0 06. PMID: 32709590. Exclusion: Ineligible population

51. Deer TR, Esposito MF, McRoberts WP, et al. A Systematic Literature Review of Peripheral Nerve Stimulation Therapies for the Treatment of Pain. Pain Medicine. 2020 08 01;21(8):1590-603. doi: https://dx.doi.org/10.1093/pm/pnaa030. PMID: 32803220. Exclusion: Systematic review used as source document

52. Dharmasri CJ, Griesemer I, Arbeeva L, et al. Acceptability of telephone-based pain coping skills training among African Americans with osteoarthritis enrolled in a randomized controlled trial: a mixed methods analysis. BMC Musculoskeletal Disorders. 2020 Aug 14;21(1):545. doi: https://dx.doi.org/10.1186/s12891-02003578-7. PMID: 32795282. Exclusion: Ineligible study design

53. Didehdar D, Kamali F, Yoosefinejad AK, et al. The effect of spinal manipulation on brain neurometabolites in chronic nonspecific low back pain patients: a randomized clinical trial. Irish Journal of Medical Science. 2020 May;189(2):543-50. doi: https://dx.doi.org/10.1007/s11845-01902140-2. PMID: 31773541. Exclusion: Ineligible study design 
54. Domingues L, Pimentel-Santos FM, Cruz $\mathrm{EB}$, et al. Is a combined programme of manual therapy and exercise more effective than usual care in patients with non-specific chronic neck pain? A randomized controlled trial. Clinical Rehabilitation. 2019

Dec;33(12):1908-18. doi: https://dx.doi.org/10.1177/02692155198766 75. PMID: 31549519. Exclusion: Ineligible intervention

55. Dowsey M, Castle D, Knowles S, et al. The effect of mindfulness training prior to total joint arthroplasty on post-operative pain and physical function: A randomised controlled trial. Complementary Therapies in Medicine. 2019 Oct;46:195-201. doi: https://dx.doi.org/10.1016/j.ctim.2019.08.01 0. PMID: 31519279. Exclusion: Ineligible population

56. Ehsani F, Hedayati R, Bagheri R, et al. The Effects of Stabilization Exercise on the Thickness of Lateral Abdominal Muscles During Standing Tasks in Women With Chronic Low Back Pain: A Randomized Triple-Blinded Clinical Trial Study. Journal of Sport Rehabilitation. 2020 Sep 01;29(7):942-51. doi:

https://dx.doi.org/10.1123/jsr.2019-0058. PMID: 31821992. Exclusion: Ineligible comparator

57. Elshiwi AM, Hamada HA, Mosaad D, et al. Effect of pulsed electromagnetic field on nonspecific low back pain patients: a randomized controlled trial. Brazilian journal of physical therapy. 2019;23(3):2449. PMID: CN-01628986. Exclusion: Inadequate duration of followup

58. Estevez-Lopez F, Maestre-Cascales C, Russell D, et al. Effectiveness of Exercise on Fatigue and Sleep Quality in Fibromyalgia: A Systematic Review and Meta-analysis of Randomized Trials. Archives of Physical Medicine \& Rehabilitation. 2021 04;102(4):752-61. doi: https://dx.doi.org/10.1016/j.apmr.2020.06.0 19. PMID: 32721388. Exclusion:

Systematic review used as source document
59. Fan Y, Li Z, Zhang H, et al. Valgus knee bracing may have no long-term effect on pain improvement and functional activity in patients with knee osteoarthritis: a metaanalysis of randomized trials. Journal of Orthopaedic Surgery. 2020 Sep

01;15(1):373. doi:

https://dx.doi.org/10.1186/s13018-02001917-x. PMID: 32873332. Exclusion:

Systematic review used as source document

60. Fernandez-Carnero J, Sierra-Silvestre E, Beltran-Alacreu H, et al. Neural Tension Technique Improves Immediate Conditioned Pain Modulation in Patients with Chronic Neck Pain: A Randomized Clinical Trial. Pain Medicine. 201906 01;20(6):1227-35. doi: https://dx.doi.org/10.1093/pm/pny115. PMID: 29945245. Exclusion: Inadequate duration of followup

61. Ferreira RM, Torres RT, Duarte JA, et al. Non-Pharmacological and Non-Surgical Interventions for Knee Osteoarthritis: A Systematic Review and Meta-Analysis. Acta Reumatologica Portuguesa. 201907 29;44(3):173-217. PMID: 31356585. Exclusion: Systematic review used as source document

62. Ferro Moura Franco K, Lenoir D, Dos Santos Franco YR, et al. Prescription of exercises for the treatment of chronic pain along the continuum of nociplastic pain: A systematic review with meta-analysis. European Journal of Pain. 2021 01;25(1):5170. doi: https://dx.doi.org/10.1002/ejp.1666. PMID: 32976664. Exclusion: Systematic review used as source document

63. Fertelli TK, Mollaoglu M, Sahin O. Aquatic Exercise Program for Individuals With Osteoarthritis: pain, Stiffness, Physical Function, Self-Efficacy. Rehabilitation nursing. 2019 Sep/Oct;44(5):290-9. doi: 10.1097/rnj.0000000000000142. PMID: 29613876. Exclusion: Inadequate duration of followup 
64. Fisher LR, Alvar BA, Maher SF, et al. Short-term Effects of Thoracic Spine Thrust Manipulation, Exercise, and Education in Individuals With Low Back Pain: A Randomized Controlled Trial. Journal of Orthopaedic \& Sports Physical Therapy. 2020 Jan;50(1):24-32. doi: https://dx.doi.org/10.2519/jospt.2020.8928. PMID: 31810405. Exclusion:Inadequate duration of followup

65. Fonseca ACS, Faria PC, Alcantara MA, et al. Effects of aquatic physiotherapy or health education program in women with fibromyalgia: a randomized clinical trial. Physiotherapy Theory \& Practice. 2021 May;37(5):620-32. doi: https://dx.doi.org/10.1080/09593985.2019.1 639229. PMID: 31305209. Exclusion: Inadequate duration of followup

66. Foo CN, Arumugam M, Lekhraj R, et al. Effectiveness of Health-Led Cognitive Behavioral-Based Group Therapy on Pain, Functional Disability and Psychological Outcomes among Knee Osteoarthritis Patients in Malaysia. International Journal of Environmental Research \& Public Health [Electronic Resource]. 202008 26;17(17):26. doi: https://dx.doi.org/10.3390/ijerph17176179. PMID: 32858791. Exclusion: Ineligible intervention

67. Foster NE, Vertosick EA, Lewith G, et al. Identifying patients with chronic pain who respond to acupuncture: results from an individual patient data meta-analysis.

Acupuncture in Medicine. 2021

04;39(2):83-90. doi: https://dx.doi.org/10.1177/09645284209203 03. PMID: 32571096. Exclusion:

Systematic review used as source document

68. Fraenkel L, Buta E, Suter L, et al. Nonsteroidal Anti-inflammatory Drugs vs Cognitive Behavioral Therapy for Arthritis Pain: A Randomized Withdrawal Trial. JAMA Internal Medicine. 202009 01;180(9):1194-202. doi: https://dx.doi.org/10.1001/jamainternmed.20 20.2821. PMID: 32702101. Exclusion:

Ineligible intervention
69. Francescato Torres S, Brandt de Macedo AC, Dias Antunes M, et al. Effects of electroacupuncture frequencies on chronic low back pain in older adults: triple-blind, 12-months protocol for a randomized controlled trial. Trials [Electronic Resource]. 2019 Dec 23;20(1):762. doi: https://dx.doi.org/10.1186/s13063-0193813-6. PMID: 31870456. Exclusion: Not a study

70. Frutiger M, Borotkanics R. Systematic Review and Meta-Analysis Suggest Strength Training and Workplace Modifications May Reduce Neck Pain in Office Workers. Pain Practice. 2021 01;21(1):100-31. doi: https://dx.doi.org/10.1111/papr.12940. PMID: 32657531. Exclusion: Systematic review used as source document

71. Furukawa Y. Tasuki for neck pain: An individually-randomized, open-label, waiting-list-controlled trial. Journal of Occupational Health. 2020

Jan;62(1):e12097. doi: https://dx.doi.org/10.1002/13489585.12097. PMID: 31705728. Exclusion: Ineligible intervention

72. Galvao-Moreira LV, de Castro LO, Moura ECR, et al. Pool-based exercise for amelioration of pain in adults with fibromyalgia syndrome: A systematic review and meta-analysis. Modern Rheumatology. 2021 Jul;31(4):904-11. doi: https://dx.doi.org/10.1080/14397595.2020.1 829339. PMID: 32990113. Exclusion:

Systematic review used as source document

73. Garijo IH, Del Barrio SJ, Gomez TM, et al. Effectiveness of non-pharmacological conservative therapies in adults with fibromyalgia: A systematic review of highquality clinical trials. Journal of Back \& Musculoskeletal Rehabilitation. 2021 Jun 25;25:25. doi: https://dx.doi.org/10.3233/BMR-200282. PMID: 34180405. Exclusion: Systematic review used as source document 
74. Gati T, Czimer E, Cserhati G, et al. A multicentre randomized controlled followup study of the effects of the underwater traction therapy in chronic low back pain. International Journal of Biometeorology. 2020 Aug;64(8):1393-400. doi: https://dx.doi.org/10.1007/s00484-02001919-8. PMID: 32361959. Exclusion: Ineligible intervention

75. Godley E, Smith MA. Efficacy of acupressure for chronic low back pain: A systematic review. Complementary Therapies in Clinical Practice. 2020 May;39:101146. doi: https://dx.doi.org/10.1016/j.ctcp.2020.10114 6. PMID: 32379678. Exclusion:: Systematic review used as source document

76. Gohir SA, Eek F, Kelly A, et al. Effectiveness of Internet-Based Exercises Aimed at Treating Knee Osteoarthritis: The iBEAT-OA Randomized Clinical Trial. JAMA Network Open. 202102 01;4(2):e210012. doi: https://dx.doi.org/10.1001/jamanetworkopen .2021.0012. PMID: 33620447. Exclusion: Inadequate duration of followup

77. Gomez-de-Regil L, Estrella-Castillo DF. Psychotherapy for Physical Pain in Patients with Fibromyalgia: A Systematic Review. Pain Research \& Management. 2020;2020:3408052. doi: https://dx.doi.org/10.1155/2020/3408052. PMID: 32714478. Exclusion: Systematic review used as source document

78. Gonzalez-Rueda V, Hidalgo-Garcia C, Rodriguez-Sanz J, et al. Does Upper Cervical Manual Therapy Provide Additional Benefit in Disability and Mobility over a Physiotherapy Primary Care Program for Chronic Cervicalgia? A Randomized Controlled Trial. International Journal of Environmental Research \& Public Health [Electronic Resource]. 202011 11;17(22):11. doi: https://dx.doi.org/10.3390/ijerph17228334. PMID: 33187167. Exclusion: Ineligible intervention
79. Gonzalez-Rueda V, Lopez-de-Celis C, Bueno-Gracia E, et al. "Short- and mid-term effects of adding upper cervical manual therapy to a conventional physical therapy program in patients with chronic mechanical neck pain. Randomized controlled clinical trial.". Clinical Rehabilitation. 2021 Mar;35(3):378-89. doi: https://dx.doi.org/10.1177/02692155209650 54. PMID: 33076707. Exclusion: Ineligible intervention

80. Gopichandran L, Srivastsava AK, Vanamail P, et al. Effectiveness of Progressive Muscle Relaxation and Deep Breathing Exercise on Pain, Disability, and Sleep Among Patients With Chronic Tension-Type Headache: A Randomized Control Trial. Holistic Nursing Practice. 2021 May 28;28:28. doi: https://dx.doi.org/10.1097/HNP.0000000000 000460. PMID: 34054116. Exclusion: Inadequate duration of followup

81. Gould HM, Atkinson JH, Chircop-Rollick T, et al. A randomized placebo-controlled trial of desipramine, cognitive behavioral therapy, and active placebo therapy for low back pain. Pain. 2020 06;161(6):1341-9. doi: https://dx.doi.org/10.1097/j.pain.000000000 0001834. PMID: 32068667. Exclusion: Inadequate duration of followup

82. Groessl EJ, Liu L, Richard EL, et al. Costeffectiveness of Yoga for Chronic Low Back Pain in Veterans. Medical Care. 2020 09;58 Suppl 2 9S:S142-S8. doi: https://dx.doi.org/10.1097/MLR.000000000 0001356. PMID: 32826784. Exclusion: Ineligible outcomes

83. Gueugnon M, Fournel I, Soilly AL, et al. Effectiveness, safety, and cost-utility of a knee brace in medial knee osteoarthritis: the ERGONOMIE randomized controlled trial. Osteoarthritis \& Cartilage. 2021

04;29(4):491-501. doi:

https://dx.doi.org/10.1016/j.joca.2020.11.00 9. PMID: 33524515. Exclusion: Ineligible population 
84. Guimaraes LS, Costa L, Araujo AC, et al. Photobiomodulation therapy is not better than placebo in patients with chronic nonspecific low back pain: a randomised placebo-controlled trial. Pain. 202106 01;162(6):1612-20. doi:

https://dx.doi.org/10.1097/j.pain.000000000

0002189. PMID: 33449509. Exclusion:

Ineligible intervention

85. Guinot M, Maindet C, Hodaj H, et al.

Effects of Repetitive Transcranial Magnetic Stimulation and Multicomponent Therapy in Patients With Fibromyalgia: A Randomized Controlled Trial. Arthritis care \& research. 2021 03;73(3):449-58. doi: https://dx.doi.org/10.1002/acr.24118. PMID: 31785190. Exclusion: Ineligible intervention

86. Gutierrez Espinoza H, Araya-Quintanilla F, Olguin-Huerta C, et al. Effectiveness of manual therapy in patients with thumb carpometacarpal osteoarthritis: a systematic review and meta-analysis. Physiotherapy Theory \& Practice. 2021 Jun 01:1-10. doi: https://dx.doi.org/10.1080/09593985.2021.1 926026. PMID: 34074220. Exclusion:

Systematic review used as source document

87. Hanel J, Owen PJ, Held S, et al. Effects of Exercise Training on Fear-Avoidance in Pain and Pain-Free Populations: Systematic Review and Meta-analysis. Sports Medicine. 2020 Dec;50(12):2193-207. doi: https://dx.doi.org/10.1007/s40279-02001345-1. PMID: 32946074. Exclusion:

Systematic review used as source document

88. Hansen S, Mikkelsen LR, Overgaard S, et al. Effectiveness of supervised resistance training for patients with hip osteoarthritis a systematic review. Danish Medical Journal. 2020 Jun 01;67(6):01. PMID: 32741435. Exclusion: Systematic review used as source document

89. Harada K, Takahashi K, Ikuta F, et al. Efficacy of a deep thermal therapy system for osteoarthritis of the knee. Journal of Nippon Medical School = Nihon Ika Daigaku Zasshi. 2020 Sep 30;30:30. doi: https://dx.doi.org/10.1272/jnms.JNMS.2021 88-505. PMID: 32999179. Exclusion: Ineligible study design
90. Haugmark T, Hagen KB, Provan SA, et al. Effects of a mindfulness-based and acceptance-based group programme followed by physical activity for patients with fibromyalgia: a randomised controlled trial. BMJ Open. 2021 Jun

29;11(6):e046943. doi: 10.1136/bmjopen2020-046943. PMID: 34187823. Exclusion: Ineligible intervention

91. Haugmark T, Hagen KB, Smedslund G, et al. Mindfulness- and acceptance-based interventions for patients with fibromyalgia - A systematic review and meta-analyses. PLoS ONE [Electronic Resource]. 2019;14(9):e0221897. doi: https://dx.doi.org/10.1371/journal.pone.0221 897. PMID: 31479478. Exclusion:

Systematic review used as source document

92. Hayden JA, Wilson MN, Stewart S, et al. Exercise treatment effect modifiers in persistent low back pain: an individual participant data meta-analysis of 3514 participants from 27 randomised controlled trials. British Journal of Sports Medicine. 2020 Nov;54(21):1277-8. doi: https://dx.doi.org/10.1136/bjsports-2019101205. PMID: 31780447. Exclusion: Systematic review used as source document

93. Hee SW, Mistry D, Friede T, et al. Identification of subgroup effect with an individual participant data meta-analysis of randomised controlled trials of three different types of therapist-delivered care in low back pain. BMC Musculoskeletal Disorders. 2021 Feb 16;22(1):191. doi: https://dx.doi.org/10.1186/s12891-02104028-8. PMID: 33593341. Exclusion: Systematic review used as source document

94. Hernandez D, Dimaro M, Navarro E, et al. Efficacy of core exercises in patients with osteoarthritis of the knee: A randomized controlled clinical trial. Journal of Bodywork \& Movement Therapies. 2019 Oct;23(4):881-7. doi: https://dx.doi.org/10.1016/j.jbmt.2019.06.00 2. PMID: 31733777. Exclusion: Ineligible comparator 
95. Hernando-Garijo I, Ceballos-Laita L, Mingo-Gomez MT, et al. Immediate Effects of a Telerehabilitation Program Based on Aerobic Exercise in Women with Fibromyalgia. International Journal of Environmental Research \& Public Health [Electronic Resource]. 202102 20;18(4):20. doi:

https://dx.doi.org/10.3390/ijerph18042075. PMID: 33672691. Exclusion: Inadequate duration of followup

96. Howarth A, Riaz M, Perkins-Porras L, et al. Pilot randomised controlled trial of a brief mindfulness-based intervention for those with persistent pain. Journal of behavioral medicine. 2019;42(6):999-1014. PMID: CN-01939048. Exclusion: Ineligible population

97. Hu L, Wang Y, Liu X, et al. Tai Chi exercise can ameliorate physical and mental health of patients with knee osteoarthritis: systematic review and meta-analysis. Clinical Rehabilitation. 2021 Jan;35(1):6479. doi:

https://dx.doi.org/10.1177/02692155209543 43. PMID: 32954819. Exclusion:

Systematic review used as source document

98. Huang CC, Wang $\mathrm{HH}$, Chen $\mathrm{KC}$, et al. Effects of a dynamic combined training on impulse response for middle-aged and elderly patients with osteoporosis and knee osteoarthritis: a randomized control trial. Aging-Clinical \& Experimental Research. 2021 Jan;33(1):115-23. doi: https://dx.doi.org/10.1007/s40520-02001508-0. PMID: 32100224. Exclusion: Ineligible study design

99. Huang JF, Zheng XQ, Chen D, et al. Can Acupuncture Improve Chronic Spinal Pain? A Systematic Review and Meta-Analysis. Global Spine Journal. 2020 Oct 09:2192568220962440. doi: https://dx.doi.org/10.1177/21925682209624 40. PMID: 33034233. Exclusion: Systematic review used as source document

100. Huang Z, Liu S, Zhou J, et al. Efficacy and Safety of Acupuncture for Chronic Discogenic Sciatica, a Randomized Controlled Sham Acupuncture Trial. Pain Medicine. 2019 11 01;20(11):2303-10. doi: https://dx.doi.org/10.1093/pm/pnz167. PMID: 31369674. Exclusion: Ineligible population
101. Huppe A, Zeuner C, Karstens S, et al. Feasibility and long-term efficacy of a proactive health program in the treatment of chronic back pain: a randomized controlled trial. BMC Health Services Research. 2019 Oct 21;19(1):714. doi:

https://dx.doi.org/10.1186/s12913-0194561-8. PMID: 31639016. Exclusion: Ineligible intervention

102. Iijima H, Eguchi R, Shimoura K, et al. Transcutaneous Electrical Nerve Stimulation Improves Stair Climbing Capacity in People with Knee Osteoarthritis. Scientific Reports. 202004 29;10(1):7294. doi: https://dx.doi.org/10.1038/s41598-02064176-0. PMID: 32350320. Exclusion: Inadequate duration of followup

103. Izquierdo-Alventosa R, Ingles M, CortesAmador S, et al. Low-Intensity Physical Exercise Improves Pain Catastrophizing and Other Psychological and Physical Aspects in Women with Fibromyalgia: A Randomized Controlled Trial. International Journal of Environmental Research \& Public Health [Electronic Resource]. 202005 21;17(10):21. doi: https://dx.doi.org/10.3390/ijerph17103634. PMID: 32455853. Exclusion: Inadequate duration of followup

104. Jafarzadeh A, Ehsani F, Yosephi MH, et al. Concurrent postural training and M1 anodal transcranial direct current stimulation improve postural impairment in patients with chronic low back pain. Journal of Clinical Neuroscience. 2019 Oct;68:224-34. doi:

https://dx.doi.org/10.1016/j.jocn.2019.07.01 7. PMID: 31350080. Exclusion: Ineligible study design

105. Jassi FJ, Del Antonio TT, Azevedo BO, et al. Star-Shape Kinesio Taping Is Not Better Than a Minimal Intervention or Sham Kinesio Taping for Pain Intensity and Postural Control in Chronic Low Back Pain: A Randomized Controlled Trial. Archives of Physical Medicine \& Rehabilitation. 2021 Jul;102(7):1352-60.e3. doi: https://dx.doi.org/10.1016/j.apmr.2021.03.0 07. PMID: 33819489. Exclusion: Ineligible intervention 
106. Javdaneh N, Molayei F, Kamranifraz N. Effect of adding motor imagery training to neck stabilization exercises on pain, disability and kinesiophobia in patients with chronic neck pain. Complementary

Therapies in Clinical Practice. 2021

Feb;42:101263. doi:

https://dx.doi.org/10.1016/j.ctcp.2020.10126

3. PMID: 33276225. Exclusion: Inadequate duration of followup

107. Jiao J, Russell IJ, Wang W, et al. Ba-DuanJin alleviates pain and fibromyalgia-related symptoms in patients with fibromyalgia: results of a randomised controlled trial. Clinical \& Experimental Rheumatology. 2019 Nov-Dec;37(6):953-62. PMID: 30789154. Exclusion: Inadequate duration of followup

108. Kamonseki DH, Lopes EP, van der Meer HA, et al. Effectiveness of manual therapy in patients with tension-type headache. A systematic review and meta-analysis. Disability \& Rehabilitation. 2020 Sep 12:110. doi: https://dx.doi.org/10.1080/09638288.2020.1 813817. PMID: 32924640. Exclusion: Systematic review used as source document

109. Kang TW, Lee JH, Park DH, et al. Effects of a finger exercise program on hand function in automobile workers with hand osteoarthritis: a randomized controlled trial. Hand surgery \& rehabilitation. 2019;38(1):59-66. PMID: CN-02084202 NEW. Exclusion: Ineligible study design

110. Kaplun A, Roitman P, Rosenbloom T. Effects of Brief Guided Imagery on Female Patients Diagnosed with Fibromyalgia: An Exploratory Controlled Trial. Alternative Therapies in Health \& Medicine. 2021 Jun;27(S1):104-13. PMID: 32827404. Exclusion: Inadequate duration of followup

111. Karadag S, Tasci S, Dogan N, et al. Application of heat and a home exercise program for pain and function levels in patients with knee osteoarthritis: A randomized controlled trial. International Journal of Nursing Practice. 2019 Oct;25(5):e12772. doi: https://dx.doi.org/10.1111/ijn.12772. PMID: 31436359. Exclusion: Inadequate duration of followup
112. Kim E, Kim YS, Kim YI, et al. Effectiveness and Safety of Polydioxanone Thread-Embedding Acupuncture as an Adjunctive Therapy for Patients with Chronic Nonspecific Neck Pain: a Randomized Controlled Trial. Journal of alternative and complementary medicine (New York, N.Y.). 2019;25(4):417-26. PMID: CN-01659482. Exclusion:Ineligible intervention

113. Kim M, Kim J. Effects of Acupressure on Pain, Flexibility, and Substance P in MiddleAge Women with Chronic Neck Pain. Journal of Alternative \& Complementary Medicine. 2021 Feb;27(2):160-7. doi: https://dx.doi.org/10.1089/acm.2020.0413. PMID: 33296258. Exclusion: Inadequate duration of followup

114. Kim S, Hsu FC, Groban L, et al. A pilot study of aquatic prehabilitation in adults with knee osteoarthritis undergoing total knee arthroplasty - short term outcome. BMC Musculoskeletal Disorders. 2021 Apr 26;22(1):388. doi: https://dx.doi.org/10.1186/s12891-02104253-1. PMID: 33902505. Exclusion: Ineligible population

115. Kim SD. Twelve Weeks of Yoga for Chronic Nonspecific Lower Back Pain: A Meta-Analysis. Pain Management Nursing. 2020 12;21(6):536-42. doi: https://dx.doi.org/10.1016/j.pmn.2020.07.00 2. PMID: 32830047.Exclusion: Systematic review used as source document

116. Kim SH, Park KN, Kwon OY. Classification-Specific Treatment Improves Pain, Disability, Fear-Avoidance Beliefs, and Erector Spinae Muscle Activity During Walking in Patients With Low Back Pain Exhibiting Lumbar Extension-Rotation Pattern: A Randomized Controlled Trial. Journal of Manipulative \& Physiological Therapeutics. 2020 02;43(2):123-33. doi: https://dx.doi.org/10.1016/j.jmpt.2019.04.00 4. PMID: 32312606. Exclusion: Ineligible comparator 
117. Kim SK, Min A, Jeon C, et al. Clinical outcomes and cost-effectiveness of massage chair therapy versus basic physiotherapy in lower back pain patients: A randomized controlled trial. Medicine. 2020

Mar;99(12):e19514. doi: https://dx.doi.org/10.1097/MD.0000000000 019514. PMID: 32195952. Exclusion: Inadequate duration of followup

118. Kim SY, Busch AJ, Overend TJ, et al. Flexibility exercise training for adults with fibromyalgia. Cochrane Database of Systematic Reviews. 2019 Sep 02;9:CD013419. doi: https://dx.doi.org/10.1002/14651858.CD013 419. PMID: 31476271. Exclusion:

Systematic review used as source document

119. Kim T, Lee J, Oh S, et al. Effectiveness of Simulated Horseback Riding for Patients With Chronic Low Back Pain: A Randomized Controlled Trial. Journal of Sport Rehabilitation. 2020 Feb 01;29(2):179-85. doi: https://dx.doi.org/10.1123/jsr.2018-0252. PMID: 30676224. Exclusion: Ineligible comparator

120. Kolbe L, Eberhardt T, Leinberger B, et al. Effectiveness of Biofeedback for Primary Headache - A Randomized Controlled Study. Psychotherapie, Psychosomatik, medizinische Psychologie. 2020;70(7):3007. PMID: $\mathrm{CN}-02073107$. Exclusion: Not English language but possibly relevant

121. Kong JT, Puetz C, Tian L, et al. Effect of Electroacupuncture vs Sham Treatment on Change in Pain Severity Among Adults With Chronic Low Back Pain: A Randomized Clinical Trial. JAMA Network Open. 202010 01;3(10):e2022787. doi: https://dx.doi.org/10.1001/jamanetworkopen 2020.22787. PMID: 33107921. Exclusion: Inadequate duration of followup

122. Krauss I, Hein T, Steinhilber B, et al. A 12week exercise program for patients with hip osteoarthritis has no influence on gait parameters: A secondary analysis of a randomized controlled trial. Gait \& Posture. 2020 05;78:6-12. doi: https://dx.doi.org/10.1016/j.gaitpost.2020.03 .001. PMID: 32151918. Exclusion:

Inadequate duration of followup
123. Krishna D, Deepeshwar S, Devi B. YogaBased Relaxation Technique Facilitates Sustained Attention in Patients with Low Back Pain: A Pilot Study. Advances in Mind-Body Medicine. 2020

Summer;34(3):11-7. PMID: 32931457. Exclusion: Ineligible study design

124. Kurlyandchik I, Tiralongo E, Schloss J. Safety and Efficacy of Medicinal Cannabis in the Treatment of Fibromyalgia: A Systematic Review. Journal of Alternative \& Complementary Medicine. 2021 Mar;27(3):198-213. doi: https://dx.doi.org/10.1089/acm.2020.0331. PMID: 33337931. Exclusion: Systematic review used as source document

125. Kurt V, Aras O, Buker N. Comparison of conservative treatment with and without neural mobilization for patients with low back pain: A prospective, randomized clinical trial. Journal of Back \& Musculoskeletal Rehabilitation. 2020;33(6):969-75. doi: https://dx.doi.org/10.3233/BMR-181241. PMID: 32144973. Exclusion: Inadequate duration of followup

126. Lascurain-Aguirrebena I, Newham DJ, Casado-Zumeta X, et al. Immediate effects of cervical mobilisations on neck muscle activity during active neck movements in patients with non-specific neck pain. A double blind placebo controlled trial. Physiotherapy. 2021 03;110:42-53. doi: https://dx.doi.org/10.1016/j.physio.2019.07. 003. PMID: 33131786. Exclusion: Inadequate duration of followup

127. Lee E, Lee S. Impact of Cervical Sensory Feedback for Forward Head Posture on Headache Severity and Physiological Factors in Patients with Tension-type Headache: A Randomized, Single-Blind, Controlled Trial. Medical Science Monitor. 2019 Dec 15;25:9572-84. doi: https://dx.doi.org/10.12659/MSM.918595. PMID: 31838486. Exclusion: Inadequate duration of followup 
128. Lee K, Lewis GN. Short term relief of multisite chronicpain with Bowen Therapy: A double-blind, randomized controlled trial. Journal of Bodywork \& Movement Therapies. 2020 Oct;24(4):271-9. doi: https://dx.doi.org/10.1016/j.jbmt.2020.06.02 5. PMID: 33218522. Exclusion: Ineligible study design

129. Lena O, Todri J, Todri A, et al. The Effectiveness of the Mezieres Method in Elite Rhythmic Gymnastics Athletes With Low Back Pain: A Randomized Controlled Trial. Journal of Sport Rehabilitation. 2020 Sep 01;29(7):913-9. doi: https://dx.doi.org/10.1123/jsr.2019-0204. PMID: 31711041. Exclusion: Ineligible population

130. Letafatkar A, Rabiei P, Alamooti G, et al. Effect of therapeutic exercise routine on pain, disability, posture, and health status in dentists with chronic neck pain: a randomized controlled trial. International Archives of Occupational \& Environmental Health. 2020 04;93(3):281-90. doi: https://dx.doi.org/10.1007/s00420-01901480-x. PMID: 31654125. Exclusion: Inadequate duration of followup

131. Li C, Pei Q, Chen Y, et al. The responsetime relationship and covariate effects of acupuncture for chronic pain: A systematic review and model-based longitudinal metaanalysis. European Journal of Pain. 2020 10;24(9):1653-65. doi: https://dx.doi.org/10.1002/ejp.1617. PMID: 32533885. Exclusion: Systematic review used as source document

132. Li R, Chen H, Feng J, et al. Effectiveness of Traditional Chinese Exercise for Symptoms of Knee Osteoarthritis: A Systematic Review and Meta-Analysis of Randomized Controlled Trials. International Journal of Environmental Research \& Public Health [Electronic Resource]. 202010 27;17(21):27. doi: https://dx.doi.org/10.3390/ijerph17217873. PMID: 33121082. Exclusion: Systematic review used as source document
133. Li YX, Yuan SE, Jiang JQ, et al. Systematic review and meta-analysis of effects of acupuncture on pain and function in nonspecific low back pain. Acupuncture in Medicine. 2020 08;38(4):235-43. doi: https://dx.doi.org/10.1136/acupmed-2017011622. PMID: 32458717. Exclusion: Systematic review used as source document

134. Liao FY, Lin CL, Lo SF, et al. Efficacy of Acupoints Dual-Frequency Low-Level Laser Therapy on Knee Osteoarthritis. Evidence-Based Complementary \& Alternative Medicine: eCAM. 2020;2020:6979105. doi: https://dx.doi.org/10.1155/2020/6979105. PMID: 33029170. Exclusion: Inadequate duration of followup

135. Lin KY, Tsai YJ, Hsu PY, et al. Effects of Sling Exercise for Neck Pain: A Systematic Review and Meta-Analysis. Physical Therapy. 2021 Apr 30;30:30. doi: https://dx.doi.org/10.1093/ptj/pzab120. PMID: 33929540. Exclusion: Systematic review used as source document

136. Lin YP, Su YH, Chin SF, et al. Lightemitting diode photobiomodulation therapy for non-specific low back pain in working nurses: A single-center, double-blind, prospective, randomized controlled trial. Medicine. 2020 Aug 07;99(32):e21611. doi: https://dx.doi.org/10.1097/MD.0000000000 021611. PMID: 32769919. Exclusion: Ineligible intervention

137. Liu J, Yeung A, Xiao T, et al. Chen-Style Tai Chi for Individuals (Aged 50 Years Old or Above) with Chronic Non-Specific Low Back Pain: a Randomized Controlled Trial. International journal of environmental research and public health. 2019;16(3) PMID: CN-01707017. Exclusion: Inadequate duration of followup

138. Liu M, Tong Y, Chai L, et al. Effects of Auricular Point Acupressure on Pain Relief: A Systematic Review. Pain Management Nursing. 2021 Jun;22(3):268-80. doi: https://dx.doi.org/10.1016/j.pmn.2020.07.00 7. PMID: 32950391. Exclusion: Systematic review used as source document 
139. Lopez-de-Uralde-Villanueva I, BeltranAlacreu H, Fernandez-Carnero J, et al. Pain management using a multimodal physiotherapy program including a biobehavioral approach for chronic nonspecific neck pain: a randomized controlled trial. Physiotherapy Theory \& Practice. 2020 Jan;36(1):45-62. doi: https://dx.doi.org/10.1080/09593985.2018.1 480678. PMID: 29889599. Exclusion: Ineligible intervention

140. Low MY, Lacson C, Zhang F, et al. Vocal Music Therapy for Chronic Pain: A Mixed Methods Feasibility Study. Journal of Alternative \& Complementary Medicine. 2020 Feb;26(2):113-22. doi: https://dx.doi.org/10.1089/acm.2019.0249. PMID: 31750726. Exclusion: Ineligible population

141. Luan L, Bousie J, Pranata A, et al. Stationary cycling exercise for knee osteoarthritis: A systematic review and meta-analysis. Clinical Rehabilitation. 2021 Apr;35(4):522-33. doi: https://dx.doi.org/10.1177/02692155209717 95. PMID: 33167714. Exclusion:

Systematic review used as source document

142. Ludvigsson ML, Peterson G, Peolsson A. Neck-specific exercise for radiating pain and neurological deficits in chronic whiplash, a 1 -year follow-up of a randomised clinical trial. Scientific Reports. 202004 21;10(1):6758. doi: https://dx.doi.org/10.1038/s41598-02062722-4. PMID: 32317700. Exclusion: Ineligible intervention

143. Lv ZT, Shen LL, Zhu B, et al. Effects of intensity of electroacupuncture on chronic pain in patients with knee osteoarthritis: a randomized controlled trial. Arthritis research \& therapy. 2019;21(1):120. PMID: CN-01940220. Exclusion: Inadequate duration of followup

144. Machado-Oliveira L, da Silva Gauto YO, de Santana Neto FJ, et al. Effects of Different Exercise Intensities on Headache: A Systematic Review. American Journal of Physical Medicine \& Rehabilitation. 2020 05;99(5):390-6. doi: https://dx.doi.org/10.1097/PHM.000000000 0001349. PMID: 31725018. Exclusion:

Systematic review used as source document
145. Madadi-Shad M, Jafarnezhadgero AA, Sheikhalizade H, et al. Effect of a corrective exercise program on gait kinetics and muscle activities in older adults with both low back pain and pronated feet: A doubleblind, randomized controlled trial. Gait \& Posture. 2020 02;76:339-45. doi: https://dx.doi.org/10.1016/j.gaitpost.2019.12 026. PMID: 31896537. Exclusion: Inadequate duration of followup

146. Mahler EAM, Minten MJ, LesemanHoogenboom MM, et al. Effectiveness of low-dose radiation therapy on symptoms in patients with knee osteoarthritis: a randomised, double-blinded, shamcontrolled trial. Annals of the rheumatic diseases. 2019;78(1):83-90. PMID: CN02000205. Exclusion: Ineligible intervention

147. Marconcin P, Yazigi F, Teles J, et al. The effectiveness of a randomised clinical trial of PLE2 NO self-management and exercise programme for knee osteoarthritis to improve self-efficacy. Musculoskeletal Care. 2021 Jun 02;02:02. doi:

https://dx.doi.org/10.1002/msc.1573. PMID: 34077602. Exclusion: Inadequate duration of followup

148. Martimbianco ALC, Porfirio GJ, Pacheco $\mathrm{RL}$, et al. Transcutaneous electrical nerve stimulation (TENS) for chronic neck pain. Cochrane Database of Systematic Reviews. 2019 12 12;12:CD011927. doi: https://dx.doi.org/10.1002/14651858.CD011 927.pub2. PMID: 31830313. Exclusion: Systematic review used as source document

149. Martinez-Calderon J, Flores-Cortes M, Morales-Asencio JM, et al. Intervention Therapies to Reduce Pain-Related Fear in Fibromyalgia Syndrome: A Systematic Review of Randomized Clinical Trials. Pain Medicine. 202102 23;22(2):481-98. doi: https://dx.doi.org/10.1093/pm/pnaa331. PMID: 32989450. Exclusion: Systematic review used as source document 
150. Mascarenhas RO, Souza MB, Oliveira MX, et al. Association of Therapies With Reduced Pain and Improved Quality of Life in Patients With Fibromyalgia: A Systematic Review and Meta-analysis. JAMA Internal Medicine. 2021 Jan 01;181(1):104-12. doi: https://dx.doi.org/10.1001/jamainternmed.20 20.5651. PMID: 33104162. Exclusion:

Systematic review used as source document

151. McCurry SM, Zhu W, Von Korff M, et al. Effect of Telephone Cognitive Behavioral Therapy for Insomnia in Older Adults With Osteoarthritis Pain: A Randomized Clinical Trial. JAMA Internal Medicine. 2021 Apr 01;181(4):530-8. doi:

https://dx.doi.org/10.1001/jamainternmed.20 20.9049. PMID: 33616613. Exclusion: Ineligible intervention

152. Mehri A, Letafatkar A, Khosrokiani Z. Effects of Corrective Exercises on Posture, Pain, and Muscle Activation of Patients With Chronic Neck Pain Exposed to Anterior-Posterior Perturbation. Journal of Manipulative \& Physiological Therapeutics. 2020 05;43(4):311-24. doi:

https://dx.doi.org/10.1016/j.jmpt.2018.11.03 2. PMID: 32723668. Exclusion: Inadequate duration of followup

153. Mohamadi M, Rojhani-Shirazi Z, Assadsangabi R, et al. Can the Positional Release Technique Affect Central Sensitization in Patients With Chronic Tension-Type Headache? A Randomized Clinical Trial. Archives of Physical Medicine \& Rehabilitation. 2020 10;101(10):1696-703. doi: https://dx.doi.org/10.1016/j.apmr.2020.05.0 28. PMID: 32673652. Exclusion: Inadequate duration of followup

154. Moseng T, Dagfinrud H, van Bodegom-Vos $\mathrm{L}$, et al. Low adherence to exercise may have influenced the proportion of OMERACT-OARSI responders in an integrated osteoarthritis care model: secondary analyses from a clusterrandomised stepped-wedge trial. BMC Musculoskeletal Disorders. 2020 Apr 13;21(1):236. doi: https://dx.doi.org/10.1186/s12891-02003235-z. PMID: 32284049. Exclusion: Ineligible intervention
155. Movahedi Najafabadi M, Ghafari S, Nazari $\mathrm{F}$, et al. The effect of acupressure on quality of life among female nurses with chronic back pain. Applied Nursing Research. 2020 02;51:151175. doi:

https://dx.doi.org/10.1016/j.apnr.2019.05.02 0. PMID: 31831270. Exclusion: Ineligible study design

156. Mu J, Furlan AD, Lam WY, et al. Acupuncture for chronic nonspecific low back pain. Cochrane Database of Systematic Reviews. 202012 11;12:CD013814. doi: https://dx.doi.org/10.1002/14651858.CD013 814. PMID: 33306198. Exclusion:

Systematic review used as source document

157. Mukhtar NB, Meeus M, Gursen C, et al. Effectiveness of Hands-Off Therapy in the Management of Primary Headache: A Systematic Review and Meta-Analysis. Evaluation \& the Health Professions. 2021 Jan 07:163278720983408. doi: https://dx.doi.org/10.1177/01632787209834 08. PMID: 33406891. Exclusion:

Systematic review used as source document

158. Munukka M, Waller B, Hakkinen A, et al. Effects of progressive aquatic resistance training on symptoms and quality of life in women with knee osteoarthritis: A secondary analysis. Scandinavian Journal of Medicine \& Science in Sports. 2020 Jun;30(6):1064-72. doi: https://dx.doi.org/10.1111/sms.13630. PMID: 31999876. Exclusion: Inadequate duration of followup

159. Murphy SL, Harris RE, Keshavarzi NR, et al. Self-Administered Acupressure for Chronic Low Back Pain: A Randomized Controlled Pilot Trial. Pain Medicine. 2019 12 01;20(12):2588-97. doi: https://dx.doi.org/10.1093/pm/pnz138. PMID: 31237610. Exclusion: Inadequate duration of followup

160. Nadal-Nicolas Y, Rubio-Arias JA, MartinezOlcina M, et al. Effects of Manual Therapy on Fatigue, Pain, and Psychological Aspects in Women with Fibromyalgia. International Journal of Environmental Research \& Public Health [Electronic Resource]. 202006 26;17(12):26. doi: https://dx.doi.org/10.3390/ijerph17124611. PMID: 32604939. Exclusion: Ineligible study design 
161. Nakamaru K, Aizawa J, Kawarada K, et al. Immediate effects of thoracic spine selfmobilization in patients with mechanical neck pain: a randomized controlled trial. Journal of bodywork and movement therapies. 2019;23(2):417-24. PMID: CN02083937 NEW. Exclusion: Inadequate duration of followup

162. Nambi G, Abdelbasset WK, Alqahtani BA, et al. Isokinetic back training is more effective than core stabilization training on pain intensity and sports performances in football players with chronic low back pain: A randomized controlled trial. Medicine. 2020 May 22;99(21):e20418. doi: https://dx.doi.org/10.1097/MD.0000000000 020418. PMID: 32481345. Exclusion: Ineligible comparator

163. Nambi G, Abdelbasset WK, Alrawaili SM, et al. Virtual reality or isokinetic training; its effect on pain, kinesiophobia and serum stress hormones in chronic low back pain: A randomized controlled trial. Technology \& Health Care. 2021;29(1):155-66. doi: https://dx.doi.org/10.3233/THC-202301. PMID: 32831210. Exclusion: Ineligible comparator

164. Nambi G, Abdelbasset WK, Alsubaie SF, et al. Short-Term Psychological and Hormonal Effects of Virtual Reality Training on Chronic Low Back Pain in Soccer Players. Journal of Sport Rehabilitation. 2021 Feb 16:1-10. doi: https://dx.doi.org/10.1123/jsr.2020-0075. PMID: 33596538. Exclusion: Ineligible comparator

165. Namnaqani FI, Mashabi AS, Yaseen KM, et al. The effectiveness of McKenzie method compared to manual therapy for treating chronic low back pain: a systematic review. Journal of Musculoskeletal Neuronal Interactions. 201912 01;19(4):492-9. PMID: 31789300. Exclusion: Systematic review used as source document

166. Nduwimana I, Nindorera F, Thonnard JL, et al. Effectiveness of walking versus mindbody therapies in chronic low back pain: A systematic review and meta-analysis of recent randomized controlled trials. Medicine. 2020 Aug 28;99(35):e21969. doi: https://dx.doi.org/10.1097/MD.0000000000 021969. PMID: 32871946. Exclusion:

Systematic review used as source document
167. Nelligan RK, Hinman RS, Kasza J, et al. Effects of a Self-directed Web-Based Strengthening Exercise and Physical Activity Program Supported by Automated Text Messages for People With Knee Osteoarthritis: A Randomized Clinical Trial. JAMA Internal Medicine. 2021 Jun 01;181(6):776-85. doi:

https://dx.doi.org/10.1001/jamainternmed.20 21.0991. PMID: 33843948. Exclusion: Ineligible intervention

168. Nery M, Natour J, Jennings F, et al. Effects of a progressive resistance exercise program in patients with hand osteoarthritis: A randomized, controlled trial with a blinded assessor. Clinical Rehabilitation. $2021 \mathrm{Jul}$ 09:2692155211030622. doi: https://dx.doi.org/10.1177/02692155211030 622. PMID: 34240642. Exclusion: Inadequate duration of followup

169. Niederer D, Engel T, Vogt L, et al. Motor Control Stabilisation Exercise for Patients with Non-Specific Low Back Pain: A Prospective Meta-Analysis with Multilevel Meta-Regressions on Intervention Effects. Journal of Clinical Medicine. 2020 Sep 22;9(9):22. doi:

https://dx.doi.org/10.3390/jcm9093058. PMID: 32971921. Exclusion: Systematic review used as source document

170. Noori SA, Rasheed A, Aiyer R, et al. Therapeutic Ultrasound for Pain Management in Chronic Low Back Pain and Chronic Neck Pain: A Systematic Review. Pain Medicine. 202011 07;21(7):1482-93. doi: https://dx.doi.org/10.1093/pm/pny287. PMID: 30649460. Exclusion: Systematic review used as source document

171. Norouzi E, Hosseini F, Vaezmosavi M, et al. Zumba dancing and aerobic exercise can improve working memory, motor function, and depressive symptoms in female patients with Fibromyalgia. European Journal of Sport Science EJSS : Official Journal of the European College of Sport Science. 2020 Aug;20(7):981-91. doi: https://dx.doi.org/10.1080/17461391.2019.1 683610. PMID: 31630663. Exclusion: Inadequate duration of followup 
172. Novak S, Guerron G, Zou Z, et al. New Guidelines for Electrical Stimulation Parameters in Adult Patients With Knee Osteoarthritis Based on a Systematic Review of the Current Literature. American Journal of Physical Medicine \& Rehabilitation. 2020 08;99(8):682-8. doi: https://dx.doi.org/10.1097/PHM.000000000 0001409. PMID: 32167955. Exclusion:

Systematic review used as source document

173. O'Keeffe M, O'Sullivan P, Purtill H, et al. Cognitive functional therapy compared with a group-based exercise and education intervention for chronic low back pain: a multicentre randomised controlled trial (RCT). British Journal of Sports Medicine. 2020 Jul;54(13):782-9. doi: https://dx.doi.org/10.1136/bjsports-2019100780. PMID: 31630089. Exclusion: Ineligible intervention

174. Oh SL, Kim DY, Bae JH, et al. Effects of rural community-based integrated exercise and health education programs on the mobility function of older adults with knee osteoarthritis. Aging Clinical \& Experimental Research. 2020 Feb 04;04:04. doi: https://dx.doi.org/10.1007/s40520-02001474-7. PMID: 32020485. Exclusion: Inadequate duration of followup

175. Ots T, Kandirian A, Szilagyi I, et al. The selection of dermatomes for sham (placebo) acupuncture points is relevant for the outcome of acupuncture studies: a systematic review of sham (placebo)controlled randomized acupuncture trials. Acupuncture in Medicine. 2020

08;38(4):211-26. doi: https://dx.doi.org/10.1177/09645284198896 36. PMID: 32026725. Exclusion:

Systematic review used as source document

176. Ouellet P, Lafrance S, Pizzi A, et al. Regionspecific exercises versus general exercises approaches in the management of spinal and peripheral musculoskeletal disorders: a systematic review with meta-analyses of randomized controlled trials. Archives of Physical Medicine \& Rehabilitation. 2021 Mar 05;05:05. doi: https://dx.doi.org/10.1016/j.apmr.2021.01.0 93. PMID: 33684362. Exclusion:

Systematic review used as source document
177. Paganini S, Lin J, Kahlke F, et al. A guided and unguided internet- and mobile-based intervention for chronic pain: health economic evaluation alongside a randomised controlled trial. BMJ open.

2019;9(4):e023390. PMID: CN-01941119.

Exclusion: Ineligible population

178. Papaconstantinou E, Cancelliere C, Verville $\mathrm{L}$, et al. Effectiveness of nonpharmacological interventions on sleep characteristics among adults with musculoskeletal pain and a comorbid sleep problem: a systematic review. Chiropractic \& manual therapies. $2021 \mathrm{Jul}$ 08;29(1):23. doi: https://dx.doi.org/10.1186/s12998-02100381-6. PMID: 34238325. Exclusion:

Systematic review used as source document

179. Pardos-Gascon EM, Narambuena L, LealCosta C, et al. Differential efficacy between cognitive-behavioral therapy and mindfulness-based therapies for chronic pain: Systematic review. International Journal of Clinical \& Health Psychology. 2021 Jan-Apr;21(1):100197. doi: https://dx.doi.org/10.1016/j.ijchp.2020.08.00 1. PMID: 33363580. Exclusion: Systematic review used as source document

180. Park S, Park S, Min S, et al. A Randomized Controlled Trial Investigating the Effects of Equine Simulator Riding on Low Back Pain, Morphological Changes, and Trunk Musculature in Elderly Women. Medicina. 2020 Nov 13;56(11):13. doi: https://dx.doi.org/10.3390/medicina5611061 0. PMID: 33202928. Exclusion: Inadequate duration of followup

181. Park SY, Hwang EH, Cho JH, et al. Comparative Effectiveness of Chuna Manipulative Therapy for Non-Acute Lower Back Pain: A Multi-Center, Pragmatic, Randomized Controlled Trial. Journal of Clinical Medicine. 2020 Jan 05;9(1):05. doi: https://dx.doi.org/10.3390/jcm9010144. PMID: 31948083. Exclusion: Ineligible population

182. Patel K, Sutherland H, Henshaw J, et al. Effects of neurofeedback in the management of chronic pain: A systematic review and meta-analysis of clinical trials. European Journal of Pain. 2020 09;24(8):1440-57. doi: https://dx.doi.org/10.1002/ejp.1612. PMID: 32502283. Exclusion: Systematic review used as source document 
183. Paulo LR, Lacerda ACR, Martins FLM, et al. Can a Single Trial of a Thoracolumbar Myofascial Release Technique Reduce Pain and Disability in Chronic Low Back Pain? A Randomized Balanced Crossover Study. Journal of Clinical Medicine. 2021 May 07;10(9):07. doi:

https://dx.doi.org/10.3390/jcm10092006. PMID: 34067152. Exclusion: Inadequate duration of followup

184. Pedersini P, Valdes K, Cantero-Tellez R, et al. Effects of Neurodynamic Mobilizations on Pain Hypersensitivity in Patients With Hand Osteoarthritis Compared to Robotic Assisted Mobilization: A Randomized Controlled Trial. Arthritis care \& research. 2021 02;73(2):232-9. doi: https://dx.doi.org/10.1002/acr.24103. PMID: 31675184. Exclusion: Ineligible comparator

185. Pei JH, Ma T, Nan RL, et al. MindfulnessBased Cognitive Therapy for Treating Chronic Pain A Systematic Review and Meta-analysis. Psychology Health \& Medicine. 2021 03;26(3):333-46. doi: https://dx.doi.org/10.1080/13548506.2020.1 849746. PMID: 33241941. Exclusion: Systematic review used as source document

186. Perlini C, Donisi V, Del Piccolo L. From research to clinical practice: a systematic review of the implementation of psychological interventions for chronic headache in adults. BMC Health Services Research. 2020 May 25;20(1):459. doi: https://dx.doi.org/10.1186/s12913-02005172-y. PMID: 32450871. Exclusion: Systematic review used as source document

187. Perlman A, Fogerite SG, Glass O, et al. Efficacy and Safety of Massage for Osteoarthritis of the Knee: a Randomized Clinical Trial. Journal of general internal medicine. 2019;34(3):379-86. PMID: CN02145187. Exclusion: Ineligible study design

188. Petrozzi MJ, Leaver A, Ferreira PH, et al. Addition of MoodGYM to physical treatments for chronic low back pain: A randomized controlled trial. Chiropractic \& manual therapies. 2019;27:54. doi: https://dx.doi.org/10.1186/s12998-0190277-4. PMID: 31673330. Exclusion: Ineligible intervention
189. Petterson S, Plancher K, Klyve D, et al. Low-Intensity Continuous Ultrasound for the Symptomatic Treatment of Upper Shoulder and Neck Pain: A Randomized, Double-Blind Placebo-Controlled Clinical Trial. Journal of pain research. 2020;13:1277-87. doi: https://dx.doi.org/10.2147/JPR.S247463. PMID: 32606899. Exclusion: Ineligible study design

190. Phattharasupharerk S, Purepong N, Eksakulkla S, et al. Effects of Qigong practice in office workers with chronic nonspecific low back pain: a randomized control trial. Journal of bodywork and movement therapies. 2019;23(2):375-81. PMID: CN02083942 NEW. Exclusion: Inadequate duration of followup

191. Pico-Espinosa OJ, Aboagye E, Cote P, et al. Deep tissue massage, strengthening and stretching exercises, and a combination of both compared with advice to stay active for subacute or persistent non-specific neck pain: A cost-effectiveness analysis of the Stockholm Neck trial (STONE). Musculoskeletal Science \& Practice. 2020 04;46:102109. doi:

https://dx.doi.org/10.1016/j.msksp.2020.102 109. PMID: 31989965 . Exclusion:

Ineligible outcomes

192. Pietrosimone B, Luc-Harkey BA, Harkey MS, et al. Using TENS to Enhance Therapeutic Exercise in Individuals with Knee Osteoarthritis. Medicine \& Science in Sports \& Exercise. 2020 10;52(10):2086-95. doi:

https://dx.doi.org/10.1249/MSS.0000000000 002353. PMID: 32251254. Exclusion: Ineligible comparator

193. Pitsillides A, Stasinopoulos D, Giannakou $\mathrm{K}$. The effects of cognitive behavioural therapy delivered by physical therapists in knee osteoarthritis pain: A systematic review and meta-analysis of randomized controlled trials. Journal of Bodywork \& Movement Therapies. 2021 Jan;25:157-64. doi:

https://dx.doi.org/10.1016/j.jbmt.2020.11.00 2. PMID: 33714488. Exclusion: Systematic review used as source document 
194. Polaski AM, Phelps AL, Smith TJ, et al. Integrated Meditation and Exercise Therapy: A Randomized Controlled Pilot of a Combined Nonpharmacological Intervention Focused on Reducing Disability and Pain in Patients with Chronic Low Back Pain. Pain Medicine. 202102 23;22(2):444-58. doi: https://dx.doi.org/10.1093/pm/pnaa403. PMID: 33621332. Exclusion: Inadequate duration of followup

195. Prado ERA, Meireles SM, Carvalho ACA, et al. Influence of isostretching on patients with chronic low back pain. A randomized controlled trial. Physiotherapy Theory \& Practice. 2021 Feb;37(2):287-94. doi: https://dx.doi.org/10.1080/09593985.2019.1 625091. PMID: 31161855. Exclusion: Inadequate duration of followup

196. Pujol J, Ramos-Lopez D, Blanco-Hinojo L, et al. Testing the effects of gentle vibrotactile stimulation on symptom relief in fibromyalgia. Arthritis Research \& Therapy. 201906 14;21(1):148. doi:

https://dx.doi.org/10.1186/s13075-0191932-9. PMID: 31200775. Exclusion: Inadequate duration of followup

197. Qing W, Shi X, Zhang Q, et al. Effect of Therapeutic Ultrasound for Neck Pain: A Systematic Review and Meta-Analysis. Archives of Physical Medicine \& Rehabilitation. 2021 Mar 17;17:17. doi: https://dx.doi.org/10.1016/j.apmr.2021.02.0 09. PMID: 33722564. Exclusion:

Systematic review used as source document

198. Racine M, Jensen MP, Harth M, et al. Operant Learning Versus Energy Conservation Activity Pacing Treatments in a Sample of Patients With Fibromyalgia Syndrome: a Pilot Randomized Controlled Trial. Journal of pain. 2019;20(4):420-39. PMID: CN-02145231 NEW. Exclusion: Ineligible comparator

199. Rae L, Dougherty P, Evertz N. Yoga vs Stretching in Veterans With Chronic Lower Back Pain and the Role of Mindfulness: A Pilot Randomized Controlled Trial. Journal of Chiropractic Medicine. 2020

Jun;19(2):101-10. doi: https://dx.doi.org/10.1016/j.jcm.2019.10.005 . PMID: 33318728. Exclusion: Ineligible study design
200. Raghava Neelapala YV, Bhagat M, Shah P. Hip Muscle Strengthening for Knee Osteoarthritis: A Systematic Review of Literature. Journal of Geriatric Physical Therapy. 2020 Apr/Jun;43(2):89-98. doi: https://dx.doi.org/10.1519/JPT.0000000000 000214. PMID: 30407271. Exclusion:

Systematic review used as source document

201. Rampazo EP, Martignago CCS, de Noronha $\mathrm{M}$, et al. Transcutaneous electrical stimulation in neck pain: a systematic review and meta-analysis. European Journal of Pain. 2021 Jul 20;20:20. doi: https://dx.doi.org/10.1002/ejp.1845. PMID: 34288255. Exclusion: Systematic review used as source document

202. Raposo F, Ramos M, Lucia Cruz A. Effects of exercise on knee osteoarthritis: A systematic review. Musculoskeletal Care. 2021 Mar 05;05:05. doi: https://dx.doi.org/10.1002/msc.1538. PMID: 33666347. Exclusion: Systematic review used as source document

203. Razzaq A, Sajjad AG, Yasin S, et al. Comparison of Cyriax manipulation with traditional physical therapy for the management of cervical discogenic problems. A randomized control trial. JPMA - Journal of the Pakistan Medical Association. 2020 Aug;70(8):1329-33. doi: https://dx.doi.org/10.5455/JPMA.13250. PMID: 32794481. Exclusion: Inadequate duration of followup

204. Rickardsson J, Gentili C, Holmstrom L, et al. Internet-delivered acceptance and commitment therapy as microlearning for chronic pain: A randomized controlled trial with 1-year follow-up. European Journal of Pain. 2021 05;25(5):1012-30. doi: https://dx.doi.org/10.1002/ejp.1723. PMID: 33460240. Exclusion: Ineligible population

205. Rodriguez-Roca B, Urcola-Pardo F, Anguas-Gracia A, et al. Impact of Reducing Sitting Time in Women with Fibromyalgia and Obesity: A Randomized Controlled Trial. International Journal of Environmental Research \& Public Health [Electronic Resource]. 2021 Jun 09;18(12):09. doi: https://dx.doi.org/10.3390/ijerph18126237. PMID: 34207661. Exclusion: Ineligible intervention 
206. Roseen EJ, Gerlovin H, Felson DT, et al. Which Chronic Low Back Pain Patients Respond Favorably to Yoga, Physical Therapy, and a Self-care Book? Responder Analyses from a Randomized Controlled Trial. Pain Medicine. 202102 04;22(1):16580. doi: https://dx.doi.org/10.1093/pm/pnaa153. PMID: 32662833. Exclusion: Inadequate duration of followup

207. Rosenberg NR, Petersen SB, Begtrup LM, et al. Early Occupational Intervention for People with Low Back Pain in Physically Demanding Jobs: 1-year Follow-up Results of the Randomized Controlled GOBACK Trial. Spine. 2021 Mar 15;46(6):347-55. doi: https://dx.doi.org/10.1097/BRS.0000000000 003793. PMID: 33181779. Exclusion: Ineligible population

208. Rubira A, Rubira MC, Rubira LA, et al. Comparison of the effects of low-level laser and pulsed and continuous ultrasound on pain and physical disability in chronic nonspecific low back pain: a randomized controlled clinical trial. Advances in Rheumatology. 201912 17;59(1):57. doi: https://dx.doi.org/10.1186/s42358-0190099-z. PMID: 31847915. Exclusion: Inadequate duration of followup

209. Salm DC, Belmonte LAO, Emer AA, et al. Aquatic exercise and Far Infrared (FIR) modulates pain and blood cytokines in fibromyalgia patients: A double-blind, randomized, placebo-controlled pilot study. Journal of Neuroimmunology. 201912 15;337:577077. doi: https://dx.doi.org/10.1016/j.jneuroim.2019.5 77077. PMID: 31655422. Exclusion: Ineligible intervention

210. Sander LB, Paganini S, Terhorst Y, et al. Effectiveness of a Guided Web-Based Selfhelp Intervention to Prevent Depression in Patients With Persistent Back Pain: The PROD-BP Randomized Clinical Trial. JAMA Psychiatry. 202010 01;77(10):100111. doi: https://dx.doi.org/10.1001/jamapsychiatry.2 020.1021. PMID: 32459348. Exclusion: Ineligible intervention
211. Sarig Bahat H, Hadar D, Treleaven J. Predictors for Positive Response to Home Kinematic Training in Chronic Neck Pain. Journal of Manipulative \& Physiological Therapeutics. 2020 10;43(8):779-90. doi: https://dx.doi.org/10.1016/j.jmpt.2019.12.00 8. PMID: 32829943. Exclusion: Ineligible study design

212. Sarmento CVM, Moon S, Pfeifer T, et al. The therapeutic efficacy of Qigong exercise on the main symptoms of fibromyalgia: A pilot randomized clinical trial. Integrative Medicine Research. 2020 Dec;9(4):100416. doi:

https://dx.doi.org/10.1016/j.imr.2020.10041 6. PMID: 32455108. Exclusion: Ineligible study design

213. Sato T, Shimizu K, Shiko Y, et al. Effects of Nintendo Ring Fit Adventure Exergame on Pain and Psychological Factors in Patients with Chronic Low Back Pain. Games for Health Journal. 2021 Jun;10(3):158-64. doi: https://dx.doi.org/10.1089/g4h.2020.0180. PMID: 33891508. Exclusion: Inadequate duration of followup

214. Sauch Valmana G, Vidal-Alaball J, Poch PR, et al. Effects of a Physical Exercise Program on Patients Affected with Fibromyalgia. Journal of Primary Care \& Community Health. 2020 JanDec;11:2150132720965071. doi: https://dx.doi.org/10.1177/21501327209650 71. PMID: 33084477. Exclusion: Inadequate duration of followup

215. Schemer L, Schroeder A, Ornbol E, et al. Exposure and cognitive-behavioural therapy for chronic back pain: an RCT on treatment processes. European journal of pain (London, England). 2019;23(3):526-38. PMID: CN-01690849. Exclusion: Ineligible comparator

216. Schiller J, Karst M, Kellner T, et al. Combination of acupuncture and medical training therapy on tension type headache: Results of a randomised controlled pilot study. Cephalalgia. 2021 Jul;41(8):879-93. doi:

https://dx.doi.org/10.1177/03331024219896 20. PMID: 33563049. Exclusion: Ineligible population 
217. Schlenk EA, Fitzgerald GK, Rogers JC, et al. Promoting Physical Activity in Older Adults With Knee Osteoarthritis and Hypertension: A Randomized Controlled Trial. Journal of Aging \& Physical Activity. 202009 04;29(2):207-18. doi: https://dx.doi.org/10.1123/japa.2019-0498. PMID: 32887850. Exclusion: Ineligible intervention

218. Schlicker S, Baumeister H, Buntrock C, et al. A Web- and Mobile-Based Intervention for Comorbid, Recurrent Depression in Patients With Chronic Back Pain on Sick Leave (Get.Back): Pilot Randomized Controlled Trial on Feasibility, User Satisfaction, and Effectiveness. JMIR Mental Health. 2020 Apr 15;7(4):e16398. doi: https://dx.doi.org/10.2196/16398. PMID: 32293577. Exclusion: Ineligible intervention

219. Schmid AA, Fruhauf CA, Sharp JL, et al. Yoga for People With Chronic Pain in a Community-Based Setting: A Feasibility and Pilot RCT. Journal of Evidence-based Integrative Medicine. 2019 JanDec;24:2515690X19863763. doi: https://dx.doi.org/10.1177/2515690X198637 63. PMID: 31394910. Exclusion: Ineligible population

220. Schmid AA, Van Puymbroeck M, Fruhauf CA, et al. Yoga improves occupational performance, depression, and daily activities for people with chronic pain. Work.

2019;63(2):181-9. doi:

https://dx.doi.org/10.3233/WOR-192919. PMID: 31156199. Exclusion: Ineligible population

221. Schulze NB, Salemi MM, de Alencar GG, et al. Efficacy of Manual Therapy on Pain, Impact of Disease, and Quality of Life in the Treatment of Fibromyalgia: A Systematic Review. Pain Physician. 2020 09;23(5):46176. PMID: 32967389. Exclusion: Systematic review used as source document

222. Seguin-Fowler R, Graham M, Ward J, et al. Feasibility of a yoga intervention to decrease pain in older women: a randomized controlled pilot study. BMC Geriatrics. 2020 10 12;20(1):400. doi: https://dx.doi.org/10.1186/s12877-02001818-y. PMID: 33046009. Exclusion: Ineligible population
223. Shamsi M, Shahsavari S, Safari A, et al. A randomized clinical trial for the effect of static stretching and strengthening exercise on pelvic tilt angle in LBP patients. Journal of Bodywork \& Movement Therapies. 2020 Jul;24(3):15-20. doi:

https://dx.doi.org/10.1016/j.jbmt.2020.02.00 1. PMID: 32825981. Exclusion: Ineligible comparator

224. Sherman KJ, Wellman RD, Hawkes RJ, et al. T'ai Chi for Chronic Low Back Pain in Older Adults: A Feasibility Trial. Journal of Alternative \& Complementary Medicine. 2020 Mar;26(3):176-89. doi: https://dx.doi.org/10.1089/acm.2019.0438. PMID: 32013530. Exclusion: Ineligible outcomes

225. Shimo K, Hasegawa M, Mizutani S, et al. Effects of a 12-week workplace counseling program on physical activity and low back pain: A pilot randomized controlled study. Journal of Back \& Musculoskeletal Rehabilitation. 2021 Apr 30;30:30. doi: https://dx.doi.org/10.3233/BMR-200178. PMID: 33935064. Exclusion: Ineligible intervention

226. Shimoura K, Iijima H, Suzuki Y, et al. Immediate Effects of Transcutaneous Electrical Nerve Stimulation on Pain and Physical Performance in Individuals With Preradiographic Knee Osteoarthritis: a Randomized Controlled Trial. Archives of physical medicine and rehabilitation. 2019;100(2):300-6.e1. PMID: CN02000235 NEW. Exclusion: Inadequate duration of followup

227. Simoni G, Bozzolan M, Bonnini S, et al. Effectiveness of standard cervical physiotherapy plus diaphragm manual therapy on pain in patients with chronic neck pain: A randomized controlled trial. Journal of Bodywork \& Movement Therapies. 2021 Apr;26:481-91. doi: https://dx.doi.org/10.1016/j.jbmt.2020.12.03 2. PMID: 33992285.Exclusion: Ineligible intervention 
228. Sitthipornvorakul E, Sihawong R, Waongenngarm $\mathrm{P}$, et al. The effects of walking intervention on preventing neck pain in office workers: A randomized controlled trial. Journal of Occupational Health. 2020 Jan;62(1):e12106. doi: https://dx.doi.org/10.1002/13489585.12106. PMID: 31849170. Exclusion: Ineligible population

229. Skillgate E, Pico-Espinosa OJ, Cote P, et al. Effectiveness of deep tissue massage therapy, and supervised strengthening and stretching exercises for subacute or persistent disabling neck pain. The Stockholm Neck (STONE) randomized controlled trial. Musculoskeletal Science \& Practice. 2020 02;45:102070. doi:

https://dx.doi.org/10.1016/j.msksp.2019.102 070. PMID: 31655314. Exclusion: Ineligible population

230. Smith J, Faux SG, Gardner T, et al. Reboot Online: A Randomized Controlled Trial Comparing an Online Multidisciplinary Pain Management Program with Usual Care for Chronic Pain. Pain Medicine. 201912 01;20(12):2385-96. doi: https://dx.doi.org/10.1093/pm/pnz208. PMID: 31498393. Exclusion: Ineligible population

231. Smith SL, Langen WH. A Systematic Review of Mindfulness Practices for Improving Outcomes in Chronic Low Back Pain. International Journal of Yoga. 2020 Sep-Dec;13(3):177-82. doi: https://dx.doi.org/10.4103/ijoy.IJOY 4 20. PMID: 33343146. Exclusion:Systematic review used as source document

232. Song HJ, Seo HJ, Kim D. Effectiveness of high-intensity laser therapy in the management of patients with knee osteoarthritis: A systematic review and meta-analysis of randomized controlled trials. Journal of Back \& Musculoskeletal Rehabilitation. 2020;33(6):875-84. doi: https://dx.doi.org/10.3233/BMR-191738. PMID: 32831189. Exclusion: Systematic review used as source document
233. Sonmezer E, Ozkoslu MA, Yosmaoglu HB. The effects of clinical pilates exercises on functional disability, pain, quality of life and lumbopelvic stabilization in pregnant women with low back pain: A randomized controlled study. Journal of Back \& Musculoskeletal Rehabilitation. 2021;34(1):69-76. doi: https://dx.doi.org/10.3233/BMR-191810. PMID: 32986655. Exclusion: Ineligible population

234. Stausholm MB, Naterstad IF, Joensen J, et al. Efficacy of low-level laser therapy on pain and disability in knee osteoarthritis: systematic review and meta-analysis of randomised placebo-controlled trials. BMJ Open. 201910 28;9(10):e031142. doi: https://dx.doi.org/10.1136/bmjopen-2019031142. PMID: 31662383. Exclusion: Systematic review used as source document

235. Suman A, Schaafsma FG, van Dongen JM, et al. Effectiveness and cost-utility of a multifaceted eHealth strategy to improve back pain beliefs of patients with nonspecific low back pain: a cluster randomised trial. BMJ Open. 201912 05;9(12):e030879. doi: https://dx.doi.org/10.1136/bmjopen2019-030879. PMID: 31811006. Exclusion: Ineligible population

236. Teychenne M, Lamb KE, Main L, et al. General strength and conditioning versus motor control with manual therapy for improving depressive symptoms in chronic low back pain: A randomised feasibility trial. PLoS ONE [Electronic Resource]. 2019;14(8):e0220442. doi: https://dx.doi.org/10.1371/journal.pone.0220 442. PMID: 31369613. Exclusion: Ineligible population

237. Thompson AR, Christopherson Z, Marshall LM, et al. A Pilot Randomized Controlled Trial for Aerobic and Strengthening Exercises on Physical Function and Pain for Hip Osteoarthritis. Pm \& R. 2020 03;12(3):229-37. doi: https://dx.doi.org/10.1002/pmrj.12262. PMID: 31600429. Exclusion: Inadequate duration of followup 
238. Tonye-Geoffroy L, Mauboussin Carlos S, Tuffet S, et al. Efficacy of a combination of hypnosis and transcutaneous electrical nerve stimulation for chronic non-cancer pain: A randomized controlled trial. Journal of Advanced Nursing. 2021 Jun;77(6):2875-86. doi: https://dx.doi.org/10.1111/jan.14833. PMID: 33783846. Exclusion: Ineligible population

239. Tse M, Li Y, Tang SK, et al. An Exploration of the Effectiveness of a Peer-Led Pain Management Program (PAP) for Nursing Home Residents with Chronic Pain and an Evaluation of Their Experiences: A Pilot Randomized Controlled Trial. International Journal of Environmental Research \& Public Health [Electronic Resource]. 202006 08;17(11):08. doi:

https://dx.doi.org/10.3390/ijerph17114090. PMID: 32521785. Exclusion: Ineligible population

240. Tsuboi Y, Oka T, Nakatsuka K, et al. Effectiveness of workplace active rest programme on low back pain in office workers: a stepped-wedge cluster randomised controlled trial. BMJ Open. 202106 25;11(6):e040101. doi: https://dx.doi.org/10.1136/bmjopen-2020040101. PMID: 34172540. Exclusion: Ineligible study design

241. Tu JF, Wang LQ, Shi GX, et al. Effect of acupuncture on knee injury and osteoarthritis outcome score in patients with knee osteoarthritis. Zhongguo zhen jiu [Chinese acupuncture \& moxibustion]. 2021;41(1):27-30. PMID: CN-02232691

NEW. Exclusion: Not English language but possibly relevant

242. Tu JF, Wang LQ, Shi GX, et al. [Effect of acupuncture on knee injury and osteoarthritis outcome score in patients with knee osteoarthritis]. Zhongguo Zhenjiu. 2021 Jan 12;41(1):27-30. doi: https://dx.doi.org/10.13703/j.02552930.20191212-0001. PMID: 33559438.

Exclusion: Not English language but possibly relevant
243. Turner MN, Hernandez DO, Cade W, et al. The Role of Resistance Training Dosing on Pain and Physical Function in Individuals With Knee Osteoarthritis: A Systematic Review. Sports \& Health. 2020

Mar/Apr;12(2):200-6. doi: https://dx.doi.org/10.1177/19417381198871 83. PMID: 31850826. Exclusion: Systematic review used as source document

244. Udina-Cortes C, Fernandez-Carnero J, Romano AA, et al. Effects of neuro-adaptive electrostimulation therapy on pain and disability in fibromyalgia: A prospective, randomized, double-blind study. Medicine. 2020 Dec 18;99(51):e23785. doi: https://dx.doi.org/10.1097/MD.0000000000 023785. PMID: 33371148. Exclusion: Ineligible intervention

245. Uebelacker LA, Van Noppen D, Tremont G, et al. A pilot study assessing acceptability and feasibility of hatha yoga for chronic pain in people receiving opioid agonist therapy for opioid use disorder. Journal of Substance Abuse Treatment. 2019 10;105:19-27. doi:

https://dx.doi.org/10.1016/j.jsat.2019.07.015 . PMID: 31443887. Exclusion: Ineligible population

246. Vaegter HB, Ussing K, Johansen JV, et al. Improvements in clinical pain and experimental pain sensitivity after cognitive functional therapy in patients with severe persistent low back pain. The Pain Report. 2020 Jan-Feb;5(1):e802. doi: https://dx.doi.org/10.1097/PR9.0000000000 000802. PMID: 32072097. Exclusion: Ineligible study design

247. Valera-Calero A, Lluch Girbes E, GallegoIzquierdo T, et al. Endocrine response after cervical manipulation and mobilization in people with chronic mechanical neck pain: a randomized controlled trial. European journal of physical and rehabilitation medicine. 2019;55(6):792-805. PMID: CN01690485. Exclusion: Inadequate duration of followup 
248. Van Dyke BP, Newman AK, Morais CA, et al. Heterogeneity of Treatment Effects in a Randomized Trial of Literacy-Adapted Group Cognitive-Behavioral Therapy, Pain Psychoeducation, and Usual Medical Care for Multiply Disadvantaged Patients With Chronic Pain. Journal of Pain. 2019 10;20(10):1236-48. doi: https://dx.doi.org/10.1016/j.jpain.2019.04.00 6. PMID: 31022555. Exclusion: Ineligible population

249. Veronese N, Smith L, Bolzetta F, et al. Efficacy of conservative treatments for hand osteoarthritis : An umbrella review of interventional studies. Wiener Klinische Wochenschrift. 2021 Mar;133(5-6):234-40. doi: https://dx.doi.org/10.1007/s00508-02001702-0. PMID: 32607645. Exclusion:

Systematic review used as source document

250. Villafaina S, Collado-Mateo D, DominguezMunoz FJ, et al. Effects of exergames on heart rate variability of women with fibromyalgia: A randomized controlled trial. Scientific Reports. 202003 20;10(1):5168. doi: https://dx.doi.org/10.1038/s41598-02061617-8. PMID: 32198423. Exclusion: Ineligible outcomes

251. Vining R, Long CR, Minkalis A, et al. Effects of Chiropractic Care on Strength, Balance, and Endurance in Active-Duty U.S. Military Personnel with Low Back Pain: A Randomized Controlled Trial. Journal of Alternative \& Complementary Medicine. $2020 \mathrm{Jul} ; 26(7): 592-601$. doi: https://dx.doi.org/10.1089/acm.2020.0107. PMID: 32543211. Exclusion: Inadequate duration of followup

252. Walsh N, Jones L, Phillips S, et al. Facilitating Activity and Self-management for people with Arthritic knee, hip or lower back pain (FASA): A cluster randomised controlled trial. Musculoskeletal Science \& Practice. 2020 12;50:102271. doi:

https://dx.doi.org/10.1016/j.msksp.2020.102 271. PMID: 33068901. Exclusion:

Ineligible intervention
253. Wang F, Zhang X, Tong X, et al. The effects on pain, physical function, and quality of life of quadriceps strengthening exercises combined with Baduanjin qigong in older adults with knee osteoarthritis: a quasiexperimental study. BMC Musculoskeletal Disorders. 2021 Mar 29;22(1):313. doi: https://dx.doi.org/10.1186/s12891-02104179-8. PMID: 33781238. Exclusion: Ineligible study design

254. Williams ACC, Fisher E, Hearn L, et al. Psychological therapies for the management of chronic pain (excluding headache) in adults. Cochrane Database of Systematic Reviews. 202008 12;8:CD007407. doi: https://dx.doi.org/10.1002/14651858.CD007 407.pub4. PMID: 32794606. Exclusion: Systematic review used as source document

255. Wippert PM, Drieslein D, Beck H, et al. The Feasibility and Effectiveness of a New Practical Multidisciplinary Treatment for Low-Back Pain: A Randomized Controlled Trial. Journal of Clinical Medicine. 2019 Dec 31;9(1):31. doi: https://dx.doi.org/10.3390/jcm9010115. PMID: 31906224. Exclusion: Ineligible population

256. Wu YL, Fang SC, Chen SC, et al. Effects of Neurofeedback on Fibromyalgia: A Randomized Controlled Trial. Pain Management Nursing. 2021 Feb 09;09:09. doi:

https://dx.doi.org/10.1016/j.pmn.2021.01.00 4. PMID: 33579615. Exclusion: Inadequate duration of followup

257. Xiao C, Zhuang Y, Kang Y. Effects of Wu Qin xi Qigong exercise on physical functioning in elderly people with knee osteoarthritis: A randomized controlled trial. Geriatrics \& gerontology international. 2020 Oct;20(10):899-903. doi: https://dx.doi.org/10.1111/ggi.14007. PMID: 32886828. Exclusion: Inadequate duration of followup 
258. Xie SH, Wang Q, Wang LQ, et al. Effect of Internet-Based Rehabilitation Programs on Improvement of Pain and Physical Function in Patients with Knee Osteoarthritis:

Systematic Review and Meta-analysis of Randomized Controlled Trials. Journal of Medical Internet Research. 202101 05;23(1):e21542. doi: https://dx.doi.org/10.2196/21542. PMID: 33399542. Exclusion: Systematic review used as source document

259. Yang Q, Yu S, Wang J, et al. Effects of Baduanjin on patients with chronic nonspecific low back pain: A randomized controlled trial. Medicine. 2021 Jan 29;100(4):e24448. doi: https://dx.doi.org/10.1097/MD.0000000000 024448. PMID: 33530252.Exclusion: Not a study

260. Yao C, Li Z, Zhang S, et al. Effects of Wuqinxi in the Patients with Chronic Low Back Pain: A Randomized Controlled Trial. Evidence-Based Complementary \& Alternative Medicine: eCAM. 2020;2020:1428246. doi: https://dx.doi.org/10.1155/2020/1428246. PMID: 32908554. Exclusion: Ineligible comparator

261. Ye J, Zheng Q, Zou L, et al. Mindful Exercise (Baduanjin) as an Adjuvant Treatment for Older Adults (60 Years Old and Over) of Knee Osteoarthritis: A Randomized Controlled Trial. EvidenceBased Complementary \& Alternative Medicine: eCAM. 2020;2020:9869161. doi: https://dx.doi.org/10.1155/2020/9869161. PMID: 32617115. Exclusion:Inadequate duration of followup

262. Yeh SW, Hong CH, Shih MC, et al. LowLevel Laser Therapy for Fibromyalgia: A Systematic Review and Meta-Analysis. Pain Physician. 2019 05;22(3):241-54. PMID: 31151332. Exclusion: Systematic review used as source document
263. Yoo SA, Kim CY, Kim HD, et al. Effects of progressive muscle relaxation therapy with home exercise on pain, fatigue, and stress in subjects with fibromyalgia syndrome: A pilot randomized controlled trial. Journal of Back \& Musculoskeletal Rehabilitation. 2021 Jun 15;15:15. doi: https://dx.doi.org/10.3233/BMR-191703. PMID: 34151818. Exclusion: Inadequate duration of followup

264. You Y, Liu J, Tang M, et al. Effects of Tai Chi exercise on improving walking function and posture control in elderly patients with knee osteoarthritis: A systematic review and meta-analysis. Medicine. $2021 \mathrm{Apr}$ 23;100(16):e25655. doi: https://dx.doi.org/10.1097/MD.0000000000 025655. PMID: 33879749. Exclusion: Systematic review used as source document

265. Zaworski K, Latosiewicz R. The effectiveness of manual therapy and proprioceptive neuromuscular facilitation compared to kinesiotherapy: a four-arm randomized controlled trial. European journal of physical \& rehabilitation medicine. 2021 Apr;57(2):280-7. doi: https://dx.doi.org/10.23736/S19739087.21.06344-9. PMID: 33650840.

Exclusion: Ineligible population

266. Zhang C, Li Y, Zhong Y, et al. Effectiveness of motor control exercise on non-specific chronic low back pain, disability and core muscle morphological characteristics: A meta-analysis of randomized controlled trials. European journal of physical \& rehabilitation medicine. 2021 May 07;07:07. doi: https://dx.doi.org/10.23736/S19739087.21.06555-2. PMID: 33960180.

Exclusion: Systematic review used as source document

267. Zhang L, Yuan H, Zhang L, et al. Effect of acupuncture therapies combined with usual medical care on knee osteoarthritis. Journal of traditional chinese medicine $=$ chung $i$ tsa chih ying wen pan. 2019;39(1):103-10. PMID: CN-02133212 NEW.Exclusion: Inadequate duration of followup 
268. Zhang Q, Fang J, Chen L, et al. Different kinds of acupuncture treatments for knee osteoarthritis: a multicentre, randomized controlled trial. Trials [Electronic Resource]. 2020 Mar 14;21(1):264. doi:

https://dx.doi.org/10.1186/s13063-0194034-8. PMID: 32171318. Exclusion: Not a study

269. Zhao L, Cheng K, Wu F, et al. Effect of Laser Moxibustion for Knee Osteoarthritis: A Multisite, Double-blind Randomized Controlled Trial. Journal of Rheumatology. 2021 Jun;48(6):924-32. doi:

https://dx.doi.org/10.3899/jrheum.200217. PMID: 32611673. Exclusion: Ineligible intervention
270. Zheng Z, Gibson S, Helme RD, et al. Effects of Electroacupuncture on Opioid Consumption in Patients with Chronic Musculoskeletal Pain: a Multicenter Randomized Controlled Trial. Pain medicine (Malden, Mass.). 2019;20(2):397-410.

PMID: CN-01943577. Exclusion: Ineligible population

271. Zhu F, Zhang M, Wang D, et al. Yoga compared to non-exercise or physical therapy exercise on pain, disability, and quality of life for patients with chronic low back pain: A systematic review and metaanalysis of randomized controlled trials. PLoS ONE [Electronic Resource]. 2020;15(9):e0238544. doi:

https://dx.doi.org/10.1371/journal.pone.0238 544. PMID: 32870936. Exclusion:

Systematic review used as source document 


\section{Appendix G. Updated or New Meta-Analyses}

Figure G-1. Exercise versus usual care, an attention control, or a placebo intervention for chronic low back pain: effects on function, excluding outlier trial ${ }^{\mathrm{a}}$

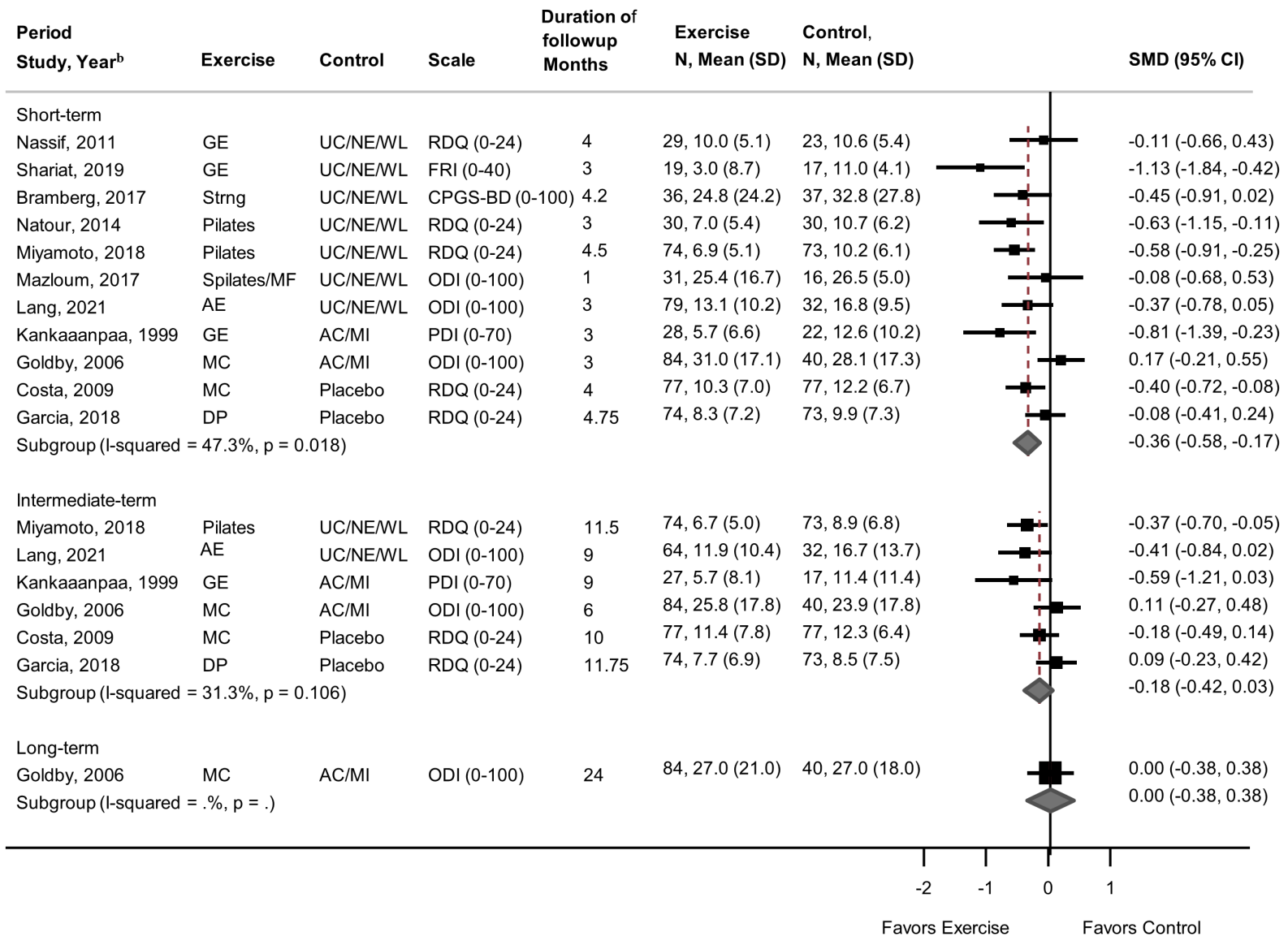

$\mathrm{AC}=$ attention control; $\mathrm{AE}=$ aerobic exercise (walking); $\mathrm{CI}=$ confidence interval; $\mathrm{CPGS}-\mathrm{BD}=$ Von Korff Chronic Pain Grade Score Back Disability; DP $=$ directional

preference; $\mathrm{GE}=$ general exercise; $\mathrm{MC}=$ motor control; $\mathrm{MF}=$ mobility/flexibility; $\mathrm{MI}=$ minimal intervention; $\mathrm{N}=$ number; $\mathrm{NE}=$ no exercise; $\mathrm{NM}=$ neuromuscular re-education ODI = Oswestry Disability Index; PDI = Pain Disability Index; RDQ = Roland-Morris Disability Questionnaire; SD = standard deviation; SMD = standardized mean difference; Spilates $=$ selective Pilates; Strng=Strength training; $\mathrm{UC}=$ usual care; $\mathrm{WL}=$ waitlist

${ }^{a}$ Areeudomwong 2017, included in prior report.

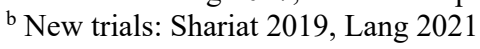


Figure G-2. Psychological therapy versus usual care or an attention control for chronic low back pain: effects on function, excluding outlier trial ${ }^{\mathrm{a}}$

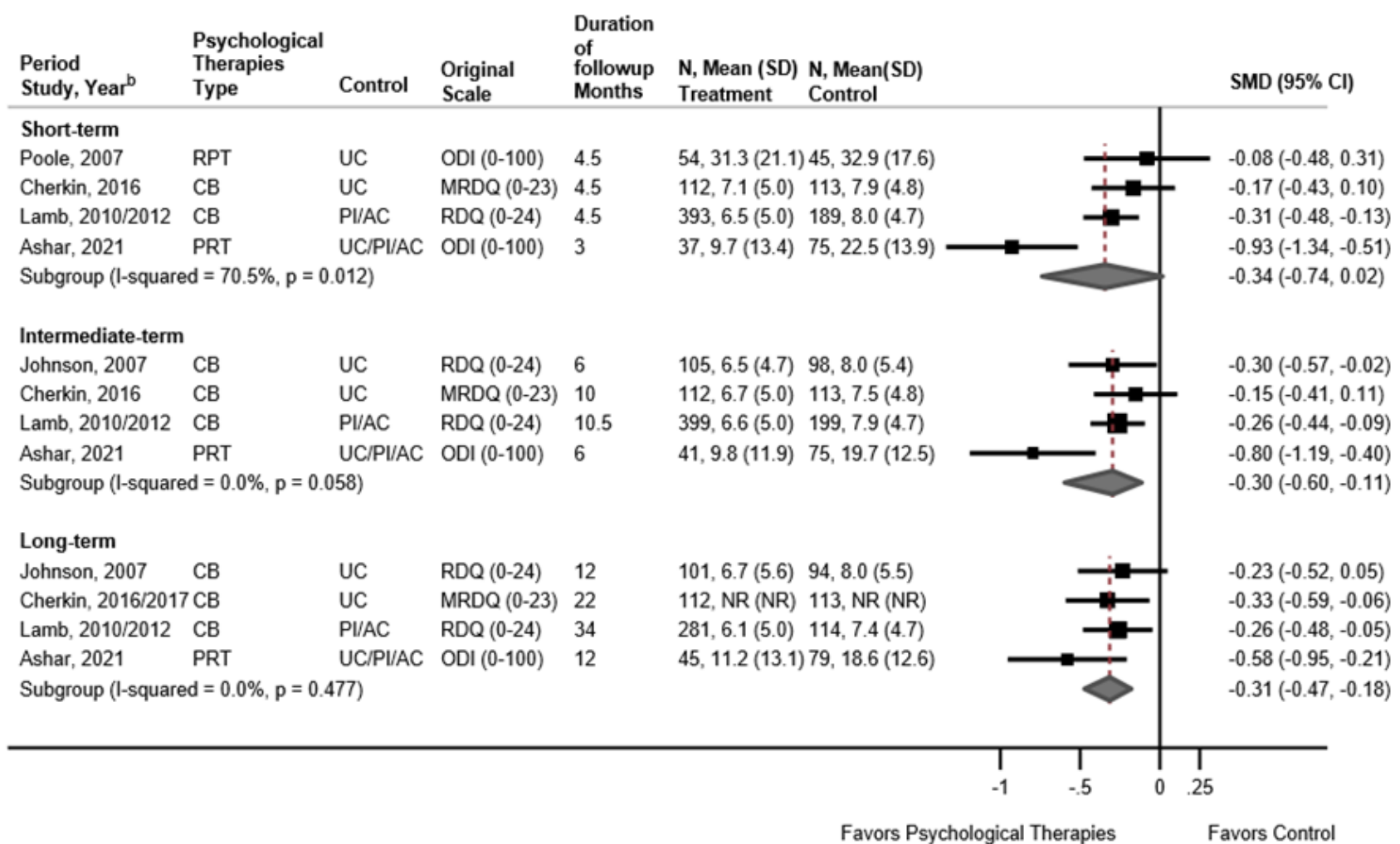

$\mathrm{AC}=$ attention control; $\mathrm{CB}=$ cognitive-behavioral therapy; $\mathrm{CI}=$ confidence interval; $\mathrm{MRDQ}=$ Modified Roland-Morris Disability Questionnaire; $\mathrm{N}=$ number; ODI = Oswestry Disability Index; PI = placebo intervention; PRT = pain reprocessing therapy; RDQ = Roland-Morris Disability Questionnaire; RPT = respondent therapy (progressive relaxation); $\mathrm{SD}=$ standard deviation; $\mathrm{SMD}=$ standardized mean difference; $\mathrm{UC}=$ usual care

${ }^{a}$ Shariat 2019, new trial.

${ }^{b}$ New trial: Ashar 2021 
Figure G-3. Spinal manipulation versus sham manipulation, usual care, an attention control, or a placebo intervention for chronic low back pain: effects on function

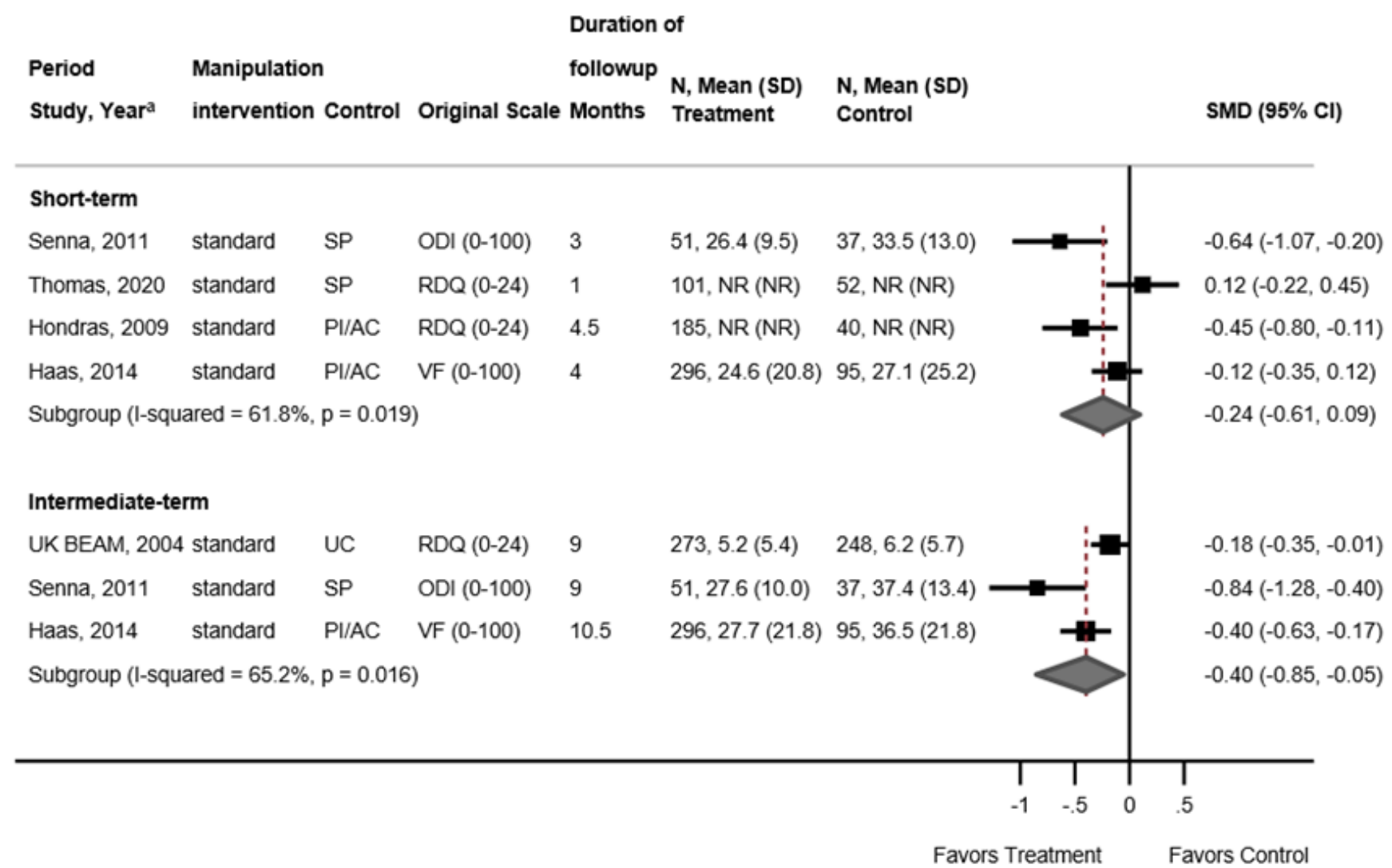

$\mathrm{AC}=$ attention control; $\mathrm{CI}=$ confidence interval; $\mathrm{N}=$ number; $\mathrm{ODI}=$ Oswestry Disability Index; PI = placebo intervention; RDQ = Roland-Morris Disability Questionnaire; SD = standard deviation; $\mathrm{SMD}=$ standardized mean difference; $\mathrm{SP}=$ sham manipulation; $\mathrm{UC}=$ usual care; UK BEAM = UK Back pain exercise and manipulation trial; $\mathrm{VF}=\mathrm{Von}$ Korff functional disability

b New trial: Thomas 2020 
Figure G-4. Exercise versus usual care, no treatment, sham, or an attention control for osteoarthritis knee pain: effects on function, excluding outlier trial ${ }^{\mathrm{a}}$

\begin{tabular}{|c|c|c|c|c|c|c|c|}
\hline $\begin{array}{l}\text { Period } \\
\text { Author, Year }\end{array}$ & $\begin{array}{l}\text { Exercise } \\
\text { Type }\end{array}$ & Control & Scale & $\begin{array}{l}\text { Duration } \\
\text { of } \\
\text { Followup } \\
\text { Months }\end{array}$ & $\begin{array}{l}\mathrm{N}, \text { Mean (SD) } \\
\text { Treatment }\end{array}$ & $\begin{array}{l}\mathrm{N}, \text { Mean (SD) } \\
\text { Comparison }\end{array}$ & SMD (95\% Cl) \\
\hline \multicolumn{8}{|l|}{ Short term } \\
\hline Quilty 2003 & com & uc & WOMAC (0-68) & 2.5 & $43,26.5(13.2)$ & $44,27.5(10.7)$ & $-0.08(-0.50,0.34)$ \\
\hline Williamson 2007 & com & uc & OKS (12-60) & 1.5 & $41,38.8(8.7)$ & $35,40.8(8.1)$ & $-0.23(-0.69,0.22)$ \\
\hline Lund 2008 & com & uc & KADL $(0-100)$ & 3 & $52,63.4(13.5)$ & $27,61.4(13.5)$ & $-0.15(-0.61,0.32)$ \\
\hline de Rooij 2017 & com & wh & WOMAC $(0-68)$ & 3 & $51,23.5(13.1)$ & $56,31.4(12.6)$ & $-0.61(-1.00,-0.22)$ \\
\hline Rosedale 2004 & ME & uc & KADL $(0-100)$ & 2.5 & $99,61.0(17.0)$ & $59,52.0(16.0)$ & $-0.54(-0.87,-0.21)$ \\
\hline Thorstensson 2005 & MP & NT & KADL $(0-100)$ & 5 & $28,69.9(18.0)$ & $28,69.1(21.0)$ & $-0.04(-0.56,0.48)$ \\
\hline Rewald 2019 & MP & uc & $\operatorname{KPF}(0-100)$ & 3 & $46,69.0(16.8)$ & $38,65.4(18.0)$ & $-0.20(-0.64,0.23)$ \\
\hline Bennell 2005 & NR & Sham & WOMAC (0-68) & 3 & $73,20.0$ (11.1) & $67,21.7$ (11.1) & $-0.15(-0.48,0.18)$ \\
\hline Segal 2015 & NR & uc & LLFDI (0-100) & 3 & $27, \mathrm{NR}(\mathrm{NR})$ & $18, \mathrm{NR}$ (NR) & $-0.35(-0.95,0.25)$ \\
\hline \multicolumn{4}{|c|}{ Subgroup (1-squared $=4.2 \%, p=0.444$ ) } & & & & $-0.29(-0.44,-0.12)$ \\
\hline \multicolumn{8}{|l|}{ Intermediate term } \\
\hline Sullivan 1998 & com & uc & $\operatorname{APC}(0-10)$ & 10 & $29,6.1(3.0)$ & $23,6.2(2.8)$ & $-0.04(-0.59,0.51)$ \\
\hline Quilty 2003 & com & uc & WOMAC (0-68) & 10.5 & $43,29.7$ (11.2) & $44,28.3(11.3)$ & $0.12(-0.30,0.54)$ \\
\hline Messier 2004 & com & uc & WOMAC $(0-68)$ & 6 & $70,22.1(15.1)$ & $70,22.0(15.1)$ & $0.01(-0.32,0.34)$ \\
\hline Mat 2017 & com & uc & $\operatorname{KADL}(0-100)$ & 6 & $17,75.0$ (21.9) & $17,80.4$ (15.8) & $0.28(-0.40,0.95)$ \\
\hline Allen 2018 & com & wL & WOMAC (0-68) & 8 & $140,-3.3(0.8)$ & $68,-1.5(1.1)$ & $-0.20(-0.49,0.09)$ \\
\hline Huang 2005a & MP & $A C$ & $\mathrm{Lu}(0-24)$ & 10 & $26,5.8(1.8)$ & $28,8.1(1.5)$ & $-1.37(-1.97,-0.78)$ \\
\hline Huang 2005b & MP & $A C$ & L $(0-24)$ & 10 & $21,5.1(1.8)$ & $24,7.8(1.7)$ & $-1.52(-2.19,-0.85)$ \\
\hline Weng 2009 & MP & $A C$ & LL (0-24) & 10 & $28,6.3(1.7)$ & $26,7.3(1.7)$ & $-0.58(-1.13,-0.03)$ \\
\hline Messier 2021 & MP & $A C$ & WOMAC (0-68) & 6 & $177,18.4(8.3)$ & $88,18.1(8.4)$ & $0.04(-0.22,0.30)$ \\
\hline Huang 2003 & MP & NT & $\mathrm{Lu}(0-24)$ & 10 & $87,4.0(1.5)$ & $27,7.6(1.5)$ & $-2.39(-2.93,-1.86)$ \\
\hline Chen 2014 & MP & NT & $\mathrm{L}(0-24)$ & 6 & $25,5.4(1.7)$ & $24,7.6$ (1.6) & $-1.31(-1.93,-0.69)$ \\
\hline Segal 2015 & NR & uc & LLFDI (0-100) & 9 & $24, N R$ (NR) & 18, NR (NR) & $-0.08(-0.69,0.54)$ \\
\hline \multicolumn{4}{|c|}{ Subgroup (1-squared $=91.9 \%, p=0.000$ ) } & & & & $-0.57(-1.07,-0.08)$ \\
\hline \multicolumn{8}{|l|}{ Long term } \\
\hline Messier 2021 & MP & $A C$ & WOMAC $(0-68)$ & 18 & $177,16.3(9.1)$ & $88,16.4(9.6)$ & $-0.01(-0.26,0.25)$ \\
\hline Munukka 2020 & MP & uc & WOMAC (0-68) & 12 & $40,8.5(9.0)$ & $37,9.0(12.0)$ & $-0.05(-0.49,0.40)$ \\
\hline Thomas 2002 & com & $A C$ & WOMAC (0.68) & 24 & 466, NR (NR) & $316, \mathrm{NR}(\mathrm{NR})$ & $-0.25(-0.39,-0.10)$ \\
\hline Messier 2004 & com & uc & WOMAC (0-68) & 18 & $64,27.1(11.6)$ & $67,29.4$ (11.5) & $-0.20(-0.54,0.14)$ \\
\hline Allen 2018 & com & wL & WOMAC (0-68) & 12 & $142,-3.4(0.9)$ & $68,-1.5(1.1)$ & $-0.20(-0.49,0.09)$ \\
\hline & & wh & KADL $(0-100)$ & 12 & $40,89.2(11.2)$ & $36,88.3(11.0)$ & $-0.08(-0.53,0.37)$ \\
\hline \multicolumn{4}{|c|}{ Subgroup (1-squared $=0.0 \%, p=0.680$ ) } & & & & $-0.18(-0.28,-0.03)$ \\
\hline & & & & & & T & \\
\hline & & & & & & t & Favors Control \\
\hline
\end{tabular}

$\mathrm{AC}=$ attention control; APC $=$ Arthritis Impact Measurement Scale (AIMS) physical activity component; $\mathrm{CI}=$ confidence interval; $\mathrm{COM}=$ combination exercise therapy; KADL $=$ Knee Injury and Osteoarthritis Outcome Score (KOOS) ADL subscore; LI = Lequesne Index; LLFDI = Late Life Function and Disability Index Basic Lower Limb Function Score; $\mathrm{ME}=$ mobility exercise; $\mathrm{MP}=$ muscle performance exercise; $\mathrm{NR}=$ neuromuscular reeducation exercise; $\mathrm{NT}=$ no treatment; $\mathrm{OKS}=\mathrm{Oxford}$ Knee $\mathrm{Score} ; \mathrm{SD}=$ standard deviation; SMD = standardized mean difference; UC = usual care; WOMAC = Western Ontario and McMaster's Universities Osteoarthritis Index

a Dias 2003, included in prior report.

${ }^{b}$ New trials: Messier 2021, Munukka 2020 and Rewald 2019. 
Figure G-5. Exercise versus usual care, no treatment, sham, or an attention control for osteoarthritis knee pain: effects on pain

\begin{tabular}{|c|c|c|c|c|c|c|}
\hline $\begin{array}{l}\text { Period } \\
\text { Author, Year }\end{array}$ & $\begin{array}{l}\text { Exercise } \\
\text { Type }\end{array}$ & Control & $\begin{array}{l}\text { Duration } \\
\text { of } \\
\text { Followup } \\
\text { Months }\end{array}$ & $\begin{array}{l}\mathrm{N}, \text { Mean (SD) } \\
\text { Treatment }\end{array}$ & $\begin{array}{l}\mathrm{N}, \text { Mean (SD) } \\
\text { Comparison }\end{array}$ & $\begin{array}{l}\text { Mean Difference } \\
(95 \% \mathrm{Cl})\end{array}$ \\
\hline \multicolumn{7}{|l|}{ Short term } \\
\hline Quilty 2003 & COM & UC & 2.5 & $43,4.3(2.5)$ & $44,5.0(2.6)$ & $-0.77(-1.84,0.30)$ \\
\hline Williamson 2007 & сом & uC & 1.5 & $41,6.4(2.6)$ & $35,7.2(2.1)$ & $-0.80(-1.88,0.28)$ \\
\hline Lund 2008 & COM & UC & 3 & $52,6.1(1.3)$ & $27,6.3(1.3)$ & $0.13(-0.49,0.74)$ \\
\hline de Rooij 2017 & COM & WL & 3 & $51,3.3(1.8)$ & $56,4.3(1.8)$ & $-1.00(-1.68,-0.32)$ \\
\hline Rosedale 2004 & ME & UC & 2.5 & $99,5.6(1.7)$ & $59,4.6(1.6)$ & $-1.00(-1.54,-0.46)$ \\
\hline Thorstensson 2005 & MP & NT & 5 & $28,6.3(1.8)$ & $28,6.3(1.9)$ & $-0.02(-0.99,0.95)$ \\
\hline Rewald 2019 & MP & uc & 3 & $46,6.4(1.7)$ & $38,5.7(1.9)$ & $-0.71(-1.49,0.07)$ \\
\hline Bennell 2005 & NR & Sham & 3 & $73,2.9(1.5)$ & $67,3.0(1.6)$ & $-0.10(-0.62,0.42)$ \\
\hline Segal 2015 & NR & uc & 3 & 27, NR (NR) & $18, \mathrm{NR}$ (NR) & $-0.37(-1.19,0.45)$ \\
\hline \multicolumn{6}{|c|}{ Subgroup (I-squared $=37.5 \%, p=0.094$ ) } & $-0.50(-0.84,-0.16)$ \\
\hline \multicolumn{7}{|l|}{ Intermediate term } \\
\hline Sullivan 1998 & $\mathrm{COM}$ & UC & 10 & $29,5.0(2.8)$ & $23,5.4(3.1)$ & $-0.40(-2.01,1.21)$ \\
\hline Quilty 2003 & COM & UC & 10.5 & $43,4.8(2.6)$ & $44,5.4(2.3)$ & $-0.60(-1.61,0.41)$ \\
\hline Messier 2004 & $\mathrm{COM}$ & UC & 6 & $70,3.1(1.9)$ & $70,3.1(1.9)$ & $0.01(-0.62,0.65)$ \\
\hline Mat 2017 & COM & UC & 6 & $17,8.1(2.2)$ & $17,8.0(1.5)$ & $-0.12(-1.40,1.16)$ \\
\hline Allen 2018 & сом & WL & 8 & $140,-0.7(0.3)$ & $68,-0.6(0.4)$ & $-0.03(-0.45,0.40)$ \\
\hline Huang 2005a & MP & $A C$ & 10 & $26,3.9(1.4)$ & $28,6.6(1.5)$ & $-2.70(-3.48,-1.92)$ \\
\hline Huang 2005b & MP & $A C$ & 10 & $21,3.5(1.7)$ & $24,6.0(1.7)$ & $-2.50(-3.50,-1.50)$ \\
\hline Weng 2009 & MP & $A C$ & 10 & $28,3.6(1.6)$ & $26,5.0(1.4)$ & $-1.40(-2.20,-0.60)$ \\
\hline Messier 2021 & MP & AC & 6 & $177,2.5(1.2)$ & $84,2.5(1.3)$ & $0.06(-0.26,0.38)$ \\
\hline Huang 2003 & MP & NT & 10 & $88,2.7(1.3)$ & $27,6.1(1.3)$ & $-3.38(-3.95,-2.80)$ \\
\hline Chen 2014 & MP & NT & 6 & $25,4.0(1.4)$ & $24,6.5(1.3)$ & $-2.50(-3.26,-1.74)$ \\
\hline Segal 2015 & NR & uC & 9 & 24, NR (NR) & $18, N R(N R)$ & $-0.72(-1.62,0.18)$ \\
\hline \multicolumn{6}{|c|}{ Subgroup $(1-$ squared $=92.1 \%, p=0.000)$} & $-1.21(-1.96,-0.44)$ \\
\hline \multicolumn{7}{|l|}{ Long term } \\
\hline Messier 2021 & MP & $A C$ & 18 & $177,2.4(1.4)$ & $84,2.5(1.4)$ & $-0.07(-0.43,0.29)$ \\
\hline Munukka 2020 & MP & UC & 12 & $40,5.0(6.0)$ & $37,6.8(6.5)$ & $-1.75(-4.54,1.04)$ \\
\hline Thomas 2002 & com & AC & 24 & $467, \mathrm{NR}$ (NR) & 316, NR (NR) & $-0.41(-0.66,-0.16)$ \\
\hline Messier 2004 & сом & UC & 18 & $64,3.1(1.9)$ & $67,3.0(1.8)$ & $0.11(-0.53,0.75)$ \\
\hline Allen 2018 & $\mathrm{COM}$ & WL & 12 & $142,-1.1(0.3)$ & $68,-0.6(0.4)$ & $-0.25(-0.69,0.18)$ \\
\hline Waller 2017 & MP & WL & 12 & $40,8.7(1.1)$ & $36,8.5(1.2)$ & $-0.17(-0.69,0.35)$ \\
\hline \multirow{2}{*}{\multicolumn{6}{|c|}{ Subgroup $(1-$ squared $=0.0 \%, p=0.422)$}} & $-0.26(-0.43,-0.01)$ \\
\hline & & & & & & \\
\hline
\end{tabular}

Favors Treatment Favors Control

$\mathrm{AC}=$ attention control; $\mathrm{CI}=$ confidence interval; $\mathrm{COM}=$ combination exercise therapy; $\mathrm{ME}=$ mobility exercise; $\mathrm{MP}=$ muscle performance exercise; $\mathrm{NR}=$ neuromuscular reeducation exercise; $\mathrm{NT}=$ no treatment; $\mathrm{SD}=$ standard deviation; $\mathrm{SMD}=$ standardized mean difference; $\mathrm{UC}=$ usual care

a New trials: Messier 2021, Munukka 2020 and Rewald 2019. 
Figure G-6. Low-level laser therapy versus usual care or sham for osteoarthritis knee pain: effects on function (new meta-analysis)

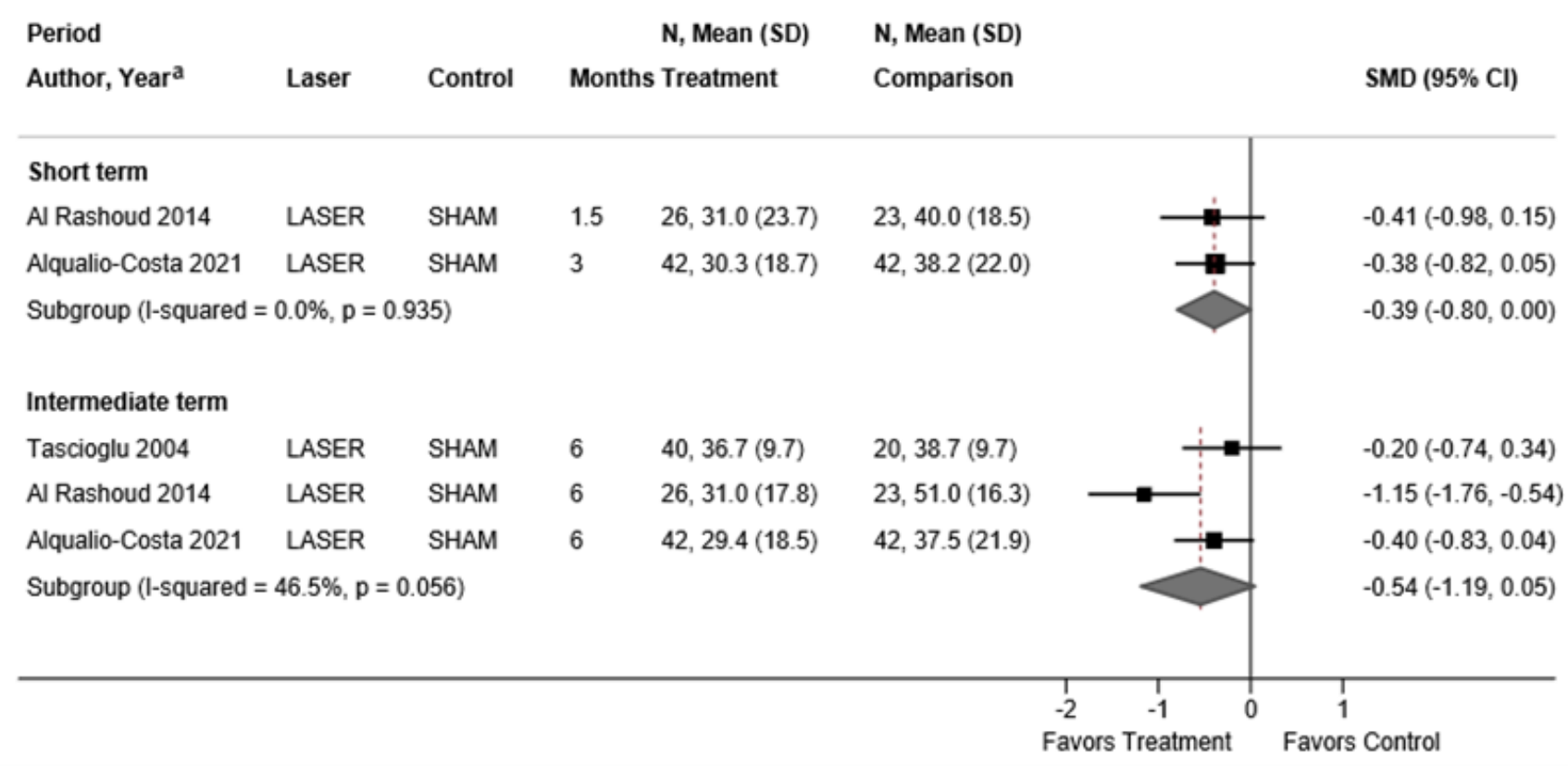

$\mathrm{CI}=$ confidence interval; $\mathrm{SD}=$ standard deviation; $\mathrm{UC}=$ usual care

a New trial: Alqualio-Costa 2021 
Figure G-7. Low-level laser therapy versus usual care or sham for osteoarthritis knee pain: effects on pain

\begin{tabular}{|c|c|c|c|c|c|c|}
\hline $\begin{array}{l}\text { Period } \\
\text { Author, Year }\end{array}$ & Laser & Control & Months & $\begin{array}{l}\mathrm{N} \text {, Mean (SD) } \\
\text { Treatment }\end{array}$ & $\begin{array}{l}\mathrm{N}, \text { Mean (SD) } \\
\text { Comparison }\end{array}$ & $\begin{array}{l}\text { Mean difference } \\
(95 \% \mathrm{Cl})\end{array}$ \\
\hline \multicolumn{7}{|l|}{ Short term } \\
\hline Hegedus 2009 & LASER & SHAM & 2 & $18,1.2(1.4)$ & $9,4.1(1.7)$ & $-2.94(-4.19,-1.69)$ \\
\hline Al Rashoud 2014 & LASER & SHAM & 1.5 & $26,3.0(1.9)$ & $23,4.2(1.8)$ & $-1.20(-2.24,-0.16)$ \\
\hline Alqualio-Costa 2021 & LASER & SHAM & 3 & $42,3.1(2.8)$ & $42,3.5(2.9)$ & $-0.40(-1.62,0.82)$ \\
\hline Subgroup (I-squared & $=76.5 \%$ & $=0.014)$ & & & & $-1.50(-3.18,0.16)$ \\
\hline \multicolumn{7}{|l|}{ Intermediate term } \\
\hline Tascioglu 2004 & LASER & SHAM & 6 & $40,6.4(1.3)$ & $20,6.2(1.7)$ & $0.23(-0.61,1.07)$ \\
\hline Al Rashoud 2014 & LASER & SHAM & 6 & $26,3.4(1.9)$ & $23,5.2(1.8)$ & $-1.80(-2.84,-0.76)$ \\
\hline Alqualio-Costa 2021 & LASER & SHAM & 6 & $42,2.6(2.3)$ & $42,3.9(3.1)$ & $-1.30(-2.47,-0.13)$ \\
\hline \multicolumn{6}{|c|}{ Subgroup $(I-$ squared $=6.5 \%, p=0.136)$} & $-1.24(-2.22,0.12)$ \\
\hline & & & & & $\begin{array}{l}1 \\
-4\end{array}$ & 2 \\
\hline & & & & & & rs Control \\
\hline
\end{tabular}

$\mathrm{CI}=$ confidence interval; $\mathrm{SD}=$ standard deviation; $\mathrm{UC}=$ usual care

${ }^{a}$ New trial: Alqualio-Costa 2021 